\title{
NEW ZEALAND NURSES USE OF HUMOUR IN SURGICAL NURSING PRACTICE
}

\author{
By \\ Shelley Rose van der Krogt \\ A thesis \\ submitted to the Victoria University of Wellington \\ in partial fulfilment of the requirements for the degree of \\ Master of Health Care
}

Victoria University of Wellington

2019 


\begin{abstract}
Humour is a tool that can build rapport, establish communication and enable a therapeutic relationship: all of which are essential skills for nurses. For nurses to use humour in their practice they need to know when it is appropriate and when it could be beneficial for patients. However, much of the literature on nursing humour focusses on when not to use humour or provides contradictory messages about the use of humour. This is problematic as with little guidance, nurses may be hesitant to deploy humour with patients, potentially missing important opportunities to deliver more effective care.
\end{abstract}

The lack of evidence-based guidance about use of humour for nurses was a key driver for this study. Furthermore, with even less research in the surgical care setting, a stressful environment for patients and staff, the need to explore how and when humour is used in surgical nursing practice was important.

A qualitative descriptive methodology was used to explore how registered nursing working in a surgical environment decide when and how to use humour within nurse-patient interactions, and the use of humour during nurse-patient communication is assessed. Data collection was carried out in two surgical wards within a single site tertiary hospital in New Zealand. Nine registered nurses participated in group or individual interviews that were conducted using an interview guide incorporating semi-structured questions. Data were analysed thematically.

Findings demonstrate the humour is a significant feature of practice for surgical nurses with its use being purposeful and undertaken after careful consideration and assessment. Within three themes (assessing openness, building a connection, protection against vulnerability), humour was described as enabling nurses to quickly connect with patients and establish a therapeutic relationship. Humour facilitates communication, even under difficult circumstances, and provides an outlet for the perceived physical and emotional vulnerability experienced by both patients and nurses within the surgical environment.

Humour forms an integral part of surgical nursing practice. This thesis challenges surgical nurses to place an emphasis on raising the profile of humour in practice and develop skills to assess when to use, and when not to use humour. This will require the development of specific educational and professional strategies. 


\section{DEDICATION}

To my parents,

for teaching me to see the humour in all things. 


\section{ACKNOWLEDGEMENTS}

Completion of this research was made possible from the support of the following people, to whom I am greatly and forever indebted.

To my husband Francis, you have been an absolute rock of support, taking the children when I needed more time to study, re-arranging work commitments to fit in with my schedule, printing all my articles without any issue at all, and encouraging me to keep going even when I had lost all motivation. You lifted me up by reminding me of my strengths and helped me move forward when I had become stuck. Your encouragement to talk things through and plan then next steps was invaluable, you are simply amazing.

To my children who had to put up with a grumpy mummy due to late nights and early mornings, William and Isabelle you are very special and I appreciate you understanding mummy needing to work. Thank you for resisting the urge to mess up all of the piles of paper that covered the house for months at a time and to refrain from pulling the post it notes off the wall.

To my parents, Jenny and Roger Clark, you were always so interested in this project, asking me how I was doing and how I was progressing, making my study a priority regardless of what was happening in your life. You encouraged me and told me how proud you were of my achievements, no matter how small they were at the time. Your interest and faith that I could achieve this was a driving force allowing me to succeed and helped me push through when things got hard.

To my dear friend Amelia Howard-Hill who was a sounding board and provided very wise and clear council, who never let me take myself too seriously and reminded me that apparently this was the start towards a PhD journey, so I had better 'suck it up and get on with it'. Thank you for keeping it real.

To my friend Darren Brown who was always there at the end of the phone, when all sane people were asleep, your support gave me a much-needed distraction and brought laughter when it was desperately needed. 
To Dr Helen Rook and Professor Maureen Coombs who were hands down the most phenomenal supervisors imaginable. The support you gave me both academically and personally was humbling and overwhelming. You passed on your knowledge and advice without hesitation and provided me with all the skills and support imaginable to navigate my rocky maiden voyage into the research world. You never ceased to provide positive feedback and encouragement, and your unfailing belief in my abilities (when I couldn't see it) allowed me to re-focus and strive to excel throughout the tough times. The laughter and tears we shared along this journey will never be forgotten, but instead will be very fondly remembered, as will the versatile use of a tea towel.

And finally, to the research participants, thank you for giving me your time and trusting me with your thoughts and experiences. You provided insight into your world allowing me to use this to complete my research. I loved my time with you and the stories you shared. Many, many thanks to you all, because without you this simply would not have been possible. 


\section{TABLE OF CONTENTS}

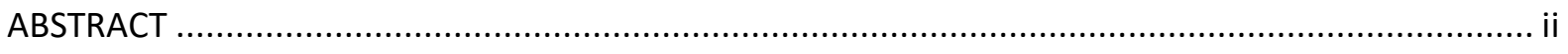

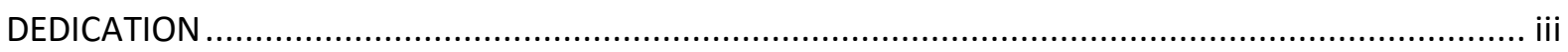

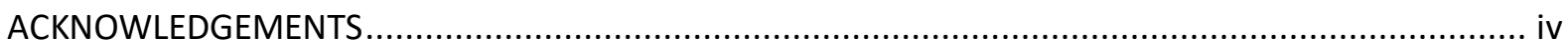

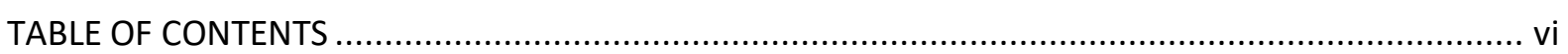

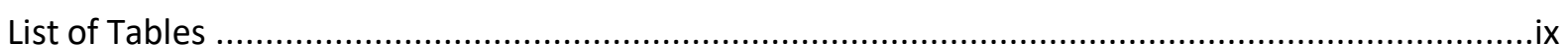

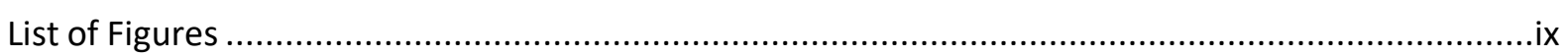

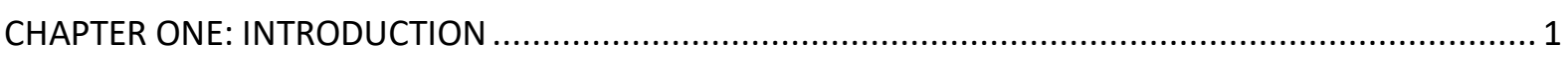

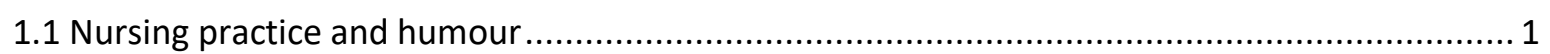

1.1.1 Humour within nurse-patient interactions.......................................................... 2

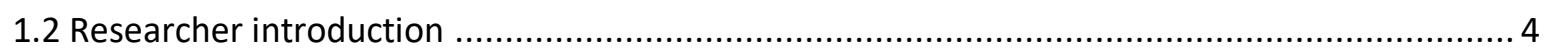

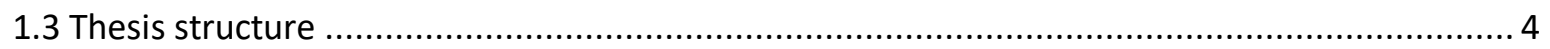

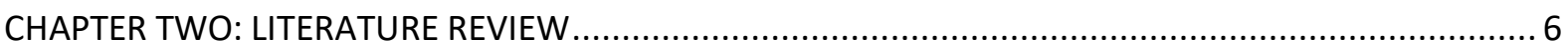

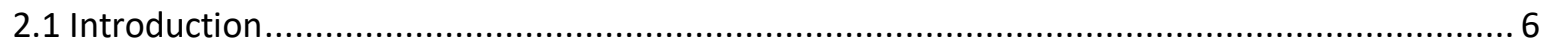

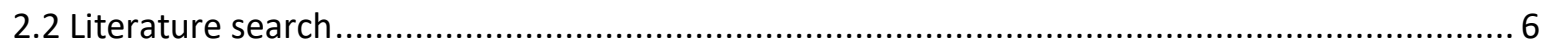

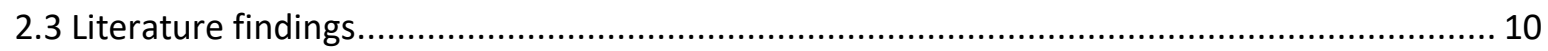

2.3.1 Humour use within the nurse-patient relationship .................................................... 10

2.3.2 The effect of humour on the nurse-patient relationship ............................................... 13

2.3.3 Nurses' understanding of and responses to patients' use of humour.............................. 16

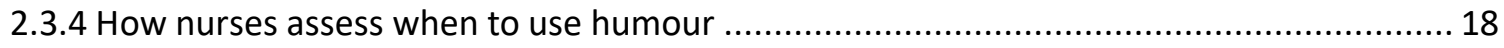

2.3.5 Barriers to nurses using humour in the nurse- patient relationship................................ 20

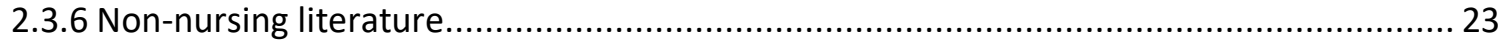

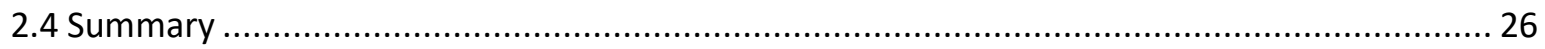

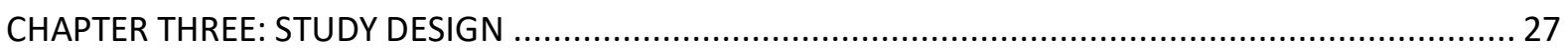

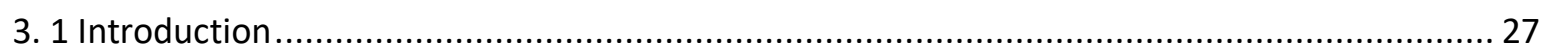

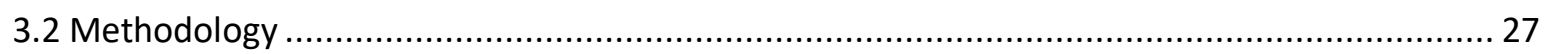

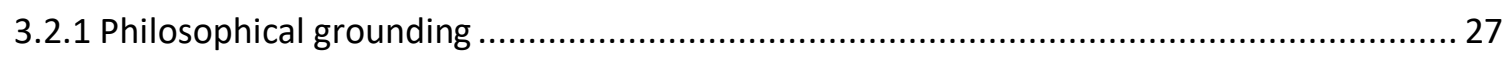

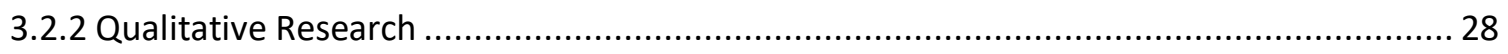

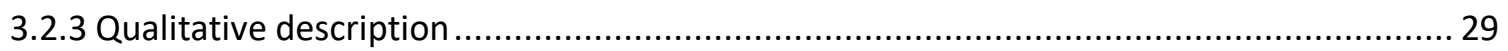

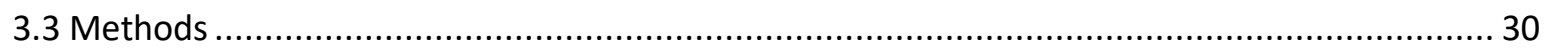

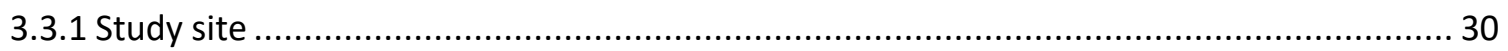

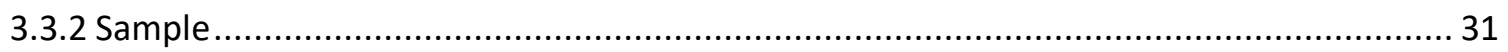

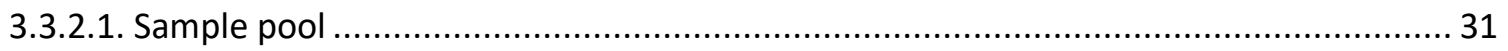

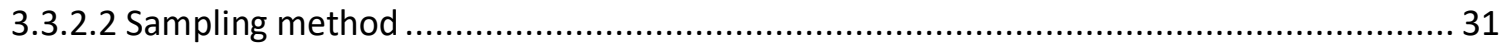




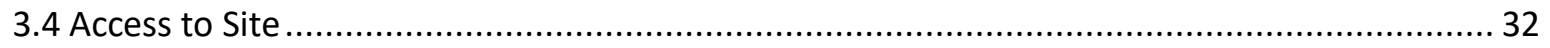

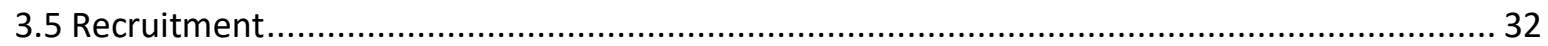

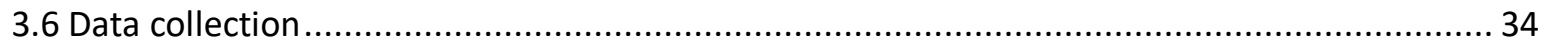

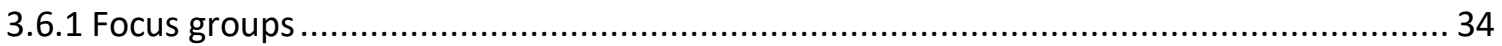

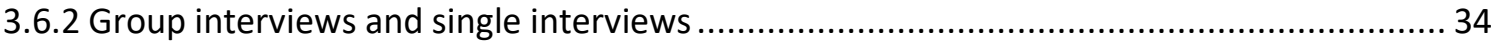

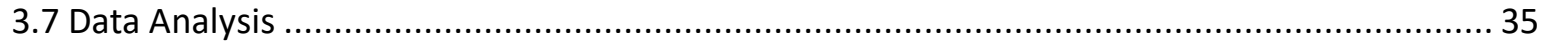

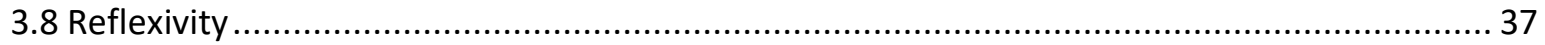

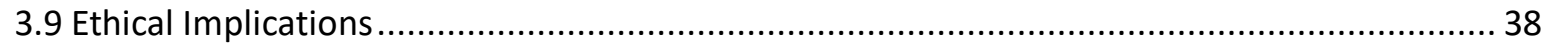

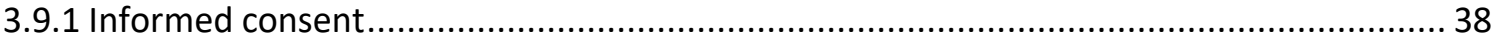

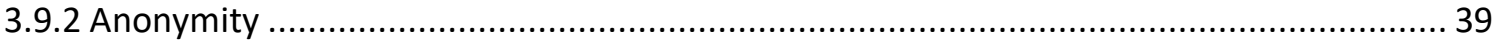

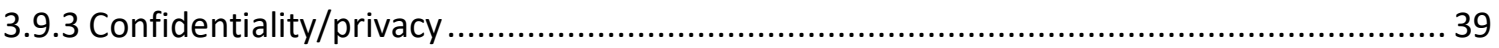

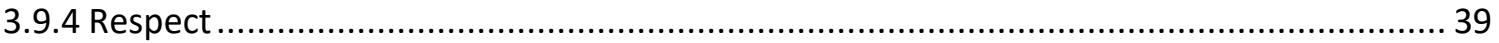

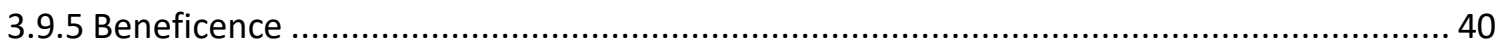

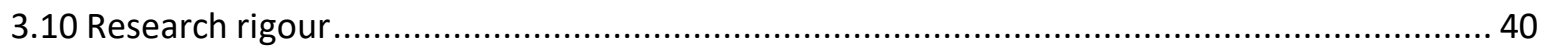

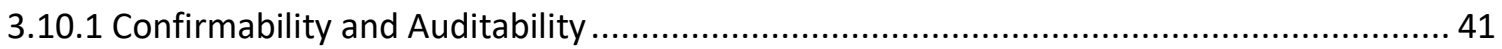

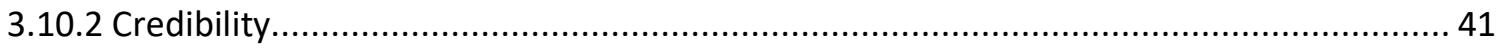

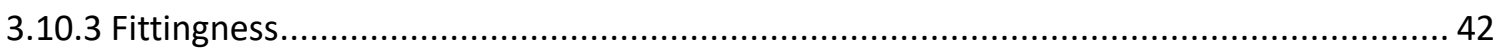

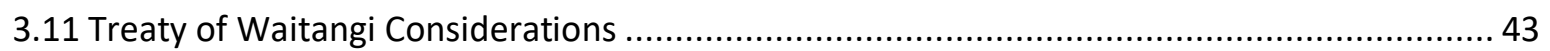

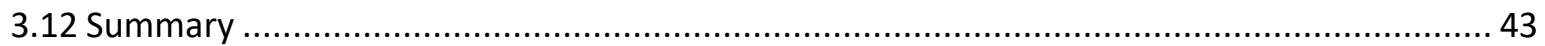

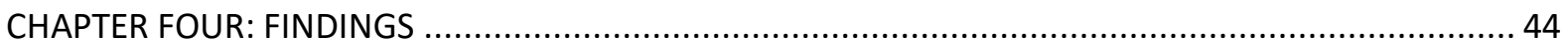

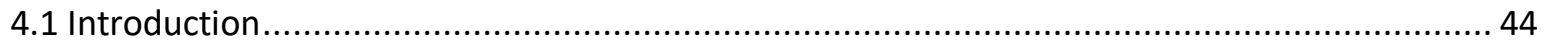

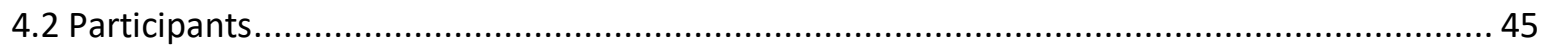

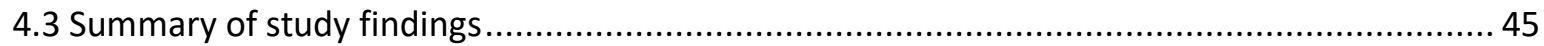

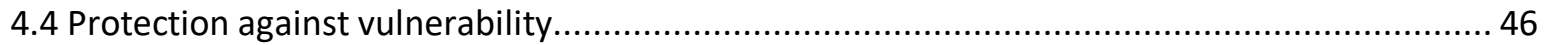

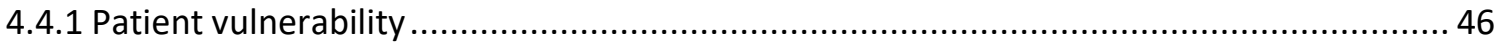

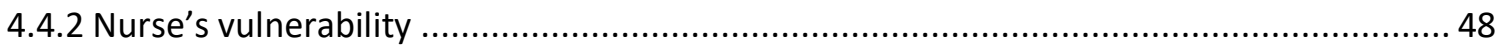

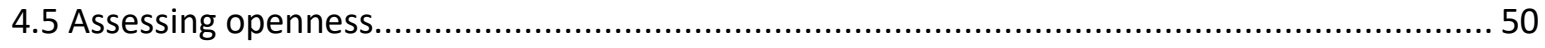

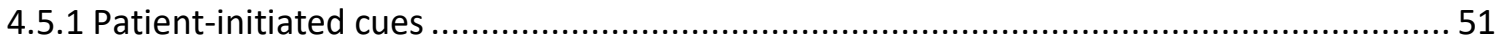

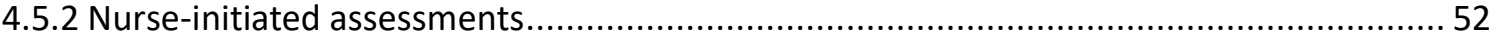

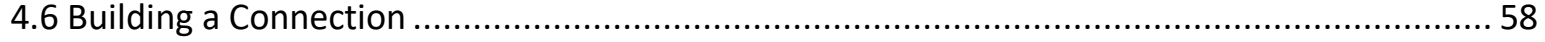

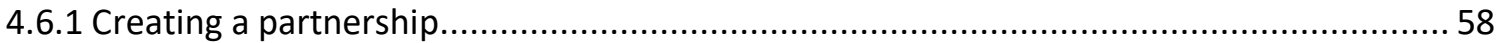

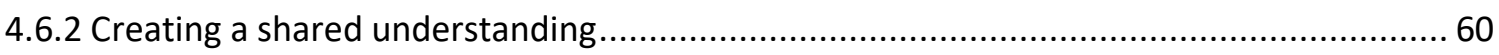

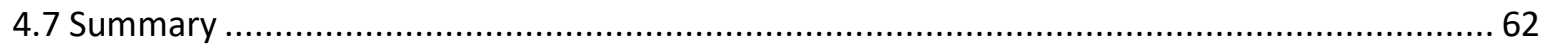

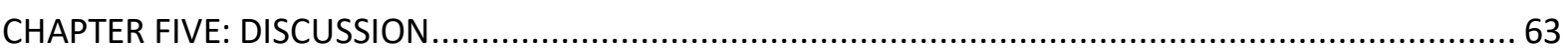

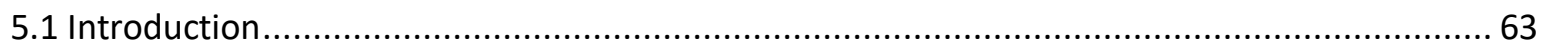

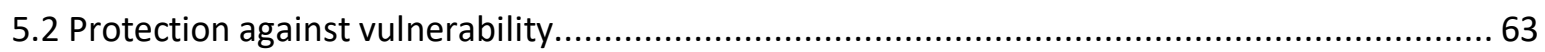


5.2.1 Patient vulnerability

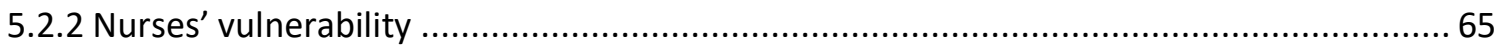

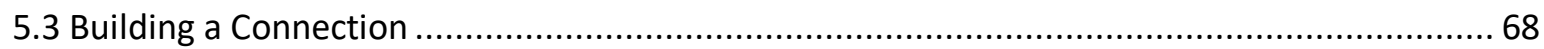

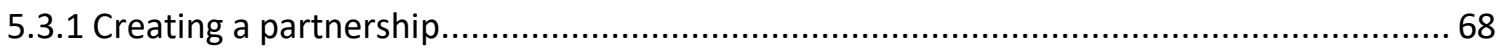

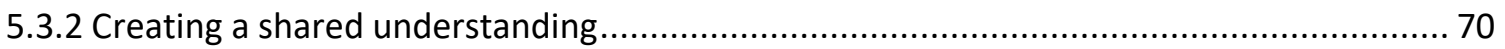

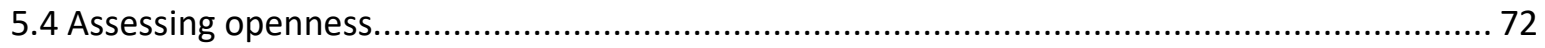

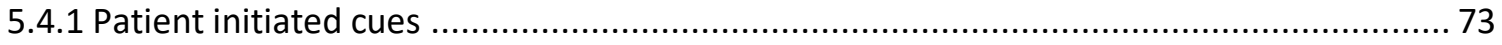

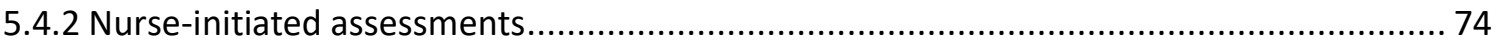

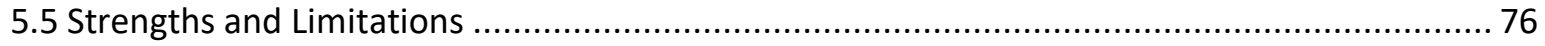

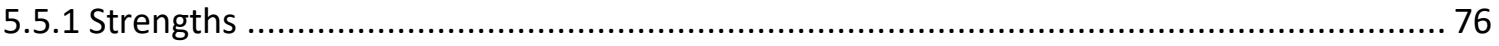

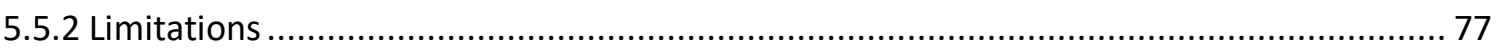

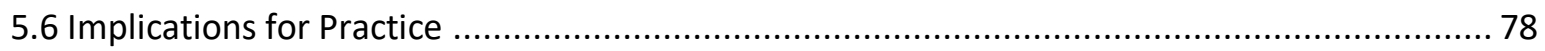

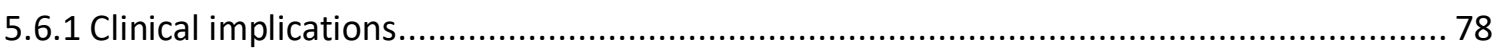

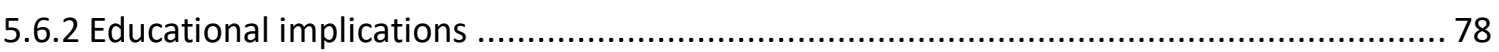

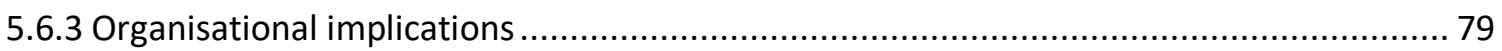

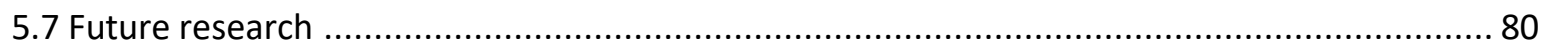

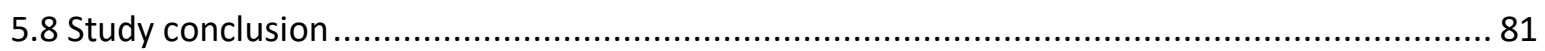

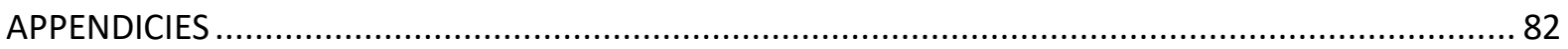

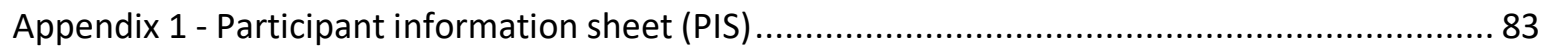

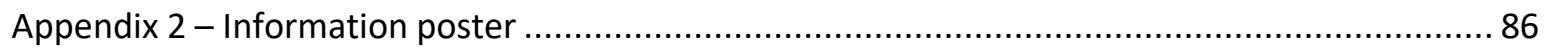

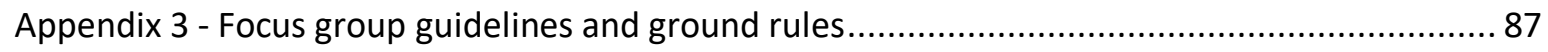

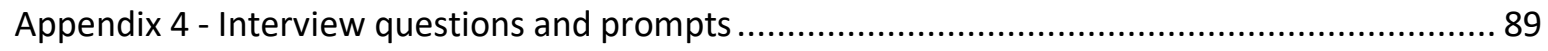

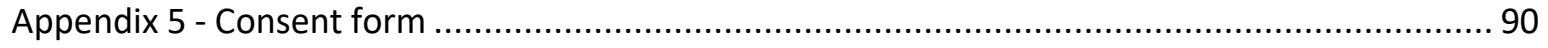

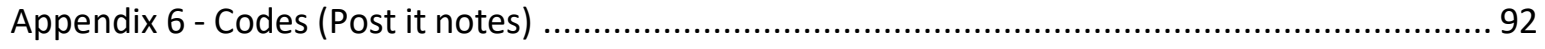

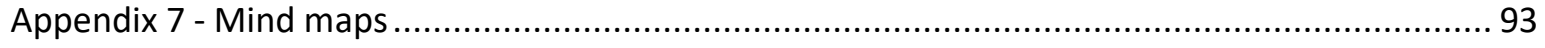

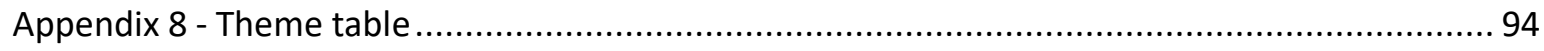

Appendix 9 - Ethics Approval from Victoria University of Wellington .......................................... 96

Appendix 10 - Ethics approval from Research Governance Group - Research site ....................... 97

Appendix 11- Ethics amendment approval - Victoria University of Wellington ............................ 98

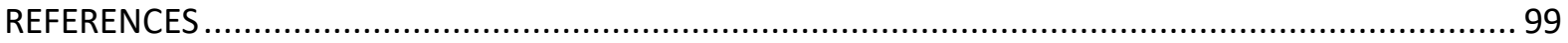




\section{List of Tables}

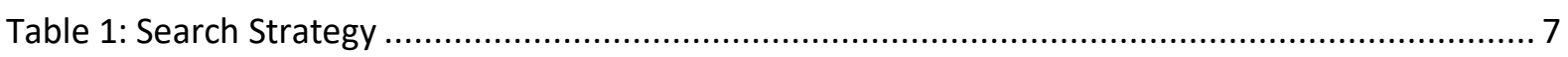

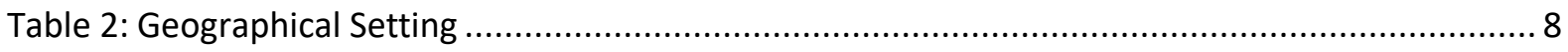

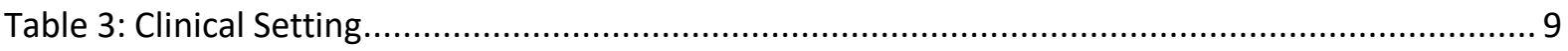

\section{List of Figures}

Figure 1: Key themes and subthemes 


\section{CHAPTER ONE: INTRODUCTION}

\subsection{Nursing practice and humour}

Nursing is a profession that requires clinical knowledge and advanced interpersonal skills (Sellman, 2011). Balancing the art and science of nursing is difficult, but crucial to effectively address the fluctuating physical and psychological needs of patients (McCabe, 2004; Sawbridge \& Hewison, 2013). Healthcare environments are challenging, high nurse-topatient ratios, increased acuity and limited resources can impact on the delivery of personalised care (Jangland et al., 2011; McCormack \& McCance, 2010). Nurses can become task focussed causing the nurse-patient relationship to suffer (Jangland et al., 2011). Use of humour is one strategy that can be deployed to build and maintain the nurse-patient relationship even in challenging environments. The purpose of this thesis is to explore how surgical nurses know when and how to use humour.

Establishment of the therapeutic relationship is central to the practice of nursing and for achieving positive health outcomes (Jangland et al., 2018; McCormack \& McCance, 2010). Humour is known to play a role in facilitating positive nurse-patient relationships and in forging and maintaining effective communication (Marshall et al., 2012; McCabe, 2004; Scholl, 2007; Wiechula et al., 2015). Nurses who initiate or reciprocate humour are viewed as friendlier, easier to communicate with and providers of a higher quality of care (McCabe, 2004; Tanay et al., 2014; Thorsteinsson, 2002). Humour offers the potential to build rapport quickly and connect on a personal level (Dean \& Major, 2005; Marshall et al., 2012; Thornton \& White, 1999).

Internationally, there is a drive to ensure the delivery of nursing care is person-centred as this protects the patient and provides the best care (Jangland et al., 2018; McCormack \& McCance, 2010). Acknowledging and understanding the uniqueness of each patient and tailoring care to meet individual needs are also principles embedded within the New Zealand Code of Conduct for nurses (Nursing Council of New Zealand, 2012). Nursing care that provides a partnership of care, embodies respect, maintains dignity and instils trust is the professional responsibility of every nurse (Nursing Council of New Zealand, 2012). In this regard, humour can be appreciated as a nursing skill to support professional practice. 
Humour has been shown to convey trust and respect (McCreaddie, 2010; Scanlon, 2006) and to maintain dignity within the nurse-patient relationship (Ghaffari et al., 2015; Haydon

\& van Reit; 2014; Jones \& Tanay, 2016; Walsh \& Kowanko; 2002). When nurses use humour, it provides patients with a sense of quality time with the nurse (Johnson, 2002) and a feeling of being seen as an individual, instead of being a task to 'be attended to' (McCreaddie, 2010; Scanlon, 2006). Humour is not a panacea providing the only way to achieve a therapeutic relationship or individualised care. Humour is however an important conduit enabling nurses to quickly connect with patients, thereby aiding communication to identify patient needs. As such, understanding how and when to use humour within the nursepatient relationship is a valuable skill for nurses to develop.

\subsubsection{Humour within nurse-patient interactions}

Within the healthcare context, humour is prevalent in patient and staff discourse. However, the significance of humour within these interactions has, until recently, been poorly understood or dismissed (Dean \& Major, 2008; McCreaddie \& Wiggins, 2008). Aptly described by Roberts and Wilbanks (2012) 'humours pervasiveness in human interaction blinds us to its existence, importance, and influence', and 'the commonness of humour use might cause it to be taken for granted' (p. 1093). Consequently, the acceptance of nurses utilising humour within their practice has been gradual; as has the research examining this. International nursing research does not provide a clear indication of how and when to use humour to the benefit of the patient (McCreaddie \& Wiggins, 2008) and there is little known about what influences nurses to use humour with patients. Conversely, recommendations of when to avoid using humour with patients to prevent potential harm are frequently mentioned. Although, this offers inconsistent and contradictory guidance creating uncertainty of when humour can be used safely within patient care, and how nurses can assess this (McCreaddie \& Wiggins, 2008).

Humour is ubiquitous in all human relationships and cannot be avoided (Jordan, 2017). Therefore, embracing and engaging with humour as an active participant creates multiple possibilities for its use. The opportunity to engage with and explore the qualities of humour within a health care environment has drawn the researcher to this research subject. 
Specifically, how nurses use humour and what guides their decisions in this process. The research aim of this study is to examine how nurses, practising in surgical environments, determine when and how to use humour.

The objectives of the study are to:

- explore the use of humour in nurse-patient communication by registered nurses practising in surgical wards

- describe the potential benefits and risks received by registered nurses practising in surgical wards of using humour during nurse-patient communication

- describe how registered nurses practising in surgical wards assess how and when to use humour within nurse-patient communication

- provide practical guidance on humour to inform professional surgical nursing practice

The context of surgical nursing was chosen as it is a fast-paced technical environment focussed on efficient and rapid through-put of patients, with surgical patients requiring an increased need for psychological support (Jangland et al., 2018). There is also a lack of humour research focussed within a surgical environment. Investigating current practices of how surgical nurses use humour and identifying their decisions that guide this process, will bring greater understanding to how surgical nurses use humour in nurse-patient relationships. An increased understanding of the drivers for surgical nurses to use and assess when and how to use humour with patients will provide evidence for clinical practice and provide insight into how the surgical context may shape humour use. Offering nurses, a greater understanding of the therapeutic benefits of humour for patients and themselves will build an appreciation of the use of humour in practice. Given that enhanced therapeutic connection between nurses and patients augments delivery of safe and responsive nursing care (McCormack \& McCance, 2010), this in turn may direct how humour can be used as a tool to support engagement and connection with patients. 


\subsection{Researcher introduction}

I have been a practicing registered nurse for 19 years working in a variety of clinical settings, ranging from medical to surgical, acute in-patient care to primary healthcare. Whilst my role has frequently changed, one factor has remained constant - a passion for enhancing patient care through active use and recognition of humour. My interest in humour stems from the belief that humour is so ingrained into our nature and way of being it would be erroneous not to examine it in the context of healthcare. To maintain a holistic view of the patient and provide care to address all areas of wellbeing, I believe the use of humour needs to be understood in the clinical setting.

A sense of humour has provided me, both personally and professionally, with the ability to manage highly emotional and stressful situations and gain perspective and insight. I have witnessed humour reach "difficult" patients through its ability to connect with and demonstrate value to the patient and provide perspective and reflection in situations that seemed desperate. I have also seen humour create an awkward silence or fracture in the nurse-patient relationship, hindering communication. My clinical experiences have provided an understanding that whilst clinical competence is important, the ability to relate to patients is paramount, as without this the experience for both parties is unsatisfactory and unfulfilling. My family has also taught me that to be able to make someone smile is a gift not be underestimated, and that is what I see humour bringing to the nursing profession. This ethos drives me to complete this research and explore humour within the realms of surgical nursing.

\subsection{Thesis structure}

There are five chapters to this thesis, an introduction, literature review, study design, findings and a discussion section. In the introduction, a brief overview of humour within healthcare and the link between humour and the role it has in creation of the nurse-patient relationship is discussed. The literature is reviewed in the second chapter and provides an outline of the body of research regarding humour within the nurse-patient relationship, which offers insight into what is already known and where research may be useful to extend the current understanding of humour. The third chapter, study design, provides the 
justification for the choice of method, methodology, sampling, data analysis framework and presents the components ensuring an ethical and rigorous research project. Following this is an exploration of the findings within chapter four, presenting the overarching finding that humour is used by nurses through judgement and with purpose. Description of the three themes that were developed through the process of thematic analysis is also outlined. The final chapter, the discussion, explores the significance of the findings and provides possible clinical, educational and organisational implications for surgical nurses. Future research avenues and the strengths and limitations of the study are also outlined, and conclusion to the study offered. 


\section{CHAPTER TWO: LITERATURE REVIEW}

\subsection{Introduction}

The focus of this research is the use of humour in surgical nursing practice. This literature review explores research in this area, surveying what is known - and what is not known - in order make clear the value and purpose of this study. The review provides insights into humour use in health care, with a particular focus on how nurses assess when to use humour. A discussion of non-nursing literature is also included to provide an alternative lens with which to understand the phenomenon of humour. The literature reviewed is presented in sections exploring the following key topics;

- Humour within the nurse-patient relationship

- The effect humour has on the nurse-patient relationship

- $\quad$ Nurses' understanding of and responses to patients use of humour

- How nurses assess when to use humour

- $\quad$ Barriers to nurses using humour within clinical practice

- Non-nursing literature exploring humour.

\subsection{Literature search}

The literature that informed this section was sourced over a two-week period in July 2017 using the following databases; CINAHL, PsycINFO, PubMed and Scopus. The broader literature was revisited during September, October and November 2018 to deepen data analysis and the formulation of the discussion. This process of re-engagement with the literature is a feature of the iterative process of qualitative descriptive methodology. To capture papers with a focus on humour (something funny) as opposed to humour (fluid in the body - vitreous humour) the search term wit and humor was used. Wit and Humor is a MeSH heading (Medical Subject Heading) and also a CINAHL Subject Heading provided by the databases. Wit and humor was therefore used to search PubMed, Scopus and CINAHL. Humor is a PsycINFO subject heading and was thus used to search PsycINFO. A sensitive search approach was used to ensure relevant material was not missed (Cargill, 2015), therefore, the date range was left open as nursing research on humour has emerged in the 
last 60 years (Ghaffari, Dehghan-Nayeri \& Shali, 2015; McCreaddie \& Wiggins, 2008). The following search terms; nursing, nurse-patient relations, interpersonal relations, relationships, emotional intelligence, human interactions, empathy, and communication were added with the Boolean operator AND to moderate the results and focus on humour within nurse- patient interactions and communication (Table 1). Additional searches were conducted using humor* and humour* to account for variations of word stems (e.g. humorous) and English UK language.

Table 1: Search Results

\begin{tabular}{|c|c|c|c|c|c|c|}
\hline $\begin{array}{l}\text { MeSH/ } \\
\text { Subject } \\
\text { Heading }\end{array}$ & Search terms & CINAHL & SCOPUS & PubMed & Subject Heading & PsycINFO \\
\hline $\begin{array}{l}\text { Wit and } \\
\text { Humor }\end{array}$ & & 5,848 & 4,790 & & 249 Humor & 9,112 \\
\hline $\begin{array}{l}\text { Wit and } \\
\text { Humor }\end{array}$ & AND Nursing & 1157 & 439 & & 76 Humor AND Nursing & 240 \\
\hline $\begin{array}{l}\text { Wit and } \\
\text { Humor }\end{array}$ & $\begin{array}{l}\text { AND Nurse Patient } \\
\text { Relations }\end{array}$ & 192 & 132 & & $\begin{array}{l}37 \text { Humor AND Nurse } \\
\text { patient relations }\end{array}$ & 35 \\
\hline $\begin{array}{l}\text { Wit and } \\
\text { Humor }\end{array}$ & $\begin{array}{l}\text { AND Interpersonal } \\
\text { Relationships }\end{array}$ & 80 & 0 & & \begin{tabular}{l|l}
80 & Humor AND \\
Interpersonal \\
Relationships
\end{tabular} & 31 \\
\hline $\begin{array}{l}\text { Wit and } \\
\text { Humor }\end{array}$ & AND Relationships & 342 & 282 & & $17 \mid \begin{array}{l}\text { Humor AND } \\
\text { Relationships }\end{array}$ & 338 \\
\hline $\begin{array}{l}\text { Wit and } \\
\text { Humor }\end{array}$ & $\begin{array}{l}\text { AND Emotional } \\
\text { Intelligence }\end{array}$ & 7 & 4 & & $\begin{array}{l}11 \mid \begin{array}{l}\text { Humor AND emotional } \\
\text { Intelligence }\end{array}\end{array}$ & 84 \\
\hline $\begin{array}{l}\text { Wit and } \\
\text { Humor }\end{array}$ & $\begin{array}{l}\text { AND Human } \\
\text { Interactions }\end{array}$ & 6 & 8 & & \begin{tabular}{l|l}
18 Humor AND Human \\
Interactions
\end{tabular} & 1056 \\
\hline $\begin{array}{l}\text { Wit and } \\
\text { Humor }\end{array}$ & AND Empathy & 66 & 51 & & 9 Humor AND Empathy & 202 \\
\hline $\begin{array}{l}\text { Wit and } \\
\text { Humor }\end{array}$ & $\begin{array}{l}\text { AND } \\
\text { Communication }\end{array}$ & 365 & 395 & & $\begin{array}{l}88 \text { Humor AND } \\
\text { Communication }\end{array}$ & 1630 \\
\hline
\end{tabular}


The number of potential articles identified was 19,750, however after application of the above search terms this reduced to 3,862. From the available abstracts those that were not available in English were omitted, with all other abstracts read, totalling 650. Citation searching was also carried out to ensure that all relevant papers were found and considered. After accounting for relevancy; nursing and focussed on humour within the nurse-patient relationship; and removing all duplications, 68 articles were reviewed and read in full. The criteria of the articles needing to be research- based was applied, reducing the total to 42 articles. A further three narrative papers were identified during the literature search, and whilst not reporting research findings, they were deemed important to debate and were included in the review. Whilst narratives can potentially be seen as subjective accounts with authors only drawing on research that supports their view (Schneider, Whitehead, LoBiondo-Wood, \& Haber, 2016), the three narrative articles were included in areas where there was a dearth of research- based papers available. A total of 45 articles were included in the review.

The following section presents an overview of the geographic and clinical settings of the sourced papers and will be followed by a deeper exploration of the research findings.

Most of the literature identified originated from America, the United Kingdom, Australia and Scandinavia (Table 2). This is important to note as the geographical settings in which humour is studied will affect study findings by reflecting the unique cultural and environmental elements of each setting (Tavory, 2014). Noticeably absent in this review is any research on humour from New Zealand. Exploring how nurses use humour in New Zealand would provide a unique cultural insight into how New Zealand nurses perceive, use and react to humour.

Table 2: Geographical Setting

\begin{tabular}{ll}
\hline Geographical Setting & Number of papers \\
\hline America & 18 \\
Australia & 8 \\
Canada & 1 \\
Scandinavia & 6 \\
United Kingdom & 10 \\
Middle East & 2 \\
\hline
\end{tabular}


The most commonly researched clinical settings were specialised environments such as oncology/palliative care, mental health, intensive care and paediatrics (Table 3). There is relatively little research in a surgical context with only three studies examining humour in a surgical environment. Surgical contexts are therefore a relatively under explored area.

The majority of research- based papers utilised for this literature review used qualitative methodologies $(n=40)$ with only two using quantitative approaches. This reflects the use of qualitative research to explore in-depth beliefs, values and interpretations (Denscombe, 2014) associated within a phenomenon such as humour. Findings from qualitative studies are often viewed as highly context specific and are not generalisable (Denscombe, 2014). As the use of humour in one nursing context may not generalise to another, dedicated surgical research is required to understand how nurses use humour in a surgical context.

Table 3: Clinical Setting

\begin{tabular}{ll}
\hline Clinical Setting & Number of papers \\
\hline Elderly Care & 3 \\
Education & 3 \\
Intensive Care & 4 \\
Medical & 9 \\
Mental Health & 6 \\
Oncology/Palliative care & 10 \\
Paediatrics & 4 \\
Surgical & 3 \\
Mixed clinical areas & 1 \\
Not stated & 2 \\
\hline
\end{tabular}

International research confirms humour is widely used in a range of clinical settings and is beneficial for nursing practice. Providing insight that humour can facilitate the nurse-patient relationship. These papers offer an understanding of the phenomenon of humour and how humour can affect the therapeutic relationship. However, as will be seen through the following discussion, research that explores how nurses prioritise when and how to use humour is far from comprehensive. 


\subsection{Literature findings}

\subsubsection{Humour use within the nurse-patient relationship}

Nurses are cognisant that the hospital environment is unfamiliar and foreign for patients and their families, causing stress and anxiety (Thornton \& White, 1999). Using humour is one strategy nurses use to help both family and patients adapt to the imposed conditions. In a United Kingdom study situated in an intensive care unit (ICU) nurses discussed humour providing family with a sense of normality (Thornton \& White, 1999). In regaining an aspect of 'normal' social interaction, humour helped relieve anxiety and provided an opportunity for family to connect with the nurses caring for their family member. Thornton and White's (1999) phenomenological study provides an understanding of how nurses' humour within an ICU environment can provide a sense of familiarity and comfort to family whilst being surrounded by frightening and uncertain circumstances.

Humour use to create comfort was also present in a Finnish study by Astedt-Kurki and Liukkonen (1994). Described as lifting the patient's spirits and creating a sense of joy, nurses used humour to provide the patient the opportunity to release tension, promoting relaxation and comfort. Using a larger sample size than other qualitative studies, AstedtKurki and Liukkonen's (1994) work included 32 nurses written experiences of humour, however it is unclear what clinical areas the nurses practiced. Therefore, the results provide an overview of humour in nursing care, rather than one that can be linked to a specific clinical area.

Using humour to create distance between the patient and their illness thereby promoting relaxation was reported by James, Andershed, Gustavsson and Ternestedt (2010). Given an opportunity to relax, humour allowed the patient to be momentarily freed from the stress of their illness to share their true feelings with the nurse. Whilst the focus of this Swedish ethnographic study by James et al. (2010) was not aimed at exploring humour within the nurse-patient relationship, humour was observed to be constantly present and to provide repeated opportunities for nurses to connect with patients. Use of both observation an interview data strengthens James et al.'s (2010) argument that humour was a deliberate 
strategy used by nurses ${ }^{1}$ to engage patients in conversation allowing the patient to freely communicate with the nurse. Engaging with patients through the medium of humour was also a key finding in Costello's (2016), McCreaddie's (2010) and Scanlon's (2006) work. Whilst the clinical settings were different, varying from in-patient psychiatric and medicalsurgical units to an out-patient gynaecology clinic, similar findings of humour enabling communication were reported.

Embracing the idea that meeting patient needs correlates with increased patient satisfaction, Costello (2016) identified surgical nurses in the United States of America who were, as described by patient satisfaction surveys, providers of exceptional nursing care. Using focus groups to explore the nurses' opinions on what qualities made their care exceptional, two key themes were identified; knowing the patient and being present. Humour was a component of being present. Again, this study was not solely focused on humour within the nurse-patient relationship, however the findings of what constitutes 'superior' nursing care found that humour was as a key component. Costello (2016) reported nurses used humour to connect with their patients allowing them to learn what was important to the patient in turn enabling individualised patient care.

Provision of individualised care requires an open line of communication and a relationship to be established. When working with marginalised patients this becomes even more pronounced. Using humour to connect with marginalised patients was explored by both McCreaddie (2010) and Scanlon (2006). Both populations studied shared a social stigma associated either with their lifestyle choice or diagnosis and were seen as 'hard to reach' clients; McCreaddie (2010) studied American patients with an addiction and Scanlon (2006) studied Irish psychiatric patients. McCreaddie (2010) and Scanlon (2006) describe humour as a specific tool to maintain patient engagement with health services. Using a negative case analysis McCreaddie (2010) studied one Clinical Nurse Specialist's (CNS) use of humour during interactions with nine of her female drug addicted patients. The use of purposeful harsh humour ${ }^{2}$ by the CNS, McCreaddie (2010) posits engaged and allowed connection with

\footnotetext{
${ }^{1}$ In this research both nurses and nurse assistants were included in the observations, however nursing assistant roles were not further defined.

${ }^{2}$ Harsh humour as defined by McCreaddie (2010) is humour that is unpleasant and exacting to the point of being cruel in action but not necessarily in effect. It is humour that taken out of context lacks any aesthetic appeal and is unrefined and vulgar.
} 
patients by acknowledging areas of their life and behaviour that were seen as socially unacceptable, but in way that was not construed as judgemental by the patient. Using interview excerpts to create a vivid picture of how humour effectively engaged patients, McCreaddie (2010) infers the CNS's unorthodox approach allowed the patient to see the nurse's "human" side, humour in their situation and feel at ease to share without fear of discrimination. Scanlon (2006) agrees that patients seeing the nurse as "human" is important and adds that psychiatric nurses use humour (not further defined) as an equalising measure to subvert the imposed authoritarian relationship with their patients, thus creating the feel of a friendship instead. Scanlon (2006) found nurses described humour as a fundamental skill to engage with patients, promoting feelings of equality and friendship to build the therapeutic relationship and reach positive health outcomes.

Also focussed on the mental health context, Gilberg, Bradley, Paaske and Hounsgaard (2014) conducted a literature review on the significance of humour within mental health settings. Whilst small, Gildberg et al.'s (2014) study reviewing 12 papers found humour allowed practitioners to appear more approachable to their clients supporting similar findings by McCreaddie (2010) and Scanlon (2006). As Gilberg et al. (2014) and Scanlon (2006) identify, nurses deliberately used humour with patients who were challenging to connect with because humour offered a 'different' means of connection bringing humanity and equality to the relationship. This in turn created an environment conducive to communication and building a therapeutic relationship (Gildberg et al., 2014; McCreaddie, 2010; Scanlon, 2006).

Fostering a therapeutic relationship and dealing with 'difficult patients' were two of the five findings from a phenomenological study focussed on exploring the meaning behind nurses' humour. Using the written experiences of 21 nurses from undisclosed clinical backgrounds in the United States of America, Beck (1997), described the meaning of humour for nurses. Her findings outlined that humour fosters cohesion between nurses and patients, humour can be either spontaneous or planned and humour has a lasting effect on the patient and the nurse long after the humours episode had finished. Beck (1997) discusses how nurses used humour routinely but also in circumstances when they had exhausted other methods of communication. When patients were in distress, humour was able to break through this distress, and provide the patient respite from either physical or emotional upset (Beck 1997). 
The literature about why nurses use humour demonstrates that humour is used to provide some sense of normalcy in an environment that can be frightening and intimidating to patients and their families. Allowing patients respite from concentrating on their illness, humour allows the patients focus to move towards open communication with the nurse and establishment of the nurse-patient relationship. Connecting with patients through humour, especially for those patients who are deemed to be challenging to connect with was achieved by conveying an element of being 'human' and 'just like the patient'. Humour created a relaxed environment which from the nurse's perspective, tilts the power balance towards a status of equality. Nurses deliberately use humour within nurse-patient to benefit the patients. Enhancing the connection between the nurse and patient ultimately flows onto to the nurse-patient relationship, that will be discussed in the next section.

\subsubsection{The effect of humour on the nurse-patient relationship}

The connection between the discussion above detailing why nurses use humour and how humour can affect the nurse-patient relationship is evident. The nurse-patient relationship is a central component of nursing care, and involves a complex set of expectations, attitudes and actions (Jangland et al., 2011). Effective communication is seen as a core requirement in creating a therapeutic relationship (Geanellos 2005; Jangland et al., 2011; Marshall et al., 2012; McCabe, 2008). It has been argued that humour can provide an environment that facilitates development of the nurse-patient relationship through enabling open communication and a sense of equality (Gildberg et al., 2014; James et al., 2010; McCreaddie, 2010; Scanlon, 2006). Therefore, exploring the effect humour has on communication and building and maintaining the nurse-patient relationship is important.

Using an exploratory descriptive approach Lotkzar and Bottorff (2001) determined the elements required to develop a positive nurse- patient relationship. In their study they observed one female nurse and one male oncology patient's interactions over three consecutive days. Humour was found to be present within every interaction and used extensively by both the nurse and patient. Lotkzar and Bottorff (2001) identified humour as a tool for dissolving tension related to differences and to soften the discussions of unresolved issues of care. Throughout nurse-patient interactions, humour allowed ongoing 
communication, irrespective of the issues that arose, thereby promoting maintenance of the relationship. Whilst this was the experience of only one nurse and one patient, Lotkzar and Bottorff's (2001) findings are reinforced by use of interviews, focus groups and audiovisual recording. Using multi-methods of data collection captured the subtleties of the interactions, that can be missed when relying solely on of self-reporting data. This study, whilst not aimed at exploring humour, inadvertently uncovered humour as feature of the nurse-patient relationship.

Creating an environment of open communication is also evident in other nursing literature (Marshal et al., 2012; Scholl, 2007; Schopf, Martin \& Keating, 2017). Based in a medical institute for recovery through humour (MIRTH) unit, Scholl's (2007) ethnographic observations over a three-month period, revealed humour achieved a sense of immediacy (being present) and liberated the patient to be open and unapologetic about their concerns and requests to the nurse. The sense that the nurse was 'one of us' and the associated familiarity humour created, allowed open communication within the nurse-patient relationship facilitating patient-centred care (PCC). Mirrored in Marshall et al.'s (2012) research into what it meant to receive PCC, humour was found to help the patient relate to the nurse and feel like an equal. Humour allowed the patient's needs to be voiced and met, also promoting PCC. Achieving PCC relies on understanding and acknowledge the uniqueness of each patient and tailoring care to meet their specific needs through effective communication and action (Marshall et al., 2012; McCormack \& McCance, 2010; Nursing Council of New Zealand, 2012; Wiechula et al., 2015). Marshal et al. (2012) and Scholl's (2007) studies detail humour creates an environment that encourages PCC through open communication.

Humour use to enable connection and discussion of topics that were difficult, or challenging was found in Schopf et al.'s (2017) ethnographic study. Humour created a sense of familiarity that was seen to support communication and trust between the health professional and patient. Allowing patients to be honest about not adhering to their prescribed diabetes regime, humour provided patients the ability to 'save face' with the health professional (Schopf et al., 2017).

Humour as a face-saving tool to avoid humiliation was detailed in a similar sized qualitative study based in the United States of America by Ragan (1990). Analysing 41 audiotaped 
interactions between nurses and patients during a gynaecological exam, humour between the nurse and patient provided a mutual understanding of the situation, a way to relieve tension and avoid the associated embarrassment of the gynaecological examination. Humour allowed the patient to maintain their dignity. The importance of humour is not in the content but how it conveys empathy and recognises the dignity of the patient (Dean \& Major, 2008). "The value of humour resides not its capacity to alter physical reality, but in its capacity for affective or psychological change which enhances the humanity of an experience for both care providers and recipients of care" (Dean \& Major, 2008, p. 1095). This position of maintaining dignity through empathetic humorous communication is further enhance by an Australian phenomenological study. In this study the researchers specifically focussed on the perception of dignity exploring the meaning of dignity from both the nurse and patient perspective (Walsh \& Kowanko, 2002). In this research it was found that one of the factors to maintain and facilitate patients' dignity was humour. Through reframing the 'extraordinary to the ordinary' and reducing embarrassment, humour was an attribute to enable patient dignity (Walsh \& Kowanko, 2002).

The personality and attitude of the nurse is often perceived to influence the success of the therapeutic relationship, so Geanellos (2005) explored how nurse friendliness enhanced the relationship. Patients defined friendliness as respect, attention, engagement, companionship, reciprocity and shared humour. When a nurse was perceived as friendly, the patient felt supported, valued and their spirits lifted, bolstering their inner coping mechanisms to deal with their illness (Geanellos; 2005). The patients also reported that their feelings of fear and isolation reduced, whilst the levels of trust in the nurse increased. This complements the finding that nurse friendliness was linked with clinical competence and technical skill, this aligns with similar findings from Johnson (2002) and McCreaddie and Payne (2010). Patients perceived nurses who were friendly and used humour were more competent, therefore trust was built enhancing the nurse-patient relationship. Although humour is shown to be a positive force to build relationships, used at an inopportune moment humour can cause harm.

Chapple and Ziebland (2004) describe how humour use can be hurtful. Studying the experiences of men with testicular cancer, Chapple and Ziebland (2004) found jokes made by health professionals or friends about the man's prognosis or consequences of treatment 
such as incontinence or infertility, caused humiliation and stigma. These feelings caused an emotional distancing between them and the health professionals or friends. Gildberg et al., (2014) supports Chapple and Ziebland's (2004) argument and adds that misunderstandings generated by humour can damage the nurse-patient relationship. Gildberg et al. (2014) argue careful assessment is required before using humour and Chapple and Ziebland (2004) propose that humour use should be instigated by the patient to signal to the health professional humour is acceptable.

The literature has revealed that humour within the nurse-patient relationship is seen as a predominantly positive phenomenon that encourages communication by defusing tensions or disagreements and creating space for vocalising patient needs. Maintaining dignity by reducing embarrassment, fear and isolation, humour allowed the patient to feel supported and connected to the nurse because they were viewed as 'being present' in the moment and an equal. Humour, as perceived by patients was as sign of competence and therefore strengthened the patient's trust in the nurse's ability. The overarching finding of literature is that humour can strengthen the nurse-patient relationship through developing trust, communication and validating patient experiences.

\subsubsection{Nurses' understanding of and responses to patients' use of humour}

The literature in this section discusses humour being a vehicle for relaying an underlying message from either the nurse or the patient. This message is often an unconscious expression of inner anxiety, allowing relief to the individual. This relief aligns with Freudian relief/release theory and is understood to mask other motives or desires that are usually not socially acceptable to express (Branney et al., 2014; McCreaddie \& Wiggins, 2008; Smuts, n.d). The following section discusses how nurses acknowledge and respond to the unconscious expression of patient anxiety through humour. Examples from the literature will be used to demonstrate how patients use humour and the nurse's response to it.

Mallet and A'hern (1996) conducted an ethnographic study focussed on nurse-patient interactions with five renal patients who were learning to self-haemodialyse. Audio and video recordings identified that humour was initiated by patients during dialysis. They did this in Mallet and Ahern's (1996) view to manage and communicate their distress in an 
acceptable way. Nurses reciprocated with a humorous remark, using humour to acknowledge and help manage the patient's difficulties. Mallet and A'hern (1996) explain that humour is not accidental but used to achieve a social outcome. In this instance patients asked for help to manage difficulties and fear with needling via a humour exchange with the nurse. Patients used humour when the nurse inflicted pain via needling to express their discomfort and bring these feelings to the surface in a socially acceptable way. The nurse was shown to understand the patient's message and reciprocated with humour to address and mitigate the patient's feelings. Whilst only five patients and their nurses ${ }^{3}$ were observed, 126 interactions were captured therefore validating the information gained, the dual data collection method also strengthens their findings.

Haydon and van Reit (2014) provide a slightly different perspective based on their narrative inquiry of four nurses in an Australian acute care setting. Asked to describe how they perceived their patient's humour, nurses shared humour was seen to be used to deflect questioning and for avoidance of talking about topics when patients didn't want to speak about or acknowledge upsetting topics, they used humour to deflect the conversation. This use of humour is a defensive mechanism and was most noticeably seen in the male participants of the study (Haydon \& van Reit, 2014). Because patients use humour as a defensive strategy there is a risk that nurses may miss the subtleties of the unconscious message of distress. Haydon and van Reit (2014) caution nurses to pay careful attention to humorous encounters with patients less they miss underlying distress. Humour use is negotiated between the nurse and patient. If a humorous joke is used by a patient, the joke can either be accepted at face value, or the nurse can look for a deeper meaning behind the humour use (Emerson, 1969). If humour is misunderstood, and "shut down" then this can create a barrier between the nurse and patient (Emerson, 1969).

McCreaddie and Wiggins (2008) state that nurses need to consider that patient humour may originate due to an underlying cause or concern. Analysing the purpose and function of humour, McCreaddie and Wiggins (2008) reported on a literature review of 88 papers across both nursing and psychology disciplines. The key finding of this review is that patient humour can be triggered by fear, embarrassment or discontent. McCreaddie and Wiggins (2008) argue that overlooking patient humour can result in a missed opportunity for the

\footnotetext{
${ }^{3}$ The total number of nurses observed by the study was not clearly stated.
} 
nurse to address these underlying concerns. However, McCreaddie and Wiggins (2008) also argue that humour within nurse -patient communication is not widely considered as important or significant, even though it is a current topic of research. McCreaddie and Wiggins (2008) recommend until humour is considered as a significant communication medium, this may have implications for the therapeutic relationship. The literature is unequivocal that nurses view patient humour as a vehicle to send a message, however the literature surrounding nurses' awareness of how to interpret this message is limited.

\subsubsection{How nurses assess when to use humour}

Literature outlining how a nurse knows when to use humour is sparse. Only basic generalisations such as 'know your patient first' or 'avoid crisis situations' are presented to guide nurses on the appropriate time to use humour (McCreaddie \& Wiggins, 2008). Narrative and qualitative literature included in this section does offer tangible ideas such as looking for patient cues, and 'reading the room' using the signs from patients to know that humour can be used (Adamle \& Turkoski; 2006, Dean \& Gregory, 2005, Greenberg, 2003). Relying on nurses' intuition to know when to use humour is also discussed, and whilst not easily defined, it is frequently cited. Literature suggests that for a nurse to effectively initiate or reciprocate humour with their patients, they need to develop the skills to do so. "Humour is not just a joke it is, perspective and skill" (Metcalf as cited in Adamle, 2006, p. 643). However, guidance on how a nurse does this is not always clear.

Using anecdotal and personal experiences from palliative care practice in the United States of America, Adamle and Turkoski (2006) advise that three stages of assessment are required for nurses to effectively use humour with patients. These stages are, recognising, interpreting and responding. Described as looking for the objective and subjective signs, recognising encompasses what and how patients say things and their accompanying body language. Interpreting encompasses considering the recognised signs and how the context may influence the patient's humour and what message they are trying to convey. Interpreting is tied to nurses' perceptions of patient humour, which was outlined in the previous section. Responding reflects what is appropriate given the interpretation, Adamle and Turkoski (2006) argue sometimes just a smile is all that is needed. 
Adding empirical data to support Adamle and Turkoski's (2006) explanation of recognising, are two other studies from Dean and Gregory (2005) and Greenberg (2003). Both studies conducted in the United States of America detail looking for cues from patients such as a smile, a twinkling in the eye, tone of voice or exaggerated hand movements indicates the patient is receptive or inviting of humour and therefore humour could be used by the nurse. Whilst Greenberg's (2003) study is relatively small, with three nurses and three patients observed, the level of detail and description of the verbal play that was present between the nurse and patient within the medical-surgical setting makes the data very compelling. Slightly larger in scale with six nurses observed, Dean and Gregory's (2005) ethnographic study within a palliative care setting confirmed patient cues are one way to ascertain when nurses can use humour, but added the nurse needs to also draw on their own experience to know when the 'right time' is.

Knowing the right time for humour use, has been eluded to in the literature as using intuition and 'knowing' the patient (Dunn, 1993; Struthers, 1999). Struthers (1999) research advises that nurses need to 'know' their patients before attempting humour, however this is difficult when meeting with a new 'unknown' patient. Given Struthers (1999) work was based in a mental health setting with seven specialist Scottish nurse practitioners, it can be assumed that the nurses had prior and long-term relationships with their patients, therefore knowing the patient's diagnosis, and history allowed the nurses in this context the foundation for 'knowing' the patient. Dunn (1993), who also explored a mental health environment outlines knowing the patient is one of the key factors influences a nurse using humour. Dunn (1993) adds that caring and use of intuition is pre-requisite for humour. Intuitive practice is commonly cited as a pre-requisite for using humour (Dean \& Major, 2008; Dunn, 1993; Struthers; 1999; Thornton \& White, 1999), however suggestions on how a nurse develops their intuition independent of experience are not clearly explained. Dunn (1993) offers a perspective that whilst intuition develops due to experience, if nursing students are taught the value of intuitive practice, overtime this will become part of their practice. Creating opportunities for introducing intuition as a legitimate part of nursing education is seconded by Melin-Johannson, Palmqvist and Ronnberg (2017), who posit that intuition can, in part, be developed by enhancing one's ability to reflect and critically appraise the environment. Intuition whilst not taught, has been recognised as part of 
nursing practice (Dunn, 1993; Melin-Johannson et al., 2017) and in regard to humour use, intuition is loosely defined as becoming more aware of the 'feeling' of environment and then using this feeling to respond appropriately (Duffin, 2009; Ford et al., 2013; Ofir et al., 2016).

Providing guidance on developing one's intuition to increase the ability to read emotions and respond to them, is described within one nursing study influenced from findings regarding the function and abilities of medical clowns (Leef \& Hallas, 2013). Using intuitive practice or a heightened awareness of the patients' needs, 'reading a room' to engage and build a therapeutic relationship is clearly outlined as the quintessential skill of medical clowning (Duffin, 2009; Ford et al., 2013; Ofir et al., 2016). Drawing on this, Leef and Hallas (2013) studied the effectiveness of providing a clowning workshop to 131 student nurses to increase their ability and sensitivity to work with paediatric patients. Students learnt how to read verbal and non-verbal clues - body language, emotions and the climate of a room to enable development of therapeutic communication and relationships with children and their families. Effectiveness of the training was tested 18 months later by survey, and whilst the response rate was low, under $50 \%$ return rate, $88 \%$ of the respondents stated continued use of the principles taught in the workshop. Whilst the aim of this paper was focussed on working with paediatric patients, training nurses to hone their observational and communication skills may be one avenue to help develop an awareness of intuition and the 'right time' for humour with any aged patient.

For nurses looking to understand how to know when the right time to use humour is, the research is limited. Knowing the patient, using intuition and the ability to read the atmosphere in the room are a start, but the current literature provides limited details. Consequently, this area requires further investigation to build a solid foundation of knowledge about how and when to use humour.

\subsubsection{Barriers to nurses using humour in the nurse- patient relationship}

Throughout the nursing literature, brief references to the barriers nurses face when using humour are present, however one literature review by Jones and Tanay (2016) explores this 
area in depth. The themes outlined in their review article provide the structure for the following section. However, additional papers have been included to augment the findings. The literature review undertaken by Jones and Tanay (2016) focussed on nurses' perceptions of potential barriers to using humour. Only seven papers were included in the review, this is not surprising given the specific area of humour being researched. The researchers provide clear search processes and rationale for inclusion and exclusion allowing for a strong and replicable review. The resulting analysis produced five themes; inappropriate situations, being a new/ junior nurse, fear of being labelled unprofessional, differences in personality and environmental factors.

Knowing when humour can be used, and therefore when it cannot (inappropriate situations), is a key component of humour use. As previously discussed, there are few papers that focus on how nurses assess and know when to use humour, but the literature does make frequent mention of when it is best not to. Exclusion zones for humour include physical or psychological crisis, pain, death/dying (McCreaddie \& Wiggins, 2008), or unstable physical or psychological situations (Astedt-Kurki \& Liukkonen, 1994). However, Dean and Major (2008) and McCreaddie and Wiggins (2008) propose that to preclude the use of humour in highly labile situations fails to recognise that it is in these very situations that humour can break the tension and connect the nurse and patient. Mallet and A'hern's (1996) research also demonstrates at the most distressing point of care humour was present and used as a strategy to cope with the distress. These contradictory messages (of when to use or not to use humour) creates uncertainty and therefore may impact on a nurse's decisions to use humour or not.

Humour use by nurses can be inhibited by being junior or new to the clinical environment. Humour was not seen as a priority when new, with precedence being given to learning the job, and acculturating to the culture on the ward first (Jones \& Tanay, 2016). This position is supported by Sumners (1990) who posits that as nurses increase in experience so does their confidence to use humour in the workplace. Being one of the few nursing studies to use a quantitative approach, Sumners (1990) draws on results from a large sample of 204 nurses from various clinical backgrounds in the United States of America to substantiate her findings. Sumner's findings could also be used to support the idea that as experience grows, 
so too does the ability to use intuition and therefore a nurse's overall ability to use humour (Dunn, 1993).

Humour is however not something that every nurse is comfortable using within health care and this may be because nursing as a profession appears to be risk adverse (McCreaddie \& Payne, 2011; McCreaddie \& Wiggins; 2008). McCreaddie and Wiggins (2008) propose that humour is risky, and as nursing is a rule-governed risk adverse profession, humour use will not always be appreciated, utilised or reciprocated. Expanding on this, several studies by Astedt - Kurki and Liukkonen (1994) and Thornton and White (1999) found that not all nurses felt humour was necessary in clinical settings. A few nurses actively disapproved of colleagues who used humour, due to perceptions that humour use was not professional (Astedt - Kurki \& Liukkonen, 1994; Thornton \& White, 1999). Limited exposure to humour during nursing training or within the work setting could be an attributing factor here (Beck, 1994; Warner, 1998). According to Warner (1998) and Beck (1994), if nurses are not socialised to humour during their nursing training and in the workplace, then humour may not be readily accepted as either appropriate or professional.

Being perceived as unprofessional can cause nurses to become reticent in using humour for fear of being labelled incompetent or not being taken seriously by their patients (Ghaffari, Dehghan-Nayeri \& Shali, 2015; Thornton \& White, 1999). This may arise from either the belief that ill health is not funny and as such should be taken seriously (Astedt-Kurki \& Liukkonen, 1994) or the lack of understanding of the potential benefits of using humour with patients (Astedt-Kurki \& Liukkonen, 1994; McCreaddie \& Wiggins, 2008; Thornton \& White, 1999). Patients however, view humour as professional, equating humour use as a sign of competence (Johnson, 2002; McCreaddie \& Payne, 2010).

Contextual factors are also known to affect nurses' ability to use humour. In several studies, nurses who felt stressed or time poor, did not initiate or reciprocate humour with their patients (Jones \& Taney, 2016; McCreaddie \& Wiggins; 2008). Nurses perceived they had insufficient time to get to know the patient to ascertain if they were receptive to humour or indeed spend extra time "joking" with them (Dean \& Major, 2008; Ghaffari et al., 2015; Haydon \& van Reit; 2014; Jones \& Taney, 2016; McCreaddie \& Wiggins, 2008). Ironically Johnson (2002) found that nurses need to be taught how to make the most of the limited time they have with patients and suggests humour could be a tool to maximise this time. 
The ward environment with a lack of role models, or with leaders disapproving of humour also impacts on nurses' abilities to use humour (Dean \& Major, 2008; Tanay et al., 2014). Both environmental and personal factors create barriers for nurses to use humour, and without education and support, these barriers can be difficult to overcome. The literature indicates that without humour use being accepted and role modelled by senior staff, other team members may not be confident or comfortable to use humour within their own practice. Humour use may be seen as inappropriate by some continues, therefore the potential value of humour within nursing practice should be further debated and discussed.

\subsubsection{Non-nursing literature}

Reviewing literature from disciplines outside of nursing increases the appreciation of the phenomenon of humour by offering insight into the diverse but universal properties of humour, irrespective of the setting. Therefore, psychology, sociology and social work based papers were also examined to gain insight into the other perspectives on use of humour. As found with many nursing studies, the social work and sociology research is mostly qualitative in nature. However, this is in contrast to the psychology research that frequently provides a quantitative lens with which to explore humour.

Psychology-based humour research explores how humour affects what people think and feel about themselves and toward others, and the flow on effects for relationships. Positive psychology is the area of psychology that studies the character traits that contribute to people living a positive and fulfilling life, and of the 24-character strengths listed within positive psychology that enable people to flourish, humour has been identified as one of these strengths (Collicut \& Gray, 2012; Edwards \& Martin, 2014). Within the framework of positive psychology, humour is understood to be a positive personality trait that facilitates initiation and maintenance of satisfying relationships, direct confrontation of challenges and maintenance of positivity when faced with difficulties (Edwards \& Martin, 2014). Canadian psychology research with 176 undergraduate students, revealed that humour use positively correlated with resilience, evidencing humour allows people to cope with stress and regulating emotion (Edwards \& Martin, 2014). 
In developing positive psychology interpretations of humour, other psychology research has focussed on the significance of humour within initial social interactions. Exploring the link between humour and liking (both platonic and romantic), Treger, Sprecher and Erber (2014) detail that use of humour between unknown subjects, increases the feelings of platonic closeness and likeability, that in turn creates enjoyment within the interaction and provides a platform for establishment of a relationship. Results indicated that as the level of perceived humour increased, so too did the level of connection with the authors suggesting that 'humour is glue that may bind us together' (p. 543). Using undergraduate students in the United States of America as research participants, Treger et al. (2014) offer results outside of a healthcare environment providing a different yet important interpretation of humour between two individuals. Whilst the romantic desire implications are less relevant to nursing contexts Treger et al.'s (2014) findings highlight that humour plays a part in creating an environment between two strangers conducive to building a relationship.

Building and maintaining a relationship through utilisation of humour is mirrored in literature within the discipline of social work. Although linked to maintaining wellbeing of the individual, the focus of social work is around increasing the social functioning of individuals and families to address life's challenges (Aotearoa New Zealand Association of Social Workers, n.d). Humour within social worker-client relationships is perceived as a necessity (Jordan, 2017). Jordan (2017) explored the relationship between social workers and their clients and how humour affected this relationship. Social workers identified humour communicating humanity and fostering a mutual appreciation, facilitating the clients viewing the social worker in a positive light as someone who understood them and could relate. Jordan (2017) describes humour as central and valuable tool to establish and maintain relationships in difficult situations.

Also focussed within social work, Moran and Hughes (2006) researched the relationship between humour and stress related coping strategies by Australian social work students. Findings indicated that using humour socially produced social support and therefore Moran and Hughes (2006) state that humour is a valuable tool to provoke support to decreased stress. This research also argued that humour should be formally included in the social work curriculum providing discussion on how humour can provide the ability to engage support 
and reframe stressful situations, reframing also discussed in Edwards and Martins (2014) psychology work.

Working within a sociological perspective, Tavory (2014) explored the humour surrounding the AIDS epidemic in Malawi as a measure of cultural meaning. Tavory (2014) argues to understand and appreciate humour knowledge of both the person's social world and their experiences within their world, need to be considered. Describing humour being contextual to the situation but also to the wider cultural environment, Tavory (2014) positions humour as an insight into and reflection of the current and unspoken truths for the individual and society, defining their reality. Robinson and Smith-Lovin (2001) also sociologists, studied the meaning of humour within small groups during task-orientated group discussions. Humour was found to be a means for both high status ${ }^{4}$ and low status group participants to establish and maintain relationships throughout the problem solving required in the group exercise. Robinson and Smith-Loving (2001) advise whilst humour manifested in different forms dependant on the gender of the participants, the purpose of the humour appeared to remain constant.

The literature reviewed within the social sciences of sociology, psychology and social work complements the nursing understanding and application of humour within communication and relationship contexts. A common finding across the disciplines, humour was found to be an essential component to building relationships between unknown individuals, fostering a sense of humanity and the ability to relate to one another humour allowing connections to occur. Exploration of the function and purpose of humour uncovered descriptions of defining social and cultural reality and eliciting support and resilience during stressful situations. Reviewing humour from a non-nursing perspective provides an understanding of how humour operates within well populations and how the context affects the purpose and experience of humour.

\footnotetext{
${ }^{4}$ Higher status individuals are those that are defined as trying to emphasise their power or importance within the group structure. Higher status individuals typically speak more often and interrupt others to assert dominance to be viewed as a leader. Therefore, lower status individuals are those who are happy to be one of the group without having assert themselves into a position of authority.
} 


\subsection{Summary}

Humour has been researched internationally across various disciplines and clinical settings. Nursing researchers have focussed on why nurses and patients use humour, explored nurses' and patients' attitudes towards humour, and the value humour can add to therapeutic relationships. The literature presents humour as a predominantly positive attribute when used with caution, thereby providing a key component of communication and relationships. Humour can create a sense of equality and humanity providing a way to engage even in difficult situations. Interestingly, many studies reported humour was a feature of communication as a secondary finding.

Despite the general positive regard for the use of humour in professional practice, there is little research or guidance on when and how to use humour effectively. Instead there is an emphasis on when to avoid using humour to minimise potential harm. Humour can be detrimental to the nurse-patient relationship if used inappropriately, however there is a lack of research that explores how nurses know when to use humour. Research that uses a surgical setting is also lacking. This creates a gap for surgical nurses who would like guidance on how to use humour with patients. This research aims to contribute to fill this gap. 


\section{CHAPTER THREE: STUDY DESIGN}

\section{1 Introduction}

The overarching research aim of this study was to examine how nurses, practising in surgical environments, determine when and how to use humour. A descriptive qualitative research design was chosen. Data were collected using interviews and analysed by means of thematic analysis.

The research question posed was: how do registered nurses working in surgical wards use humour in their practice? The first step in answering this question was choosing an appropriate study design. Thus, this chapter concerns the rationale for methodological choice and outlines the philosophical grounding, research method, recruitment strategy and sample, process of data collection and analysis, ethical and cultural considerations and research rigour.

The objectives of the study were to:

- explore the use of humour in nurse-patient communication by registered nurses practising in surgical wards

- describe the potential benefits and risks received by registered nurses practising in surgical wards of using humour during nurse-patient communication

- describe how registered nurses practising in surgical wards assess how and when to use humour within nurse-patient communication

- provide practical guidance on humour to inform professional surgical nursing practice

\subsection{Methodology}

\subsubsection{Philosophical grounding}

The philosophical perspective of a study dictates what constitutes knowledge and how the phenomena should be studied (Bradshaw, Atkinson \& Doody; 2017). The philosophical perspective of this project is underpinned by the naturalistic paradigm. Naturalism was a 
countermovement to positivism that maintained that the only true knowledge came from direct observation and measurement of phenomenon (Polit \& Beck, 2008; Schneider, Whitehead, LoBiondo-Wood \& Haber, 2016). The positivist view rejects the idea that there is any validity in answering questions that are not amenable to scientific measure (Schneider et al., 2016). In contrast, naturalism emphasises exploring that which is non-quantifiable and acknowledges that reality is not fixed but constructed by each individual in relation to their own context (Bradshaw et al., 2017; Schneider et al., 2016). Naturalism embraces the complexity of human experience and the ability to shape and create one's own experiences (Polit \& Beck, 2008). The belief of multiple constructions of reality allows the richness of the human experience to be explored. Consequently, researching humour, a phenomenon that contains social, behavioural and contextual constructions, lends itself to be explored through a naturalist qualitative approach. Complex, dynamic and context bound, humour is difficult to define; what one person may laugh or smile in response to another may not (McCreaddie \& Wiggins, 2008); a naturalistic approach can therefore capture these distinctions.

\subsubsection{Qualitative Research}

Qualitative research aims to provide understanding of an experience described by those closest to the phenomenon through examining perceptions, beliefs, values and interpretations (Denscombe, 2015; Schneider et al., 2016). Conducted without control of variables, qualitative research allows the phenomenon to be seen as it would be if it was not being studied (Polit \& Beck, 2008; Sandelowski, 2000, 2010). When describing a phenomenon such as humour, this is an important consideration. In making sense of human reality, qualitative research provides a rich insight into an experience thereby generating understanding, meaning and, potentially, theory (Schneider et al., 2016; Vaismoradi, Turunen \& Bondas, 2013).

There is a range of qualitative approaches available, but for novice researchers there are two options that are frequently used: qualitative description and interpretive description. These approaches share many qualities and, given the interchangeable use of terms through the literature, it can be confusing when distinguishing one from the other (Bradshaw et al., 
2017). A discernible difference is that interpretive description provides unsurprisingly, a more interpretive lens to the data analysis than qualitative description (Thorne, 2008). Interpretive description aims to "move beyond generic qualitative description into the domain of interpretive explanation which examines how phenomena are similar or different from one another, how they relate to one another, what patterns exist and how they operate" (Thorne, 2008, p. 50.) Whilst qualitative description does provide an element of interpretation to the data (Sandelowski, 2010), qualitative description is more concerned with describing what is happening with the phenomenon, the who, what, were, when (Bradshaw et al., 2017). Whilst interpretive description potentially offers a more sophisticated level of knowledge, for the reasons described below, a qualitative descriptive approach was chosen instead.

\subsubsection{Qualitative description}

To obtain an in-depth understanding of how and why nurses use humour in their clinical practice, a qualitative descriptive approach has been used. This approach was chosen for several reasons. Firstly, it is an accessible method for a novice researcher (Bradshaw et al., 2017; Sandelowski, 2000). Qualitative description does not require the researcher to have extensive knowledge of qualitative methodologies or to adhere to a strict theoretical framework; therefore it provides flexibility around data collection and analytical methods (Sandelowski, 2010). Secondly there is a dearth of available research describing how nurses assess when to use or avoid humour. Therefore, researching this aspect of humour, should begin with the type of foundational knowledge that a qualitative descriptive approach can provide. Using this approach captures what is "really" going on with the phenomenon (Bradshaw et al., 2017; Sandelowski, 2000, 2010), and provides a foundational knowledge that can be built upon with future research. Without needing to analyse the data using a prescribed theoretical lens or highly interpretive lens, qualitative description stays close to the data, providing a comprehensive summary of the phenomenon using everyday language (Polit \& Beck, 2008; Sandelowski, 2000; Schneider et al., 2016; Vaismoradi et al., 2013). Describing nurse-patient humour with language that is easily relatable and understood, provides a construction of the findings that could be appreciated by surgical nurses and therefore potentially assimilated into their clinical practice (Schneider et al., 2016). 
It is this quality of providing clear evidence to influence clinical practice that frequently attracts health care researchers to use qualitative description (Bradshaw et al., 2017). Qualitative description as described by Bradshaw et al., (2017) is used in about half of the qualitative health research conducted. Astedt-Kurki and Liukkonen (1994), Costello (2016), Ford et al., (2014), Johnson (2002) and Struthers (1999) all used qualitative descriptive research to describe humour within a health care context providing clear descriptions of how humour is used and impact the nurse patient relationship. Struthers (1999) describes how community psychiatric nurses know how and when to use humour with clients, whilst Costello (2016) describes humour as building a connection between nurse and patient. A qualitative descriptive approach renders the phenomenon of humour to be self-evident without layers of interpretation. Struthers (1999) and Costello's (2016) qualitative descriptive research maintains the essence and reality of humour use in the health care context (Polit \& Beck, 2008; Sandelowski, 2000). Thus, providing a compelling argument for the findings to be acknowledged as relevant, appropriate and impactful for practice (Bradshaw et al., 2017; Sandelowski, 2010). Using qualitative description for this research project will allow the researcher to stay close to the reality of humour within surgical practice whilst describing how nurses know how and when to use humour. Findings should resonate with surgical nurses as the language used will be familiar and recognisable. Using participants own words to develop codes and themes allows a rich and detailed account of the phenomenon in ordinary language. Thematic or content analysis are common data analysis methods which support a qualitative descriptive approach (Bradshaw et al., 2017). This research will use thematic analysis, as outlined later in the chapter.

\subsection{Methods}

\subsubsection{Study site}

Undertaking research with surgical nurses required gaining access to a hospital. For the size and associated time restrictions for completion of this project, a single site, tertiary hospital in the North Island of New Zealand was utilised. The site chosen employed an equivalent of 4,500 full time staff, 2,005 of which were full time equivalent nursing positions. This site provided care to 300,000 local residents and 900,000 people for specialist services. Five 
surgical wards provided a range of general surgical, vascular, orthopaedic, ophthalmology, urology, neurology, cardiothoracic, ear nose and throat (ENT) and gynaecologic services. Each ward had between $30-40$ beds and employed approximately 100 nurses, thus providing a large pool of potential participants.

\subsubsection{Sample}

\subsubsection{Sample pool}

Participants for this study were registered nurses working in surgical services within two ward settings: a general surgical ward (including vascular and ophthalmology) and perioperative services - Surgical Day Stay Unit (SDSU). Both wards provided nursing care for patients undergoing a range of surgical procedures and were therefore generalist rather than specialist wards. As noted in Chapter 2, generalist areas especially generalist surgical areas have received limited exploration with regards to humour use in the literature. Whilst the patient cohort was almost identical for both wards, the length of stay and number of beds differentiated the sites. Patients stayed a maximum of 24 hours post- surgery in the 18- bedded unit within SDSU, contrasting an average stay of 5 days in a 36-bed unit within the general surgical ward.

\subsubsection{Sampling method}

A purposive research sampling method was used. Purposive sampling is a non-probability method that focuses on accessible participants that have a certain quality or experience required for the study (Bradshaw et al., 2017). Therefore, registered nurses who were currently employed in a surgical environment, were the target group. All registered nurses working in these wards were eligible to take part in the study. A prescriptive length of service on a surgical ward was not included in the eligibility criteria as it was deemed that the registered nurses already had an underlying understanding of the surgical context because they had made a conscious decision to work in a surgical environment. The only exclusion placed on the sample was that non-registered nurses or ancillary staff working on 
the two wards were not eligible to take part as the focus of this study was on the registered nurse perspective.

There was also an element of informal snowball sampling that also occurred in the project. Snowball sampling is when existing participants actively recruit future subjects (Denscombe, 2014). This manifested in the first participant actively encouraging other colleagues to participate and one other participant asking if she could directly ask colleagues on my behalf to take part. This was discussed with my supervisors and resulted in one further participant being recruited.

\subsection{Access to Site}

Requesting permission to conduct the research on site and gain access to staff was achieved by contacting the Executive Director of Nursing (DoN), one of the first formal gatekeepers. Gatekeepers hold the power to either block or grant access to research participants, with formal gate keepers having the authority to grant official permission to undertake the research, therefore, acceptance of such formal gatekeepers is critical (Ahern, 2014; Wanat 2008). In navigating the leadership hierarchy of formal gatekeeper within the site, communication via emails and face-to-face meetings was established with the Directorate Leader of Surgical Services and the onsite Research Governance Group. These interactions resulted in the required access paperwork being submitted enabling access to the next layer of informal gate keepers; the Associate Clinical Nurse Managers (ACNM) and Clinical Nurse Educators (CNE). It is well-recognised that informal gate keepers can block access to the participants (Ahern, 2014; Wanat, 2008), and that even receiving acceptance from these gatekeepers does not always translate to co-operative participants (Ahern, 2014; Wanat 2008); therefore a sound recruitment strategy is also required.

\subsection{Recruitment}

To facilitate recruitment of the sample population, meetings with the ACNM and CNE from the day stay unit were arranged. A verbal explanation of the significance of the research and expectations of the participants was provided, to build understanding of the research and 
associated processes. The initial discussions were received very positively. This was particularly important as I was an outsider to clinical area, and in this circumstance, could have been a disadvantage to gaining access (Wanat, 2013). Staff forums to promote recruitment were identified and agreed. The most convenient time to visit was identified i.e. early Monday morning prior to surgical cases being received on site. Presenting at a staff forum allowed the research to be visible to staff and gave opportunity to build rapport with potential participants. Engaging participants in conversation and sharing connections such as similarities in profession or circumstance e.g. demonstrating understanding of being a nurse, can create a sense of familiarity that in turn can strengthen the interest to participate in research (Ahern, 2014). Prospective participants were offered a participant information sheet (PIS) (Appendix 1), that included a detailed outline of what the research was about, the risks and benefits associated with participating, confidentiality considerations, ethics approval and contact details should participants have any questions.

An open line of communication was established in one clinical area with the ACNM and CNE. This resulted in their agreement to distribute group emails to the staff thereby promoting and reminding staff of the research project. Opportunity to speak with staff was also granted at specific times that minimised disruption to the nurse's work. With permission, general information sheets were placed in clinical areas (Appendix 2) allowing registered nurses easy access to contact details and the research outline. The recruitment process remained flexible by allowing staff interested in participating to encourage others to participate, an element of snowball sampling.

Whilst this process worked well in one ward (Day stay unit), the other ward proved more difficult due to extenuating factors i.e. sickness of informal gatekeepers. Although the same recruitment strategies were utilised, it was difficult to establish effective communication. Only a limited number of staff were involved in initial meetings. With such limited access to staff, a more flexible approach to recruitment was needed. 


\subsection{Data collection}

\subsubsection{Focus groups}

Focus groups were the planned data collection method; it was a pragmatic decision to access multiple participants at a time as this fitted with the ward schedule. Utilising four or more participants, focus groups simultaneously capture and explore a range of views and experiences and reveal the extent beliefs and opinions are shared across a group (Denscombe, 2014; Doody et al., 2013). Given the subjective nature of humour, group discussions were to be used to see the range of beliefs, shared and divided amongst the participants. However, due to study time constraints, difficulty gaining access to one clinical area, and the nature of conducting research in busy clinical areas, it was not possible to recruit sufficient staff to run focus groups. Therefore, a pragmatic approach was used and group interviews and single interviews were utilised instead.

\subsubsection{Group interviews and single interviews}

Group interviews, which include two to three participants, share similar qualities to focus groups in that they collect data from more than one participant at a time, enabling some comparison of views at the time of data collection (Denscombe, 2014). In addition, the group dynamic aids discussion and comparison between participants and this can uncover the reasoning and underlying factors that shape the expressed views (Denscombe, 2014; Doody et al., 2013). Group interviews also provide an opportunity for participants to become involved, share their ideas and reflect on the views of others. With a smaller group, sensitive information may be shared (Carey, 2016), as with only one or two other people present, views that are controversial or sensitive are more likely to be raised as there is less potential for judgement (Denscombe, 2014).

The potential to capture sensitive or seemingly controversial information is also an advantage of single interviews as the environment is conducive to establishing trust between the researcher and participant (Denscombe, 2014). Having just one participant for questioning can also provide opportunity for the researcher to probe further, capturing a 
richer description of the phenomenon. Whilst time consuming, interviews provide illuminating data provided the questions are relevant and executed well.

Relevant information pertinent to the research topic needs to be gathered for data to be useful. To achieve this, semi-structured questions (Appendix 4) were formulated. Semistructured questions offer the opportunity to stimulate discussion whilst giving flexibility to probe responses that may not have been planned for (Doody et al., 2013). Given that humour is such an individualised experience, the potential for this was substantial. Probing provides an ability to delve below the surface of a statement and gather more detailed information (Carey, 2016), therefore, open-ended probing questions were also developed and included on the question sheet (Appendix 4).

In total nine participants were recruited, and 2 group interviews and 5 single interviews were conducted. All interviews were held either in a small on-site meeting room, or in a venue of the participant's choice, such as a cafe. On arrival participants were offered refreshments, a copy of the PIS and given the opportunity to raise any questions. An explanation of the interview was provided. Participants were then asked to give verbal indication if they wished to continue and once this was given, the written consent (Appendix 5) form was provided. During the signing of the consent form participants were reminded they could withdraw from the research at any point up until April 2018, this gave participants four months to consider their withdrawal from the study. Data collection then began with the audio recording device being turned on, participants being asked to share their experiences of using humour in their clinical environment using semi-structured questioning and probing. The semi-structured questions had been previously tested with the researcher's supervisors and structured to elicit responses suitable to answer the research questions.

\subsection{Data Analysis}

Making sense of the raw data requires analysis, with the nature of the research guiding the choice of data analysis framework applied. Thematic analysis (TA) was chosen as the method of data analysis. TA is a process of systematically analysing the data as a whole to 
identify and describe the patterns of meaning within the dataset (Braun \& Clarke, 2006; 2012; Clarke \& Braun, 2017; Joffe, 2012). The identified patterns allow the researcher to make sense of the shared experiences of the phenomenon under study, rather than the idiosyncrasies found within the data set (Braun \& Clarke, 2006; 2012). Whilst there are multiple versions of TA, Braun and Clarke's TA framework stands out; it is robust, widely used and has a clear process to follow that is easily accessible to novice researchers (Clarke \& Braun, 2017; Joffe, 2012). The accessibility is found within the language used to explain the concepts behind TA and the provision of six identifiable steps to undertake the analysis. Braun \& Clarke demystify TA, a data analysis method that has historically been misunderstood (Joffe, 2012; Vaismoradi et al., 2013).

The first step of data analysis is immersion into the data (Braun \& Clarke, 2006, 2012). Transcription of the data verbatim, reading and re-reading the data and making notes and memos provided the basis of immersion. This process resulted in a very close familiarity with the data allowing initial coding to commence. Patterns and relationships relevant to the research question were then identified through the development of codes. Codes are small units of analysis that highlight interesting features of the data and can be either semantic or latent in nature (Braun \& Clarke, 2006, 2012; Clarke \& Braun, 2017; Joffe, 2012; Vaismoradi et al., 2013). Initial codes were developed from similarities and differences in the data pertinent to the research question. Codes were written on post it notes, stuck to a wall (Appendix 6) and then grouped into sub-themes and themes, based on connections and variations in the data relevant to the study's research question. Representing a significant pattern of meaning, themes provide important description of the phenomenon under study (Joffe, 2012). During this process data saturation became evident when no new codes were developing and there was an associated increase of the same codes recurring.

Data saturation within qualitative studies has been argued to be difficult to qualify as experiences are unique to each research participant and the sample sizes are usually small (Bradshaw et al, 2017). Determining if a sample is adequate is one measure of data saturation (Fusch \& Ness, 2015). According to Fusch and Ness (2015), data saturation in qualitative research can be described as achieved when the ability to gain new information is reached, indicating the sample size is sufficient. During the data analysis stage of the final 
interview, no new codes emerged whilst existing codes were replicated, therefore data saturation was considered to be reached and no further interviews were conducted.

As described by Braun and Clarke (2006; 2012), conducting thematic analysis is not a linear process. Constant examination of the data, codes and themes was needed and repeated to progress throughout each phase of the analysis process. This enabled a true emersion into the data and a sense of vivid familiarity. The list of codes and their attached data excerpts, themes and sub-themes were discussed with supervisors for verification of accuracy and relevancy, whilst mind mapping (Appendix 7), the use of a journal and being reflexive, also aided in the production of the final themes. An example of a theme table outlining the progression from initial codes to the final theme is located in Appendix 8. The three final themes are presented are discussed in the next chapter.

\subsection{Reflexivity}

Reflexivity is described as an essential component of qualitative research (Koch \& Harrington, 2002). A researcher applying reflexivity, assess their biases, preferences and preconceptions and how these could affect the data collection and interpretation (Polit \& Beck, 2008). This self-awareness forms a foundation to ensuring rigour. After the first interview, I wrote in my journal about how I felt it went and what my first impressions were. I had attempted to be neutral during the interview and avoid using leading language or phrases that could skew the answers towards the positive position, which I was naturally inclined to seek. After transcribing the early data, it was evident that there were instances where I lead the participants and this may have potentially affected the data. This was mostly evident when I summarised to the participants what they had said, I used language that was more interpretive than descriptive, using a word that I felt captured the ideas, but was not actually used by the participant. This reflection lead me to alter my future interviewing technique by being mindful to summarise ideas without using words that were not initially used by the participant. 


\subsection{Ethical Implications}

Conducting ethical research requires the protection of participants from personal, physical or psychological harm (Denscombe, 2014; Polit \& Beck, 2008). Negating potential harm for participants was accomplished by addressing the following ethical principles: informed consent, anonymity, confidentiality, privacy, respect and beneficence within both ethics applications. Ethical approval was granted on the $15^{\text {th }}$ of August 2017 by the Ethics Committee of Victoria University of Wellington (Approval number -24799), (Appendix 9). The study proposal and application was submitted to the onsite Research Governance Group and received approval on the $12^{\text {th }}$ of September 2017 (Appendix 10). An amendment to the original ethics application was made on $21^{\text {st }}$ of November to acknowledge the change of data collection from focus group to single/group interview, and this amendment was granted one day later on the 22nd of November 2017 (Appendix 11).

\subsubsection{Informed consent}

Informed consent is the process that provides the participant with all the relevant information to make a decision that upholds their personal beliefs and values, free from coercion (Schneider et al., 2016). Providing all participants with a copy of the written patient information sheet (PIS) detailing the nature of the research, the commitment required, an outline of any benefits or risks from participating and the voluntary nature of participation was the foundation of gaining informed consent (Denscombe, 2014; Schneider et al., 2016). Presentation at a staff education session and visiting the ward allowed potential participants direct access to ask any questions. Contact details of the researcher and supervisors were provided via email. Hard copies were left available on the ward offering further opportunities for potential participants to query information thereby ensuring that participants were informed prior to becoming involved in the study.

Participants involved in the research were provided with a verbal explanation of the research prior to receiving the written consent form (Appendix 5). Consent forms were signed after the participant had read the information sheet and had verbally confirmed that they understood its content and had opportunity to ask questions. Participants were made aware that could withdraw at any time before April 2018. 


\subsubsection{Anonymity}

Whilst complete anonymity is preferred in research, this is not always possible in face-toface data collection methods such as interviews and group interviews. However, in using pseudonyms (RN 1 -9) and removing all identifying details from the written transcripts, a degree of anonymity was achieved. Participants were aware of their anonymity in the written research and how this would be addressed in data management and data write up.

\subsubsection{Confidentiality/privacy}

The identity of the participants outside of the work environment, was known only to myself, and my supervisors, as the supervisors had access to the initial unedited transcripts. The audio recordings and written transcripts are stored electronically on a password protected laptop to prevent any unauthorised access and will be destroyed after five years, in line with University regulations.

Meeting with staff on the ward posed a confidentiality issue as their participation could have been noticed by other staff members working on shift. However, due to the multiple shift times and the geographic layout of the ward, the impact of this was minimised. Participants were advised that if any colleague or patient names were mentioned during data collection that this would be kept within the interview 'room' and that these specific details would be omitted from any research written material. Written consent forms and copies of the transcripts are stored in a locked cupboard and will, in line with University regulations, be destroyed after five years.

\subsubsection{Respect}

Nurses come from a variety of backgrounds and include a diverse mix of ages, genders, sexual orientation, religious beliefs and ethnicities. To respect the unique identities and needs, participants were given opportunities to communicate any specific cultural requirements to ensure they felt comfortable to participate. Communication throughout the research process with participants embodied courtesy and respect, whilst showing a 
genuine interest in the participants. This was undertaken by asking nurses about themselves, and their careers. The views of participants were respected in data collection through use of active listening and encouraging responses and demonstrating respect for their giving of time and willingness to participate in the research.

\subsubsection{Beneficence}

The sharing of personal and professional life experiences during data collection has potential to evoke memories or feelings that can cause distress. Understanding the nature of the research as outlined on the information sheet, provided a degree of protection for participants. Associate Charge Nurse Managers (ACNMs) were informed about the potential for such distress so that participants requiring support would have access to counselling via the Employee Assistance programme (EAP). I was aware of my obligations under the Health Practitioners Competence Assurance Act 2003 (HPCA). If substandard nursing care was exposed during the research, a course of action was pre-agreed. A written notification to the ACNM and the Nursing Council of New Zealand outlining the concerns would have been completed, however this was not required.

\subsection{Research rigour}

The rigour of qualitative research continues to be contested, frequently encountering criticism that it is not as valid or relevant as quantitative studies, that adhere to the 'gold standard' of generalisable research produced with an experimental design (Denscombe, 2014; Rolfe, 2009; Sandelowski, 1986; Schneider et al., 2016). In part, this argument stems from historic assessment against the same criteria designed for quantitative research (Rolfe, 2009; Sandelowski, 1986; Schneider et al., 2016), giving qualitative research the appearance of being less rigorous (Ryan-Nicolls \& Will, 2009). However, the issue is more with the application of inappropriate criteria of evaluation (Ryan-Nicolls \& Will, 2009). Application of criteria designed for qualitative studies can provide some resolution (Rolfe, 2009; RyanNicolls \& Will, 2009) as not all phenomenon can be adequately studied by quantifiable research. Qualitative research brings a quality and richness of detail and depth that cannot be achieved by quantitative research methods. Consequently, criteria to assess rigour in 
qualitative research needs to capture the detail of the "contextual and epistemological attributes of the qualitative inquiry" (Ryan-Nicolls\& Will, 2009, p. 75).

Guided by Sandelowski's (1986) criteria, the rigour of this research will be addressed, through the measures of confirmability, auditability, credibility and fittingness. Sandelowski's principles are similar to those described by Lincoln and Guba, however Sandelowski provides a more pragmatic and flexible application (Rolfe, 2006). Through articulation of the nuances of quantitative research, Sandelowski provides a compelling argument for her criteria. Widely used and discussed within the literature (Bradshaw et al., 2017), Sandelowski's criteria remain reliable and convincing for application within qualitative research.

\subsubsection{Confirmability and Auditability}

Sandelowski (1986) discusses how confirmability of research is achieved when auditability, credibility, and fittingness are adequately addressed. Describing the rationale and logic for how and why decisions were made throughout the entire research project, provides the basis of auditability (Denscombe, 2014; Sandelowski, 1986). To help meet this criterion, a detailed journal outlining the study and decision-making processes and resultant outcomes was kept. This provided the ability to revisit research decisions and reflect on how and why these were made. In addition, a visual record of codes, themes and subthemes developed from the data using mind mapping and diagrams (Appendix 6) was kept. The data analysis and resulting themes were regularly reviewed and discussed with the researcher's supervisors.

\subsubsection{Credibility}

Credibility of qualitative research is demonstrated through the researcher's ability to describe and interpret their own behaviour and separate this from the experiences of the participants (Sandelowski, 1986). Biographical details of the researcher and the rationale behind the choice of topic was detailed in the introduction to this research. Acknowledging the standpoint of the researcher and the associated pre-existing views of the phenomenon 
provides an insight into how these factors may impact the data interpretation (Denscombe, 2014; Sandelowski, 1986). Reflexivity also helps address the criteria of credibility. A reflexive journal was kept within the field journal recording initial thoughts and reflections over time, about decisions made. The reflective process provided insight into what influenced and guided my decision-making processes throughout the research.

\subsubsection{Fittingness}

Fittingness also known as transferability (Koch \& Harrington, 2002) is concerned with establishing the degree that the findings can be "transferred" from the original study into other settings (Polit \& Beck, 2010; Sandelowski, 1986). As described by Polit and Beck (2010) being able to extrapolate findings into a context other than the one in which they were generated is the basis of evidence-based practice. If research is not transferrable then it would not be valid as evidence to inform practice. However, transferability can be challenging for qualitative studies. Small sample sizes and the inherent complexity of the phenomena under study are two challenges to generalising qualitative research findings (Polit \& Beck, 2010). In both cases there is a risk that the findings are not generally representative of other times and places. Provision of details about the sample used and the setting of the research can mitigate this limitation of qualitative research, as the reader can decide for themselves how relevant or transferable the research is to other contexts. This thesis enables readers to assess fittingness, by providing details on the participants; gender, ethnicity, years of practice within a surgical practice and number of participants per group interview. These details have been included within the findings chapter, chapter four, along with the description of the site and ward settings earlier in this chapter.

Reporting the data and results in a way that is meaningful to an audience outside the research is another measure of fittingness, enabling the reader to access the findings (Sandelowski, 1986). Chapters four and five were written with the goal of maximising the accessibility of the findings and applications of this research to a wider audience. Understanding the relevance in terms of their own practice potentiates the use of this research in practice. 


\subsection{Treaty of Waitangi Considerations}

The principles of partnership, protection and participation were used to guide a culturally sensitive approach to the collection, analysis, interpretation and reporting of data, especially as it relates to Māori people and their interests.

Registered nurses' views about the use of humour were explored regardless of whether the nurse identified as Māori, with one of the nine participants doing so. None of the themes identified appeared to relate specifically to only the needs or interests of Māori, therefore, analysis and reporting as a separate topic within the thesis was not required.

\subsection{Summary}

This chapter has outlined the underlying theory and processes that shaped and guided the research, data collection and analysis. Discussion of the rationale for the chosen methodology is evident, as is the choice for using qualitative description. Qualitative description allows an explanation of humour use that is recognisable, not only to a large audience, but also generates findings that could be easily translated into guidance for nurses within surgical practice, meeting the aim and objectives of the research. Findings from the thematic analysis guided by Braun and Clarke's methods, generated three themes that are outlined in the next chapter. 


\section{CHAPTER FOUR: FINDINGS}

\subsection{Introduction}

Identifying the principal themes from interviews with the participants was developed using thematic analysis. This chapter presents these three themes; protection against vulnerability, building a connection and assessing openness, and their associated subthemes that describe how and why nurses use humour and the risks and benefits (Figure 1).

The first theme, 'protection against vulnerability' provides insight into why nurses use humour and the unique drivers in a surgical context that necessitate humour use within nurse-patient interactions. The second theme, 'building a connection' complements the first theme by developing the understanding of how and why nurses use humour. Humour building connection with patients and therapeutic relationship is explored. The final theme, 'assessing openness' presents the process of assessments required to decide whether or not to use humour. Both nurse and patient-initiated cues are previewed. A summary of findings draws on the thesis that nurses use humour consciously and purposefully.

\section{Protection against vulnerability}

- Patient vulnerability

- Nurses vulnerability

\section{Assessing \\ - Patient initiated cues \\ openness \\ - Nurse initiated assessments}

Building a connection
- Creating a partnership

- Creating a shared understanding

Figure 1: Key themes and subthemes 


\subsection{Participants}

As detailed in the previous chapter, data collection was problematic. Two group interviews with two participants in each and five single interviews were completed instead of the planned focus groups; a total of nine registered nurses participated in this study. All participants were female, and came from a variety of ethnic backgrounds, identifying themselves as either Māori, Indian, Scottish, New Zealand European, or Filipino. The participants were employed in surgical services and had worked in the context of surgical nursing for a minimum of two months. The seven interviews ranged in length from 22 minutes to 34 minutes and were transcribed by the researcher using pseudonyms to protect participants' identity.

In discussing the developed themes, quotations from each of the participants will be used throughout this chapter. To maintain confidentiality, participants will be identified by the abbreviation RN and then with unique identifying numbers (1-9). This allows for identification of the different participants without compromising their identity.

\subsection{Summary of study findings}

This study identified that surgical nurses consciously and purposefully use humour with patients. This conscious and purposeful thinking allows nurses to determine whether or not to engage in humorous moments. Nurses use this thinking along with their clinical judgement to assess a patient's physical and emotional wellbeing. This creates a foundation for nursing decisions regarding use of humour during each patient interaction. Conscious and purposeful thinking allows nurses to determine if humour is appropriate or beneficial in their interactions.

Nurses use humour with purpose: be it to test the patient's reaction to further humour use, or to provide respite for patients or themselves in situations that are stressful and difficult to manage. Humour provides a reprieve from the perceived physical and emotional vulnerability experienced by both patients and nurses within the surgical environment, allowing escape and cognitive reframing of the situation. Nurses understand that humour is a tool that can aid communication, alleviate fear, and provide comfort in a foreign surgical 
environment, therefore is used purposefully within the nurse-patient relationship to facilitate these varied functions.

\subsection{Protection against vulnerability}

This theme provides an understanding of why surgical nurses use humour with their patients. Surgery is known to induce negative emotions such as anxiety and fear. Nurses described using humour as one tool to help moderate the stressful effects of surgery and provide comfort, whilst also providing themselves an escape from the realities of their surgical environment.

\subsubsection{Patient vulnerability}

Nurses described the surgical environment and impending surgical procedures as causing anxiety and tension for both the family and the patient. Being in an unfamiliar environment combined with the unknown surgical process can evoke many emotions including fear, anxiety and nervousness. These emotions equate to an emotional vulnerability and can cause the patient distress. Nurses described using humour to distract patients from their worries and anxiety, by providing a different perspective or respite from these feelings to help the patients relax.

People going for big surgeries, they come through us all of the time and you can tell that the family are nervous and they are nervous, so so just bringing in a bit of humour and a bit of a laugh, just makes them forget about it for a split second or makes them have that better experience going into theatre'. (RN 2, LN 114-119)

Humour is really important in surgical nursing because it is a very stressful and tensed environment especially pre-operative and they go for the surgery umm, and some people umm can be stiff and only focus about umm, I'm going to sleep I might not wake up and that's very stressful for them, they feel like running away like fright and flight umm, just to distract to them, it's really a good way of distracting them and ease their nerves and yeah they feel so good'. (RN 8, LN 17-23)

Acknowledgement of the patient's feelings and attempts to mitigate these through humour use, potentiated a shared understanding between the nurse and the patient. Appreciating how the patient may be feeling and alleviating these feelings with distraction using humour 
based the relationship in a space of mutual respect and understanding. Nurses described that patients deserved respite from frightening situations, and humour could achieve this.

I've recognised that people in their darkest time do need humour and need to have something to make them smile. (RN 6, LN 227-229)

The more serious the situation I think the more necessary sometimes humour can be, to an extent, to a level. (RN 3, LN 177-178).

Whilst emotional vulnerability dominated the discussions, nurses also mentioned the physical vulnerability that patients face. Manifesting as embarrassment from the temporary inability to care for one's self or the physical impact and discomfort surgery causes, humour was viewed to address this vulnerability.

So, you have people who have been unwell, they've been urinary and faecally incontinent and they are like apologising for messing their beds and having to do all this and I'm always like 'I don't do the washing'. (RN 6, LN 122-125)

Oh I think it relaxes patients, you can see heart rates going down, blood pressures doing down, you can use it [humour] as a distraction quite a lot, pain, you know people in pain and they've had all the analgesia they can possibly have, and you know then you might crack a joke or something an it takes their mind off it you know. (RN 9, LN 94-103)

Nurses discussed how within a patients physical and emotional vulnerability, they 'lose' themselves, and humour helped patients to regain a sense of self and some degree of normalcy.

Humour with patients is important because, that it is part of the person (RN 6, LN 384-385).

The fact they are in pain, the fact they are have nausea, the fact that they've got this massive big wound across their stomach, will make a big difference to how they are, and it's the fact that they are most exposed and vulnerable, humour it makes them a perfect, um how do you say it, there's an element in Scottish language you talk about somebody being in fine fettle, so if you are in fine fettle, it means that your body soul and mind are all in one spirit, so you're not, you're not just feeling good because your strong and you're head strong but you are in fine fettle, all three elements of you are in good humour. (RN 6, LN 144-154) 
Because in everyday life we use humour and you go put someone in an incredibly stressful situation, and if all of a sudden there is no humour it turns the entire situation into a potentially even something more terrifying, and you can't remove every aspect of everyday life the second someone becomes a patient because they are still a person and you have to acknowledge that they are a person, they have their culture, they have their personality, they have things that are gonna make them happy and make them sad and why should we not treat patients like the people that they are just because they are in a gown. (RN 7, LN 305-314).

Nurses acknowledged that humour is commonly used in people's lives as a natural coping mechanism and being in hospital should not negate the usefulness of humorous moments. Providing humorous moments allowed patient's respite from the vulnerabilities they faced in a surgical hospital environment. Nurses equally experienced personal vulnerabilities in caring for surgical patients and used humour to counteract these.

\subsubsection{Nurse's vulnerability}

Nurses within a surgical environment, are required to care for and manage patients who have complicated physical demands and who may have life-threatening diagnosis or prognoses. This is not only distressing for the patient but also the nurse. The distress is shared through the relationship and connection built between them. Nurses were aware of this distress and the responsibility to keep their emotions regulated in front of the patient. Nurses shared how they used humour as a shield to prevent the patient from recognising they were themselves upset about the patient's situation.

You could be joking to make yourself feel better about their bad situation...actually, I'm not coping with what's happening so I'm going to joke as well just hide the fact that, I'm heartbroken for whatever is happening to you, and I don't want to cry. (RN 5, LN 486-489)

The emotional labour of nursing is evident in surgical nursing; surgical nurses face a constant flow of pre-surgery and post-surgery stressors from patients. Nurses are aware of the expectation to remain professional and in charge of all situations that present, including the emotions that these situations cause them. Nurses described that using humour with 
their patients in times of stress enabled them to project a face of calm, even when they might actually be panicking.

I think that [humour] will relax us and umm and bring the tension down and then we can do the job very calm without flapping around. (RN 8, LN 333-334)

I also know that I don't have a great poker face so I might use humour to distract people from the fact that I might actually be internally panicking and ,crap this patient has a heart rate of 200 and a blood pressure of 60 you know like, so kind of use humour in that it does help my practice, in that, it masks essentially, it so, it I kind of use it [humour] as a mask, yeah I think umm so patients have that confidence that you are not freaking out. (RN 7, LN 100-106)

There are specific conditions where nurses used humour as a mask. It was used to project a sense of confidence and to offer reassurance to patients particularly in circumstances of clinical deterioration. The humorous mask was also used when nurses moved from what they perceived to be a stressful or negative encounter back to the normal routine of the ward. This allowed the nurse to continue to care for allocated patients by projecting a sense of normalcy. Nurses used humour to enable positive interactions with patients to conceal they were distracted or affected emotionally.

So, when you have your humour guard up, that's what happens you just short, sharp joke about it leave the room, so you're not trying to connect with them, you just, you just need to know that I am here, I might be a shell right now, but I am here. (RN 5, LN 562-568)

Using humour to find the strength to continue working regardless of how the nurse was feeling was frequently mentioned. Whilst this context was predominantly nurse-to-nurse humour rather than nurse-to-patient humour, it is important to include. Nurses described that nurse-to-nurse humour allowed them to remain functional and interact with patients, so their emotional vulnerability would not affect the patient.

When you're in a really busy pod and you're just really stressed out someone joking with you when you are on the verge of tears basically does perk you up a little bit and you are okay cool, fine, I can get back in there, so you know it puts yourself in good spirits and the cos you're 
feeling better and you've just had someone joke with you in the hallway which has put a smile on your face, that smile goes to the next patient and whatever you have pulled out of that room isn't going to come with you to the next patient. (RN 5, LN 433-444)

It [humour] tends to de-stress colleagues, colleagues might be having a hard time with a particular patient, might be a very anxious patient or a confused patient or a family member might be intense and they come into you know, drug room to get medication or whatever and you know, they see that the body language you know, that they're about to burst with stress, and you make some joke you know, and at least for a moment, cos they've got to go back to that situation of course. (RN 9, LN 243-252)

Humour provided respite for both the patient and the nurse when in a vulnerable position. Surgery can create a vulnerability in patients, of either a physical and emotional nature. The nurse's awareness of the potential vulnerabilities that are created in the surgical environment drove their use of humour. In the surgical context, humour delivered a reprieve from both patient and nursing vulnerability and whilst this was described as fleeting, it had the potential to positively affect the future interactions between the nurse and the patients.

Protecting patients and themselves from vulnerability highlights the benefits surgical nurses perceive humour provides. Protection of the patient from the thought of or consequence of surgery motivates the nurse to use humour, to provide comfort and relief. The benefit of humour from the nurse's perspective is clear, however the decision-making process behind when to use humour needs exploration.

\subsection{Assessing openness}

This theme describes how nurses 'know' when to use humour with their patients. Nurses explained the ways they assessed whether or not to not use humour from two perspectives- patient-initiated cues and nurse-initiated assessments. Patient-initiated cues are cues that the patient provides, and nurse-initiated assessments are those that the nurse themselves instigate. Both are used in combination to provide the nurse with information to 
gauge potential receptiveness to humour. These two subthemes combined provide an insight into how nurses decide the risk of and judge the receptiveness to humour of their patients.

\subsubsection{Patient-initiated cues}

All the nurses interviewed described looking to their patients for cues that humour could be used within their interactions. These cues were key factors guiding their choices around humour use. Nurses revealed that they look for these cues, often non-verbal ones, from the first moment they saw their patient.

Actually, when you see them, when they come through examination room, they usually smile, uh, sometimes you know they're open. (RN 4, LN 42-44)

Nurses shared that how the patient presented themselves in this initial meeting in regard to their demeanour and body language, helped determine if the patient was potentially open or closed to humour use.

You can sometimes tell by, you know by how, you know how they are, by how they approach you as well, body language and things like that you pick up on. (RN 9, LN 50-52)

Yeah their body language sometimes does help like if you, if you walk into the room and someone sits up and they're quite timid and kind of turned away from you, you're like 'oh they don't trust me already', so if they are already turning away like I don't really want to engage with you, heh, then you are like, ah ok, maybe l'll just be normal at this point. (RN 5, LN 273-280)

If the patient exhibited non-verbal cues such as smiling and turning towards the nurse, they were viewed to be open and the nurses felt humour could be used. However, if the patient was visibly upset, distressed or turning away, they were viewed as closed and humour was generally avoided by the nurse. 
They are mostly tearful when they are coming, so you know you can tell by the way you see them first hand that they are not gonna, it's [humour] not going to help (RN 2, LN 233-239)

The ones that just look really timid and you're like 'oh maybe I won't joke so much with you'. (RN 5, LN 82-84)

Non-verbal signs were not the only cues focussed on by the nurse, assessing openness to humour also included verbal cues; how talkative the patient was, and whether or not the patient-initiated humour themselves within the interaction.

Umm I think just their whole umm their, when they, when you introduce yourself, you can just tell, they are already sort of like chuckling, and being really friendly and open to chit chatting when you, as soon as they sit down. (RN 2, LN 59-65)

Nurses described patient-initiated humour was often the cue that made them feel most comfortable using humour with their patients.

It has to be them instigating often. (RN 3, LN 328)

If they're joking, some patient joke to us first and then I can joke back, heh heh, and so that's the way I think it goes. (RN 8, LN 49-51)

Patient-instigated humour was a strong indicator for nurses that humour within the interaction would be appropriate and appreciated, however, confirmation of this assessment was still required by the nurses. This confirmation process became part of the nurse-initiated assessments to address the risk of having read the cues incorrectly.

\subsubsection{Nurse-initiated assessments}

Nurses described 'testing the waters' to confirm if their decision to use humour was correct with patients who were assessed as being open to humour. This took the form of the nurse trying some type of humorous comment and assessing the response.

If you do say something funny or you know try a joke or whatever and how they respond, that's how you know whether you should, you know, back off or whether you know you should keep going. (RN 9, LN 52-54) 
So usually it's a two- way street, so l'll, I'll start there and go and introduce myself and I'm like 'sorry you're stuck with me for the rest of the day' and they respond nicely, they'll be, you know, okay cool you are going to be one of those receptive people that's going to like a bit of humour. (RN 5, LN 78-81)

'Testing the waters' was part of the nurses, mitigating the potential risks of using humour with patient interactions. Nurses outlined that if they misjudged the situation, there was a risk the relationship could be harmed either through causing offence or being perceived as unprofessional.

It can be seen as unprofessional... they might think that you are a little bit too relaxed and not, you know, be taking things seriously and you know obviously their health is ultimately very serious. (RN 9, LN 175-179)

I think that it would affect your professionalism, I think especially, I think that you would offend, even now people get offended by jokes so as part of your professional responsibility you have to be mindful that you don't offend someone. (RN6, LN 216-218)

Nurses were very aware that using humour within their interactions was meant to benefit the patient and this was only possible if the situation was assessed correctly. Reading the room for cues not just from the patient but from others who were present such as family members was also highlighted.

But then you can pick up things from the family you know like how, looking after like, you know, a patient from sort of Samoa or Tonga and you know, a Pacific Island patient and if the family are making jokes with the patients and that kind of stuff, you know, you can pick up that. (RN 9, LN 165-169)

Sometimes our family members, sometimes a daughter is there with the father and she just take it so lightly and they start to joke 'oh look at your hat, oh it's so funny' and costumes something like that. (RN 8, LN 58-61)

An appreciation and assessment of culture and the potential 'taboo' subjects associated within cultures featured heavily in the discourse. Nurses described being very aware of the differences in what may be found funny or offensive by patients of a different culture and the risks of using humour in this circumstance. 
I think that is quite important, anything cultural, I think you have to be very very careful. (RN 3, LN 212-213)

Yeah culture is umm, culture does influence humour, and to understand the joke, culture is very, heh heh, a very big factor. (RN 8, LN 208-209)

I definitely think there are risks, umm, there is those cultural boundaries and and you it, it can be quite difficult to know where umm, you know obviously you're not going to know everyone's cultural history, just because someone looks one way doesn't necessarily mean their culture is that way. (RN 7, LN 127-130)

Nurses spoke of using patient and family cues to guide their decisions on appropriate use of humour when faced with cultural differences.

So I had a woman from Egypt there with a friend and her husband and they you know had established they had been in the country for you know a year and a half and she kind of made a little joke about, I told her that she was not going to be able to do any heavy lifting and she kind of looked at him and you could see she was sort of saying 'so you get to do everything' and I'm like 'so you're not going to able to lift any laundry baskets for example good thing you've got a big strapping man there', yeah but so it was because I saw that look you know, that husband and wife look. (RN 7, LN 169-180)

When you've got a couple of people from a culture together because they communicate, they, within themselves and you can see how they communicate and that, and that and the use, the more examples of communication you have the more it guides your communication. (RN 7, LN 185-189)

Having familiarity with the patient's culture or sharing the same culture was discussed as facilitating humour, as there was already an assumed understanding and even connection.

But....you know cultural ethnic patients, they they joke with me easier than they would another patient because we do have that already instant connection, like 'oh look she's, where you from? like oh from here? and they are like 'no no, like which, which like, are you Māori, are you?' I'm like 'oh I'm Māori' and then they're like ah cool and then they joke straight away, and their family jokes straight away. (RN 5, LN 335 -345) 
So, there's this automatic assumption that you're Scottish you are funny, 'so yeah I like that Scottish or that Irish comedian, or you Brits are funny', so there's a strong link with recognising Kiwi's liking British humour, yeah, I think that aspects feeds into it so it always seen that 'oh you know, guys are good for a laugh'. It's my identity as a Scottish person always gives them a good idea of what my humour will be. (RN 6, LN 102-115)

Increased knowledge of the culture allowed the nurse 'room' to use humour more freely. Whilst culture was viewed as increasing the risks of using humour, it was not seen to require a complete avoidance, rather a very careful utilisation of varied assessments.

Part of these nurses' assessment, prior to using humour, was also guided by understanding both the patient's physical condition and how this could affect their emotional state.

Probably the more sensitive surgeries, for example we get mastectomies, so we are quite cautious around those patients, I think we are generally, because it's quite an emotional time for them. (RN2, LN 214-219)

Nurses described that whilst some surgical conditions are naturally more emotional charged than others, their ability to use humour within patient interactions was not always governed by the prognosis or condition, it was guided by knowing if the patient has reached a 'crisis' point or not. If the patient was close to a crisis point, either physical or psychological, humour was avoided, however, if the patient is away from or has just passed a crisis point, humour could be used.

Our young patients who've got a really poor prognosis, who you know they've come in with abdo [abdominal] pain and they are like 30 and just found out they have got an inoperable cancer. I wouldn't want to joke with them because their life has just flipped upside down on them, but then you've got your 80-year-old patients that are like 'oh well I've had a pretty good life' so yeah you can joke with those ones. (RN 5, LN 111-122) It's very interesting that ever if they are having a bad episode you can still use humour,...it's from patient expressions really, ha ha, and yeah as long as they are safe, as long as I know they're safe. (RN 8, LN 290-295)

Assessing a patient's emotional or physical crisis point was multifaceted. Using humour appropriately avoiding a patient's crisis point, included assessment of patient-initiated cues, 
knowledge of the clinical condition, and also, as described by nurses, required insight and intuition.

It takes a while to understand, and I think that that comes with age and maturity, like understanding maybe where the line is and having personal umm, I think if you've got insight, umm and you are able to gauge a situation, that's when you can use humour effectively. (RN 3, LN 541-546)

You need to have this sensitivity, you need to be sensitive so you need to know, you know it's just, it's just like a clinical, you know clinical skills, clinical eye, that you develop clinical eye, you develop this thing umm, that umm, usually it's it's your gut you, you know, your feeling. (RN 4, LN 183-187)

Intuition and insight are developed over time, as is clinical knowledge of when and how to use humour with patients. Nurses described how as their clinical knowledge of surgical procedures and conditions increased, so did their confidence to use humour with their patients. The nurse's perceived clinical ability and skills appeared to be linked with their confidence and ability to use humour with patients.

I have been on this ward for 3 years and I am guessing for that first 6 months I was very to the point and very serious and never wanted to joke cos I didn't want to get anything wrong, cos I didn't know anything, I'd come from a tiny DHB to a regional hospital, where I couldn't even pronounce the surgeries let alone joke about them...so over that time, you know, building up my confidence in my actual job and what I did and all of that so it probably took a good year to get onto the whole I can actually joke outright now, cos well I can joke, but I can back myself up. (RN 5, LN 287-303)

It often takes a while when I start somewhere new for that side of me to come out but I think it's just because you are trying to do everything right and learn everything and you know, you want to be performing well, I think once you are comfortable and happy in your work place I think it [humour] definitely starts to come out. (RN 3, LN 820-827)

As familiarity of the surgical context increased and clinical competence was achieved, the nurses expressed feeling more confident to use humour. Commonly required nursing tasks provided recurring opportunities for the nurse to introduce humour. Many of these, while innocuous to the nurse, were recognised as unique and potentially uncomfortable for the patient. 
They have to put on booties and a hat and I make a joke about the fact that we all look like Marge Simpson. (RN 3, LN 109-110)

Also, the undies, you can tell, you can tell things like you can have these disposable undies, that's our Victoria Secret and then they laugh. (RN 4, LN 124-127)

The process of preparing surgery is rigid and prescribed, so humour was seen as a way to provide some comfort to patients during necessary and unavoidable situations created within the surgical context. Making these tasks more humorous was seen as a 'safe' as it was 'tried and true', as variations of the same joke had been used many times before by other nurses. Nurses suggested that this humour was often learnt from seeing senior staff using it.

I have seen my senior nurses umm, using humour, umm which was surprising for me when I started the job, I thought our job is asking questions doing the right things, get the you know, without any flaws without doing any mistakes....But then I saw my, umm, colleagues joking about a lot of things and these questions just become part of the conversation which is amazing and I learnt from my senior nurses. (RN 8, LN 387-397)

Where I studied was you know quite a small DHB up north so all the nurses there knew all the patient's cos they come in and out cos its small place and so they were all jokey and I was 'Oh I can be like that'. (RN 5, LN 153-158)

It was not only experiences from their professional work that nurses utilised to facilitate humour, experiences in their personal lives also contributed. Nurses spoke about the influence family had on their perceptions and use of humour.

I think it's upbringing for me, and umm, ah, I think I come from a family, umm, who are in, most of them are in the medical profession, I think some of its the, it's black humour. (RN 3, LN 538-540)

Oh, that comes from my family, I think generally my family, I think it's because of the type of, it's the the culture that I come from where you'd have to make your own entertainment like that. (RN 6, LN 393-395) 
Nurses used a range of innate and learned skills to assess when to use humour. These were shaped through personal and professional experiences practicing in a surgical ward and culminated in developing the nurse's humour judgement. Picking up patient cues and what they may indicate, combined with the nurse's own assessment provided a foundation for 'knowing' when to use humour. This process highlights the level of thought and consideration that is required to use humour within patient interactions to ensure the cues have been read correctly and the timing is right. It also highlights the nurse's acute perception of risk associated with incorrect timing of the humour, that can inadvertently affect the nurse-patient relationship.

\subsection{Building a Connection}

Establishing a relationship between the nurse and the patient is the foundation to enable provision of acceptable and effective nursing care. Building a connection is a theme that describes why nurses use humour within their patient interactions and the benefits to the nurse- patient relationship humour creates. The subthemes, creating a partnership and creating a shared understanding explore how humour can help establish communication and rapport, and convey respect and value of the patient.

\subsubsection{Creating a partnership}

Nurses shared their use of humour within patient interactions was a tool to build the therapeutic relationship. Humour was seen to facilitate the relationship by helping to develop rapport with their patients.

It's easier to make a therapeutic relationship with someone when you can joke with each other. (RN 5, LN 61-62)

I think that it is very important because its [humour], umm, one of the tools to decrease anxiety and to I think, to build rapport. (RN 1, LN 334-

336) 
Nurses discussed establishing a rapport quickly was important because they felt time limited with their patients. Nurses also described that humour transcended this time limitation expediting their ability to form a nurse-patient relationship.

Because in here it's quite a fleeting moment that we often, you know, when we come into contact with patients, umm, so gaining their trust, building rapport and having that therapeutic relationship, humour is great for that. (RN 3, LN 12-14)

It [humour] is a communication tool and we need to use every communication tool that we can to form relationships with our patients that are meaningful for the patient and the faster you can do that essentially the better because you are often only seeing them for such a short time and you have to do quite umm, invasive and very personal and private things with patients. (RN 7, LN 237-240)

In addition to maximising the time for the nurse to build a therapeutic relationship, humour was recognised by nurses as quality time with patients. The nurse's perception that quality time was being spent with patients allowed them to feel that patients were being respected.

Patients do tend to respond to it [humour] quite well, they tend to I don't know it's just umm I guess they feel that you're interested you know, that you're not just going in there and doing a task you know, you know, are you are interested in them as a person, you have got time to stop and you know, take a moment. (RN 9, LN 205-211)

And otherwise if you are too like, just by the book, and just not looking them in the eye and not going with their stories sometimes they feel like you know, you are just another a number, and you are not interested in them, so it [humour] just helps. (RN 1, LN 103-112)

Using humour has the potential to facilitate a nurse-patient relationship and develop this quickly. If a solid relationship is established, an environment is created where open and honest communication occurs, thus providing potential for patient-centred care to be achieved. 


\subsubsection{Creating a shared understanding}

Nurses described humour could be used to build a relationship with and facilitate communication with patients and explained using it to 'pick up and roll with' a topic of interest for the patient to build a connection.

So, when you are trying to make a connection with someone you will just make a joke about something in the room or you know they've got, they got a magazine on their table and you're just 'oh like that cracker like, that crack up guy right there, he's a bit of a hard case' and you just keep joking about, you, you just, you pick something that you actually genuinely want to talk to them about and so that makes an easy connection. (RN 5, LN 523-538)

By building a connection through humour, nurses were able to establish communication that was genuine and used the patient interest as a foundation. Humour was also argued as a medium to initiate conversation or action in a patient who was hesitant to communicate or engage with nursing care.

I just was like right, look I if you don't talk to me I am going to start dancing and I'm not a good dancer so you might want to start talking to me, and he still didn't so I stood there and I gave a little boogie, and he laughed at me and then he's like 'stop it now'. (RN 7, LN 66-71)

He got to the point where he just didn't want to do anything and he hadn't showered for a few days, and you know big man, quite smelly, and I was like look we're going to have a shower today and he goes 'no', I was like 'come on let's get you up and showered' and he goes 'well I can't exactly walk to it' and I was like 'well you can hop to it if you'd like', and he just cracked up laughing and he goes 'thank you, okay l'll get up'. (RN 5, LN 31-40)

Humour facilitated nurses to break through to a patient who was perceived to be disengaged, providing a connection and co-operation with the patient. Nurses advised that using humour provided a novel way to connect with patients and provided a potential solution to the communication impasse. As a component of conversation, humour was used to convey a message to the patient that engagement in their care and with the nurse was required and being playfully requested. 
Nurses also expressed that patient's humour was often perceived to be conveying feelings in a covert way. Nurses described assessing the underlying reason for the humour and reciprocating humour to keep the patient at ease and show they understood the patient's message.

You can tell with some people that are, you know using, just really, really joking with it that, ah you're actually really scared of what's going to happen aren't you, so you joke with them a little bit and then you put them at ease by saying 'hey you know this is to be fine aye'. (RN 5, LN 413-416)

I think a lot of it [humour] comes from nervousness, and that they are worried and they are scared so they're making light of whatever they can, umm to distract themselves, as well so you don't', you can't see, they think you can't see what they're thinking and how they're feeling, but then they realise that we do actually know what they are thinking. (RN 7, LN 110-113)

Conveying a message through humour within nurse-patient interactions was illustrated as coming from both the patient and the nurse. Using humour to acknowledge and build a shared understanding with the patient, nurses were able to relate to their patients. Nurses described that if a patient could relate to them, they may be more willing to share information and enjoy the nursing care provided.

I think it you know it's, it [humour] keeps them at ease, and then they share more, if they feel like they ha ha, they can relate to you, or you can say vibe with them. (RN 1, LN 97-101)

They had a family meeting one day and they asked him, what do you actually like that is going on and he goes 'oh I like that my nurse [nurse's name] calls me bro and she jokes with me cos it makes me feel better...she just jokes around but gets done everything quickly instead of making me feel dumb and using big words'. (RN 5, LN 372-374)

Nurses explained that humour allowed them the ability to both connect with their patient and establish a viable line of communication. They also described humour use resulted in patients feeling valued, and this in turn provided them with a sense of satisfaction from the nursing care provided. 


\subsection{Summary}

This chapter has outlined the findings contained in this research and provided discussion on each theme and subtheme to provide an insight of how nurses decide when to use humour their conscious thought behind this and purpose driving the humour. The potential benefits and risks from the nurse's perspective have been highlighted, building on the facets of consciousness required to effectively use humour within the nurse-patient relationship. The establishment and maintenance of nurse-patient relationship was evident throughout all of themes and reflected a compelling purpose behind the humour, with nurses discussing how the therapeutic relationship can be both strengthened and threatened with humour use. Nurses recognise that without a functioning therapeutic relationship, communication and provision of nursing care becomes difficult, but humour can facilitate relationship building. In the next chapter, further discussion of the significance and application of these findings will be explored. 


\section{CHAPTER FIVE: DISCUSSION}

\subsection{Introduction}

Chapter four identified three themes, assessing openness, building a connection and protection against vulnerability, with an overarching finding that nurses use humour consciously and purposefully. Understanding and describing the cognitive process that nurses undertake to engage humorously with patients, provides an opportunity for surgical nurses to emulate best practice in this area.

This study has found that nurses consider both patient- and nurse-initiated cues to judge whether to engage with or avoid humour with patients; this forms the foundation for decision-making around initiating humour. The driver behind humour use was either to connect with the patient or to provide respite for perceived vulnerability of either patients or nursing colleagues, within the surgical environment. This chapter describes the significance of the study themes in light of current literature and explores the potential clinical and educational implications of this research for surgical nurses. A discussion on the future research opportunities and the limitations of the study are also presented.

\subsection{Protection against vulnerability}

As discussed in the findings chapter, protection against vulnerability was a key theme developed from this study. The following section explores this theme and associated subthemes in the context of the literature. In particular, this discussion examines nursing and patient vulnerabilities and how the use of humour influences these in the surgical context.

\subsubsection{Patient vulnerability}

A key finding of this research was that nurses use humour to mitigate perceived patient vulnerabilities. This is significant as it shows nurses use humour purposefully to comfort patients.

The term 'vulnerability' is used frequently in literature, and is used widely in bioethics (Wrigley, 2015). As described by Wrigley (2015), vulnerability is "generally taken to 
designate a special state that an individual or group has, but in a way that generates an action guiding requirement to pay extra attention to their wellbeing" (p. 478). Surgical patients face unique circumstances that can alter either their physical or emotional state (Kynoch et al., 2017). Surgery is not an everyday occurrence and regardless of this being planned or urgent, surgery is a significant life event (Kynoch et al., 2017). Whilst any illness or disease can cause distress, impending surgery is known to cause elevated levels of fear and anxiety in patients (Carr, Thomas \& Wilson-Barnett, 2004; Mitchell, 2013). If not addressed, pre-surgery fear and anxiety can influence perceptions of post-operative pain and delay physical and emotional recovery (Carr et al., 2004; Mitchell, 2013). Acknowledging and addressing the potential patient vulnerabilities, caused by surgery such as fear, anxiety and pain is a fundamental role of the surgical nurse (Jangland et al., 2011; Mackintosh, 2006). Research participants in this study demonstrated that humour was a tool used to acknowledge and mitigate the patient's perceived psychological distress.

Nursing research conducted by Beck (1997), Ragan (1990), and Thornton and White (1999) supports the finding that humour use by nurses can alleviate perceived patient distress. Focussed on nursing perceptions of humour but based in different contexts, these studies all described similar patient vulnerabilities being present - fear, anxiety and embarrassment. Regardless of the context, Beck (1997), Thornton and White (1999) and Ragan (1990) found that nurses employed humour to reduce the intensity of the patient emotions and therefore the vulnerability associated with these emotions. Recognising the level of patient fear and anxiety, participants in this study described humour as an essential tool to moderate these emotions for the benefit of the patient.

As explored in psychological research (Abel, 2002; Edwards \& Martin, 2014), humour allows a shift of perspective in the face of stressful situations by creating a distance between the individual and the source of stress. Creating 'space' allows the patient time to cognitively reframe their situation to appear less threatening than first thought, reducing the impact of the negative emotions (Abel, 2002, Edwards \& Martin, 2010). An individual's stress is directly related to the level of risk perceived from the stressful event, therefore using humour to reframe the situation as less risky causes a reduction in the stress response (Abel, 2002). This cognitive reframing also provides an element of resilience for the individual by regulating negative emotions (Abel, 2002; Edwards \& Martin, 2014). In this 
research, participants described that when humour was used, patients did not seem to be as anxious or fearful. For example, as reported in Chapter 4, a sense of 'lightening the mood' was reported after sharing a humorous moment between the nurse and patient. Abel (2002) supports this finding, describing humour as allowing the individual to adapt to situations by minimising the negative emotions such as fear or anxiety and to look on the bright side'. This in turn encourages positive emotions, hope and happiness. An increase of positive emotions helps build the individual's resilience to manage their situation regardless of the context (Edwards \& Martin, 2014).

This thesis has explored use of humour within surgical nursing practice. Findings here strengthen understanding that nurses utilise humour to support patients during times of emotional and physical susceptibility. This research demonstrates that nurses are acutely aware of how admission to a surgical environment and the associated interventions, create potential vulnerability for the patients. There are many features of a surgical environment that can cause patients to be emotional vulnerable (Jangland et al., 2011) and whilst welljudged use of humour cannot change the features of the environment, humour can reduce patients' distress, thereby bringing some comfort. Jangland et al. (2011) and Rudolfsson (2014) recommend surgical nurses take time to understand vulnerabilities faced by the patient when in the surgical environment, respond to these, and to alleviate any suffering. Jangland et al. (2011) and Rudolfsson (2014) do not specifically detail humour in their studies, and therefore this research brings new knowledge about humour being important tool to address and support vulnerable surgical patients.

A principal finding to emerge from this thesis, is that humour is used as a deliberate method to support patients within the surgical environment. Humour was also found to be beneficial in addressing the nurses own stress arising from working in surgical nursing.

\subsubsection{Nurses' vulnerability}

A central finding of this study was that humour allowed nurses to cope with their own distressing emotions whilst continuing to care for patients. Nurses described humour as a way to conceal and manage their own vulnerability. 
Surgical settings are efficiency-driven environments focussed on quick processing of patients in and out of theatre; these settings are often challenging for both patients and nurses (Carr et al., 2004; Mitchell, 2013). Limited resources and increased patient acuity compound the complexity of the nurse's role (Dean \& Major, 2008; Jangland et al., 2010). Whilst duration of surgical in-patient stays has been greatly reduced through advances in technology and surgical techniques, the psychological support required for patients remains relatively unchanged (Mitchell, 2013; Wigens, 1997). Surgical nurses need to provide technically proficient care, whilst supporting the emotional wellbeing of patients in relatively short periods of time (Macintosh, 2006); this generates high levels of nursing stress. Surgical nurses require coping skills to mitigate this stress in their working environment, as otherwise, burnout is frequently encountered (Macintosh, 2006).

The use of humour as a personal coping strategy is well-recognised and referred to in the nursing and psychology research. In a British nursing study, humour is described as a tool to "assist the staff in concentrating on technical matters and avoid the human emotional side of the patient" (Emerson, 1969, p. 172). Emerson (1969) describes humour as a vehicle to allow the nurse to continue to care for the patient when faced with distressing emotions. Thornton and White (1999) also argue that humour permits nurses to distance themselves from difficult emotions, that are innate to nursing practice whilst maintaining an appearance of being emotionally present. Humour enables nurses to continue to care when faced with difficult situations, which provides an indication of the purpose behind nurses using humour.

Providing a complementary view, research from the branch of positive psychology research illustrates that humour can provide relief from stressors thereby increasing the ability of the individual to reframe a negative situation (Edwards \& Martin, 2014; Ruch \& McGhee, 2014). Therefore, use of humour during an emotionally upsetting incident can affect positive change on both nurse and patient. Ability to use humour is seen as a constructive character strength that enhances the ability of an individual to remain positive when faced with negative life events (Edwards \& Martin, 2014; Ruch \& McGhee, 2014; Wellenzohn, Proyer \& Ruch, 2018). 
Humour as a positive coping strategy to mitigate work stresses for the nursing team also needs to be explored, as this was a prominent finding of this research. Nurses not only use humour for the purpose of bringing comfort to patients, they also do so to provide comfort to colleagues. Study participants reported that joking and banter between colleagues in times of high stress helped gain perspective and respite from imminent concerns. Humorous exchanges between nursing team members built collegiality and a sense of togetherness providing the nurse with strength to 'keep going'. These are also common findings in other health research as evident in studies by Beck (1997), Dean and Major (2008) and McCreaddie and Wiggins (2008).

In fostering a sense of friendship and understanding, humour provides a foundation for building and maintaining morale. Psychology researchers, Treger, Sprecher and Erber (2014) explain that humour creates an environment of feeling closer to other people and this increases likeability of each another. This view is supported by research from two ethnographies (ICU and palliative care settings) that compared findings and described, independent of the setting. In this, humour use between nurses and within the nursing team helped to foster a team spirit and create a bond and strength between colleagues (Dean \& Major, 2008). McCreaddie and Wiggins (2008) argue that the use of humour creates positive, supportive, collegial nursing workplace environments. These researchers conducted an extensive literature review and found humour was a coping strategy employed by nurses to manage their own stress and to build positive team cultures within their nursing teams. As described by Collicut and Gray (2012) and Edwards and Martin (2014), humour promotes resilience by allowing engagement with challenging circumstances to re-evaluate the perceived threat to emotional wellbeing. Adapting one's view or approach to the stressful event through humour minimises the harm of the source of stress (Edwards \& Martin, 2014). This is significant, as humour has been repeatedly shown to provide protection to staff faced with difficult situations through sharing the experience with colleagues, bolstering the nurse's coping ability. Humour enables individuals to change their perspective to view the situation as less threatening than it is (Collicut \& Gray, 2012; Edward \& Martin, 2014).

Expanding the understanding of humour into a surgical setting, this research builds on previous health and nursing research concerned with mitigating patient and nursing 
vulnerability. Humour enables nurses to mask their vulnerability whilst also connecting with patients. This action provides protection for the patient as they continue to receive nursing care, whilst the nurse shields themselves and reframes the stressors to remain functional. Humour between nurses also increases morale positively affecting the nurse's ability to cope in stressful patient situations (McCreaddie \& Payne, 2011; McCreaddie \& Wiggins, 2008; Wiechula et al., 2015). As the individual's moral improves, this in turn bolsters the ward morale negating the effects of stress inherent in ward nursing; ultimately leading to decreased stress and increased job satisfaction (Astedt-Kurki \& Liukkonen, 1994; Dean \& Major; 2008; Wiechula et al., 2015). Humour can maintain the relationship between nurse and patient and between colleagues by reframing and lessening the perceived vulnerability.

\subsection{Building a Connection}

Building a connection is the second key theme of this research. Exploring the literature will develop the understanding of how humour contributes to the creation of the nurse-patient relationship.

\subsubsection{Creating a partnership}

Findings in this study indicate that humour mitigates time pressures nurses have with patients; this is known to be an inherent concern in surgical nursing environments (Jangland et al., 2018). An environmental factor common in surgical nursing practice is the perception of limited time due to staffing shortages and high patient loads (Sawbridge \& Hewison, 2013), adding to this is the pressure of rigid timing to process patient's pre and post-surgery to maintain efficiency (Jangland et al., 2018). Whilst stressful for the nurse, it also directly impacts on the nurse's ability to develop and maintain a therapeutic relationship (Jangland et al., 2018). Study participants described feeling time poor, but detailed humour as transcending this limitation, aiding in quickly establishing a therapeutic relationship. Participants said humour allowed them to feel like they had spent 'time' with their patients and this helped build the therapeutic relationship. Johnson (2002) proposes that humour could be a tool used to teach nurses how to maximise their time spent with patients. 
Creating a partnership infers that nurses are able to connect with the patient on an individual level. Humour has been shown to provide an element of humanity that is often missing in a hospital environment, due to the time constraints and task-centred care (Ghaffari et al., 2015; Haydon \& van Reit; 2014; Jones \& Tanay, 2016). Walsh and Kowanko (2002) describe humour as providing humanity and dignity to the patient by recognising their need to be acknowledged as a person, and not just an illness or task to be attended to. Asking both patients and nurses in an Australian hospital, to describe care that promoted dignity, humour emerged as a tool to convey dignity when faced with a potentially embarrassing situation (Walsh \& Kowanko, 2002). Humour was shown to put value on protecting the person's feelings and mitigating a potential loss of dignity (Walsh \& Kowanko, 2002). Participants within the current study described how humour created a sense of having a genuine interest and care for the patient, that took the focus away from being purely task orientated, but patient focussed.

A major finding of this research is that humour is a factor in facilitating the creation of the therapeutic relationship. Participants described humour as allowing a rapport to be developed quickly thereby paving the way to connect with the patient and build a therapeutic relationship. Geanellos (2005) and Scholl (2007) concur that humour decreases social distance between the nurse and patient and provides an invitation to start a conversation, with conversation leading to establishing rapport and a relationship. Early establishment of a therapeutic relationship is significant as it primes the environment for achieving person-centred care (PCC) (Jangland \& Gunningberg, 2011; Marshall et al., 2012).

PCC is concerned with 'treating people as individuals, respecting their rights as a person, building mutual trust and understanding and developing a therapeutic relationship" (McCormack and McCance, 2010, p. 1). As a framework PCC provides relationship focussed, collaborative and holistic care allowing the shift away from the dominating medical model that is often fragmented and disease not person orientated (McCormack \& McCance, 2010). Internationally recognised as the desired framework of care, PCC is aspired to but hard to achieve (Jangland et al., 2011; McCormack \& McCance, 2010). Whilst humour cannot be touted as the only solution to realise PCC, this research shows that humour is a significant factor for increasing the potential to achieve PCC. Humour assists connection thus building the foundation for the nurse-patient relationship, which is a central component of PCC. 
Marshall, Kitson and Zeitz (2012) present humour is a component of PCC, described in terms of connectedness. They describe humour connects the patient and nurse creating a sense of relating to one another and feeling 'human'. This is important given a surgical ward is a foreign environment to most people, with patients feeling lost and disempowered in this setting (Jangland et al, 2010). Patients who receive individualised care feel appreciated and valued as individuals, and as a result patient satisfaction increases reinforcing the established therapeutic relationship (Marshall, Kitson \& Zeitz, 2012; McCabe, 2004; Wiechula et al., 2015).

Creating an environment that allows for PCC empowers the patient to participate in their care and helps them reconnect with their inner strength to cope with their illness (Geanellos, 2005). As discussed by participants in this research, humour was an important factor in creating a partnership with patients. Humour also increased the potential of PCC, through facilitating a rapport between nurse and patient. As expressed by McCreaddie and Wiggins (2008) "humour could be the fulcrum for establishing the relationship that the individual patient's desires" (p. 59). There is a growing body of research concentrated on PCC, but there is little that is solely focussed on humour and how this affects PCC. The current research project proposes that humour is one tool that can contribute to care being more patient centred through showing respect and value for the patient and ultimately building a relationship with the patient.

\subsubsection{Creating a shared understanding}

A central finding in this study further develops the idea of creating a partnership through establishing rapport, with humour facilitating communication between the nurse and patient.

Establishing communication between the nurse and patient is essential (McCabe, 2004; Schopf et al., 2017). Effective communication can enable positive health outcomes through successfully achieving instrumental and relational goals ${ }^{5}$ (Schopf et al., 2017). Communication does however require two people who are willing to engage with one

\footnotetext{
${ }^{5}$ Instrumental goals are goals to achieve a particular task and relational goals refer to how patients and their health care providers seek to negotiate their relationship.
} 
another (Schopf et al., 2017) and for many reasons, patients are not always willing to engage with care or communicate with nurses. Participants explained how humour was a tool to initiate communication in this patient. Understanding how to communicate with such patients is an important skill for nurses to develop.

Studies by McCreaddie (2010) and Scanlon (2006) agree with this finding. Studying 'hard to reach' patient populations, such as those with a mental health diagnosis, McCreaddie (2010) and Scanlon (2006) described the use of humour by the nurse within the initial appointment. They discuss that the humour conveyed an acknowledgement of the patient's situation without judgment, this in turn created a feeling of acceptance from the nurse (McCreaddie, 2010; Scanlon, 2006). The environment created by humour enhanced the patient's feelings of value, smoothing conversation and permitting on-going dialogue and connection.

Another important finding of this research is that nurses perceived that, when patients used humour, it was conveying other feelings in a covert way. Participants described recognising patient humour may be masking an underlying concern (fear, anxiety or embarrassment). When nurses acknowledged this with reciprocal humour use, it was purposefully done to convey that they understood the stressors and challenges being faced.

Haydon, van Riet and Browne (2015), Mallet and A'Hern (2008) and Tanay et al. (2013) also identified that patient use of humour it is not accidental but deliberate to achieve a social outcome. In this, humour conveys feelings that patients are uncertain about sharing, or would prefer to avoid talking about (Haydon et al., 2015; Mallet \& Ahern, 2008; Tanay et al., 2013). This resonates with the Freudian relief/release theory where humour is described as a release of nervous energy that masks other motives or desires that are not socially acceptable to express (Branney et al., 2014; McCreaddie \& Wiggins, 2008; Smuts, n.d). Nurses in this thesis argued that using humour to acknowledge masked patient feelings, conveyed that they understood this, that in-turn created a shared understanding that strengthened communication.

Literature supports the finding that humour is a convert way to share a message, and that nurses understand this. Dean and Major (2008) described how nurses felt patient humour 
was used in a way to make clear anxieties about their condition or current situation. Humour use by patients to convey their emotional needs to staff was also found by Mallet and A'Hern (1996) and Tanay et al. (2013). Communicating frustrations or concerns through humour, as opposed to a non-humorous approach, was perceived by patients to elicit a better response from the nurse (Mallet \& A'Hern, 1996; Tanay et al., 2013).

Interpreting a different message from patients' humour use, Haydon and van Reit's (2014) narrative inquiry with Australian nurses described how patient humour was seen to deflect questioning and for avoidance of talking about distressing topics. Patient humour, especially by men, was perceived by nurses to be a defence mechanism diverting conversation away from sensitive subjects. The authors therefore state that humour use by patients may cause nurses to overlook cues indicating patient concern. McCreaddie and Wiggins (2008) concur and argue that when patients use humour, nurses should acknowledge that this may be raising covert messages of distress. Findings from this thesis demonstrate that nurses are aware of why patients use humour and acknowledge patient concerns raised using humour.

This thesis has identified that humour is a conduit that allows individual connection to occur, builds rapport and provides opportunity for communication. Findings of this research highlight the role humour contributes to in initiating and maintaining communication between nurses and patients, even with seemingly disengaged patients. The above discussion has highlighted the purposeful nature of humour and its role in addressing patient concerns creating a mutual understanding of the challenges faced by patients in the surgical environment.

\subsection{Assessing openness}

Assessing openness is the final key theme reported in this research. This theme provides information to answer a central area of inquiry in this thesis: determining how nurses assess whether to use humour with their patients. The following discussion details how nurses use patient assessments and knowledge combined with patient cues to assess when to use humour. 


\subsubsection{Patient initiated cues}

A major finding of this research was that patient cues such as body language and verbal signals form the foundation for nurses in assessing whether or not patients are receptive to humour. This is important as there are few nursing studies detailing how to use or interpret patient cues to assess in humour use.

'What' and 'how' a person says something, and their associated body language can provide valuable information reflecting how they are feeling physically and psychologically (Adamle, \& Turkoski, 2006). In relation to humour, and the findings of this study, physical and verbal patient clues revealed if patients were likely to respond positively to humour. Nurses looking and listening for clues from patients before using humour is an important finding. There are only three other studies that report a similar finding (Adamle et al., 2008; Adamle \& Turkoski, 2006; Greenberg, 2003).

The importance of body language is detailed by Greenberg (2003) and Adamle and Turkoski (2006). Specific physical signs cues such as smiling and twinkling of the eyes (Greenberg, 2003) and general inferences to facial expressions, gestures and body language of the patient (Adamle \& Turkoski, 2006) were discussed as signs to inform appropriate humour use. This mirrors finding in this thesis and the description of 'openness'. Patients described as weeping or appearing 'sad' were interpreted as signs the patient would not be receptive to humour (Adamle \& Turkoski, 2006; Greenberg, 2003), aligning with this studies description of the patient being assessed as 'closed'. This study reinforces and extends the limited knowledge around the physical patient cues being a useful and robust sign guiding nurses' decision-making processes regarding humour.

Verbal cues, including patient-initiated humour and the inflection of the patient's voice, were also signalled by participants as reliable signs to consider before using humour. When patients used humour, this provided compelling indication to the nurses that the patient was amenable to humour. This is supported by Adamle et al.'s (2008) research that presents patient- initiated humour is the strongest indication to nurses that a patient is open to humour. Adamle et al. (2008) and Ridley, Dance and Pare (2014) suggest that humour may be one of the only personal attributes that is not affected by ill health and will be present if 
it is important to the patient. Therefore, recognising patient humour and other verbal cues given are the areas for the nurse to assessing whether or not, to use humour.

Humour is a phenomenon that is interwoven into every aspect of our daily lives and social interactions and as such can be easily overlooked as 'just part of the conversation' (Dean \& Major, 2008; Haydon \& van Reit, 2014; Mallet \& A'hern, 2008; McCreaddie \& Wiggins, 2008; Smuts, n.d). This thesis has described how participants made assessments for patientinitiated humour to inform their decision about whether to use humour.

There is very little corresponding research that offers physical clues for nurses to look for to indicate 'openness' to humour. This research provides findings to construct a foundation of knowledge and fill the current gap in this area of nursing humour research. Patient-initiated humour and the tone of verbal communication are intertwined with the physical clues and present another facet of patient indicators that can guide nurses when humour is suitable.

\subsubsection{Nurse-initiated assessments}

An important finding of this research was that nurses use their intuition to guide them on when to use or avoid humour. Developed over time and with experience, familiarity of the surgical environment and clinical routine helped to enhance the nurse's intuition.

More than half the study participants said that intuition or a 'gut feeling' influenced their decision to use humour. This finding is consistent with Dean and Gregory (2005), Dunn (1993) and Struthers (1999) who found that intuition plays a key part in nurses using humour with patients. Dunn (1993) argues that whilst intuition cannot be taught, it is inherent, and as experience grows so too does one's intuition. As a nurse becomes more experienced, their confidence using humour increases (Thornton \& White, 1999; Sumners, 1990). This is an important finding as it provides an understanding of how nurses consciously draw on their experience to inform their decisions around humour use.

This finding is also important as humour has not been routinely recognised as a nursing skill (Dunn, 1993). Intuition is similar to being on 'the same wavelength', assisting the nurse to know 'when the right time is for humour' (Dunn,1993; Struthers, 1999). Drawing on Benner's novice to expert framework, intuitive practice is characterised in the expert level 
(Dunn, 1993). Dunn (1993) and Struthers (1999) theorise intuition is more likely to provide information on when to avoid humour rather than use it, with Tanay et al. (2104) adding intuition and the correct timing of humour are inter-connected. This research provides further support to the argument that intuition and humour are viable nursing skills with one informing the other.

In this thesis, a key component of the nurse-initiated assessment was recognising when the patient was reaching 'crisis point' in their emotions due to the pressures of receiving prognosis, progression of their illness or recovery. As described in Chapter 4, participants described evaluating the patient's demeanour and clinical condition, their nursing knowledge of the expected outcome and intuition to assess if patients had reached a crisis point. Participants were clear if a patient was assessed as being at crisis point, then humour use was avoided. The need to recognise the right timing and avoid crisis points when using humour, prevents the nurse appearing insensitive and causing damage to the nurse-patient relationship (Astedt-Kurki \& Liukkonen, 1994; Dean \& Gregory, 2005).

Literature in the area of humour use during crisis points appears to be inconclusive. International research from Scandinavia, the Middle East, and Britain, shows that nurses are reluctant to use humour in unknown or serious situations with patients (Astedt-Kurki \& Liukkonen, 1994; Ghaffari et al., 2015; McCreaddie \& Wiggins, 2008; Tanay et al., 2016), preferring to err on the side of caution rather than potentially causing offense. Offering a contrasting view, McCreaddie and Wiggins (2008) and Mallet and A 'Hern (1996) discuss that in moments of distress, humour can break the tension and provide a moment of reflection, helping to 'reset' the perspective of the patient. This 'reset' complements the principal view of humour allowing distance to chance perspective as discussed by psychology literature (Edwards \& Martin, 2014).

Within the literature, distress and crisis points are not well defined and are assumed to be interchangeable. In this thesis, whilst crisis points were also not well defined, the components that nurses used to assess a crisis point, were. This is significant as it provides a clear explanation of what to consider when assessing if a patient would be receptive to humour. The decision to use humour will vary with each nurse's interpretation of their assessments; however, this research provides insight into how these decisions can be reached. 
This research has provided understanding of how nurses use their innate skills combined with patient cues to assess the receptivity of the patient to humour. Experiential learning in the surgical environment hones nurses' skills to assess whether or not the patient has reached a crisis point. Sensitive and appropriate humour use relies on the nurse's assessment of the patient, context and utilisation of intuition and experience. These components guide the nurse to assess if a patient is at crisis point and whether humour will be appreciated providing respite or instead be perceived as flippant and disrespectful. Without the skills to interpret these cues correctly nurses can mistakenly use humour when it would be best avoided, therefore training around this would be beneficial and is outlined below.

\subsection{Strengths and Limitations}

\subsubsection{Strengths}

This research detailed the methods that surgical nurses use to assess when to use humour, which has been previously unclear in the literature. Descriptions of this process provides clarity of how nurses decide when to use or avoid humour which is valuable for surgical nurses to enable them to encorperate these skills within their practice.

The findings also contribute to the body of knowledge that surgical nurses use humour with a clear purpose and value humour as an important skill to build and maintain therapuetic relationships. This research strenghtens the argument for humour to be acknowledged and considered as a professional skill with surgical nursing practice in New Zealand.

This research project whilst small, has been the first nursing study in New Zealand to focus on nurses use of humour within the nurse-patient relationship. Capturing a rich description of the partipcants experiences provides a unique addition to both the national and international literature. This research project also creates a potential platform for future researchers to use to explore other areas of New Zealand nurses experiences with humour. 


\subsubsection{Limitations}

Whist this study has provided justification and evidence for decisions made throughout the research process to ensure robust and rigorous results, limitations of the study need to be acknowledged. The difficulty encountered in recruiting nurses to participate resulted in a sample size of nine participants. Whilst this is small sample size, data saturation was reached. Data saturation occurs when no new information is being gathered (Fusch \& Ness, 2015) and this was evident during the data analysis stage. No new understanding emerged after coding the last interview; therefore, the sample size was deemed to be sufficient. Whilst a small sample size impacts on the ability to gain a fully representative view of how surgical nurses use humour, it has however, produced a rich description of the use of humour, provided valuable knowledge of humour within the specialty of surgical nursing, and provided an exploratory sample of New Zealand surgical nurses (Denscombe, 2014).

A further limitation to the representativeness of the sample occurred because only nurses who themselves had an enthusiasm for humour participated in this study, whereas nurses with a difference of opinion of humour use did not, resulting in response bias. Using a degree of self-selection of participants there is an unavoidable response bias as those who are more motivated or interested in the research are more likely to take part (Denscombe, 2014) with the researchers own enthusiasm potentially compounding this. In the future a more measured approach when interacting face-to-face would be used and inclusion in the written and verbal information for differing opinions on humour, would be applied.

Finally, only one method of data collection was used, limiting the triangulation of data collection. Triangulation is important as the use of multiple sources of information strengthens the findings (Denscombe, 2014), and although triangulation was not used whilst gathering data, it was used in the interpretation of the data. Data triangulation involves use of contrasting sources of information (Denscombe, 2014), therefore the use of supporting literature in the discussion chapter provides this element of triangulation. Investigator triangulation was also employed to provide a consistency and rigour to the findings, which was evidenced in chapter three, with review of the codes and themes by the researcher's supervisors. 


\subsection{Implications for Practice}

\subsubsection{Clinical implications}

This research has shown that humour forms an integral part of surgical nursing practice and is used with purpose to alleviate perceived patient vulnerability and to establish a therapeutic relationship between the nurse and patient. Nurses perceive humour as a source of comfort for patients and colleagues in times of distress, therefore this thesis challenges surgical environments to acknowledge humour as an appropriate nursing skill and intervention. A belief that humour is not professional or appropriate within nursepatient interactions or between staff members need to be challenged. This research has shown the value of humour within the therapeutic relationship, and as a tool to achieve PCC. Nursing leaders need to increase the understanding and use of humour in nursepatient interactions through role modelling and encouraging humour use with all staff. Acknowledgment of the use of humour as part of nursing practice in nursing policy and guidelines about patient wellbeing or communication should also be implemented; this will promote recognition of humour as a clinical skill. Creating an environment where humour is visibly present and actively discussed and encouraged, supports staff to consciously adopt humour within their own practice.

Humour is an intervention that requires a negligible financial cost to be implemented or encouraged; this is a significant consideration given health care environments are governed by tight budget restraints. Evidence-based research is required to justify any new initiatives. This research can be used to justify education sessions focussed on how nurses can include humour as part of their nursing assessment and to enhance building therapeutic relationship with patients and achieve person-centred care.

\subsubsection{Educational implications}

Whilst recognised as an important skill in practice, humour is rarely formally recognised as a feature of nursing practice and receives little mention within nursing textbooks or teaching curricula (Dunn, 1993; Struthers, 1999). This disconnect reinforces the notion that humour is not an important skill to be practised or implemented within nurse-patient interactions. This research has shown to the contrary that humour is an important factor in patient care and, 
whilst the ability to use of humour can be innate, some aspects can be learnt. Providing education in these areas would increase the ability of nurses to use humour. For example, sensitivity training on how to 'read a room' would amplify skills that some already possess but may not recognise as necessary for assessing humour use. Training nurses to heighten their awareness of the emotions of the patient and their family and to be 'present' from the moment they enter the room allows nurses to gain or hone their skills in how non-verbal signs indicate the underlying physical and psychological condition of the patient (Duffin, 2009; Leef \& Hallas, 2013). These skills can then be applied to improve the nurse's awareness of when a patient is near a crisis point. Without these skills, valuable cues may be missed, subsequently increasing the potential for humour to cause offense. Uncertainty on when to use humour can be mitigated if nurses are taught sensitivity skills and provided with an explanation on how these skills directly relate to using humour in the clinical setting. Sensitivity training is an initial approach to formally recognise the skills required to use humour that could provide surgical nurses with the tools and confidence to try using humour with patients.

\subsubsection{Organisational implications}

Retaining a skilled and stable workforce is a key priority of any organisation and directly impacts on the provision of safe and appropriate patient care (Moloney et al., 2018). This research has shown that nurses use humour to help themselves cope with work-related stress and help other team members cope with stress. As a coping strategy, humour brings staff together and creates a sense of team. Humour is a tool for building and maintaining relationships within teams and therefore drawing on findings from this thesis humour should be encouraged within the work environment to help maintain morale and job satisfaction. Job satisfaction creates a positive work environment, ultimately influencing the retention of staff within the area, sustaining skilled and experienced staff (Moloney et al., 2018).

This research has shown that humour can facilitate the nurse-patient relationship even under stressful and time pressured environments. Humour may be perceived as light- 
hearted fun, but it is a medium to create connection and as such it aligns with the profession standards of nursing care.

\subsection{Future research}

This research provides insight into how surgical nurses use humour within nurse-patient interactions, however further research exploration is required to extend and build on this knowledge. A qualitative descriptive methodology was used in this research, which provided foundational knowledge of humour within the surgical context. Employing other methodologies for future research would increase the scope and depth of nursing knowledge surrounding humour use. To reach a wider cross-section of surgical nurses resulting in a representative sample of surgical nurses' views on humour, a quantitative survey could be used (Denscombe, 2014). Structuring the survey questions around the themes and findings of the current research would build on the current knowledge and provide a wider view of the prevalence of humour use by surgical nurses.

The surgical environment was the focus in this research, and this limits the application of findings to other nursing environments. Research situated in contrasting clinical contexts would provide insight into the similarities and differences of humour use found in different environments and offer unique understanding of how context affects nursing humour. Surgical environments have quick turn over of patients, by contrast, medical wards provide care for patients over a more sustained period.

Patient perspectives were not explored in this research, therefore the use of humour within the nurse-patient relationship is only described from the nurse's perspective. Conducting research with surgical patients would provide the patients perspective presenting an accurate account of how patients feel humour affects their relationship with nurses. A patient perspective could also potentially evidence and substantiate the nurse's perceptions, further strengthening the findings of this research.

From the demographic data collected about the participants, a range of different ethnic and cultural backgrounds was evident. New Zealand has a multi-cultural population, with the nursing workforce being no exception, therefore further investigation into creating an understanding of how the nurse's culture impacts on the ability to use humour with patients 
would be beneficial. Focussing on Māori and their cultural beliefs of humour would also be valuable, especially as Māori are the indigenous peoples of New Zealand and are known to face an increased requirement for healthcare services (Ministry of Health, n.d).

\subsection{Study conclusion}

This research has provided an insight into how New Zealand nurses working in a surgical environment use humour with their patients. It has shown that nurses use humour consciously and purposefully. Humour is used deliberately by nurses to provide an environment that brings comfort to patients, themselves or nursing colleagues. Humour is also used intentionally to initiate the nurse-patient relationship, an integral part of a therapeutic relationship.

Humour forms an important facet of nursing care. Application of the findings in this research for surgical nurses could raise awareness of humour as an effective tool to build a therapeutic relationship and provide comfort for both patients within a surgical environment.

Humour is not a panacea and cannot replace all other forms of interpersonal skills or completely mitigate stress related to staff shortages and work stresses. However, humour is valuable tool to assist nurses in providing care that is rewarding for both nurse and patient, and as a coping strategy to manage immediate stress. 


\section{APPENDICIES}




\title{
Appendix 1 - Participant information sheet (PIS)
}

\section{VICTORIA UNIVERSITY OF WELLINGTON \\ Te Whare Wananga o te Upoko o te Ika a Maui}

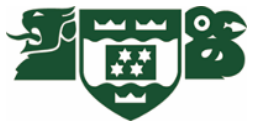

Graduate School of Nursing, Midwifery and Health

\section{Use of humour in surgical nursing - PARTICIPANT INFORMATION SHEET}

\author{
Principal Researcher \\ Shelley van der Krogt \\ Registered Nurse \\ BN, PG Dip Health Care
}

Contact Information

My name is Shelley van der Krogt and I am a Master's student in the Graduate School of Nursing, Midwifery and Health at Victoria University of Wellington. This research project is work towards my Master's award.

\section{INTRODUCTION:}

You are invited to take part in a study to explore the experiences of surgical nurses using humour with their patients. Please read this information before deciding whether to take part. You are under no obligation to take part. If you agree to take part in this study, I will discuss the study with you prior to commencement and then you will be asked to sign a consent form. You will be given a copy of both the Participant Information Sheet, the Consent Form and Focus Group ground rules to keep.

\section{ABOUT THE STUDY:}

This project will explore the experiences of surgical nurses using humour with patients. I am interested in how nurses use humour with their patients and why they use humour in their clinical practice.

All Registered Nurses currently employed in the Short Stay Surgical Unit and General Surgery (7 North) wards are eligible to participate in the study. The study will involve taking part in a focus group; this is an interview with a group of people. During the focus group, we will discuss humour and your experiences of humour during patient care. The focus group will be audio recorded and then transcribed (written out exactly as said) by me. During the focus groups, I will also take notes about the thoughts and opinions expressed. 


\section{BENEFITS, RISKS AND SAFETY}

Understanding how nurses use humour during patient care has the potential to influence nursing practice and benefit nurse-patient communication. However, there are no immediate benefits of taking part in this study.

Participating in the focus group may have an emotional impact on you. This can happen when sharing private experiences that have affected you in some way. If you begin to feel uncomfortable sharing your experiences, you can choose to leave the focus group at any time, without giving a reason. Taking part in a focus group will also take one hour of your personal time. To minimise any inconvenience, every effort will be made to offer a variety of times for the focus groups that occur around the start and finish of established shifts. This will help you choose a time that minimises disruption to your lifestyle.

\section{PARTICIPATION}

Your participation in this study is voluntary (your choice). You will be part of a group with a maximum of seven other people. Before the focus groups can start, a set of ground rules need to be discussed and agreed upon. During the focus groups, which will be held on site in the hospital, you can choose not to answer any question and withdraw at any time. You can withdraw from the study without an explanation by contacting me at any time before April 1st, 2019. Due to the nature of focus group interviews, if you withdraw during or after the focus group, your contribution up to the point of withdrawal will remain with the study and will be included in the data analysis.

You may discuss participation with friends, family or whānau to help you understand the risks and/or benefits of this study and any other explanation you may require.

\section{CONFIDENTIALITY}

In this research, only the focus group members and myself will be aware of your identity. The focus group rules and consent form outline a commitment from all participants to maintain the confidentiality of all other participants, but I cannot guarantee this. However, in the transcripts and written research data, reports and presentations a pseudonym will used be protect your identity.

Only my supervisors (listed below) and I will have access to the audio recordings and written transcripts. All audio recordings and notes will be stored in a secure and locked environment. After the study has been completed and the results have been published the data collected will be stored for five years in a secure locked environment and then destroyed.

\section{GENERAL}

If you have any questions, either now or in the future, please feel free to contact myself or one of my supervisors:

\begin{tabular}{|l|l|}
\hline Supervisors & \\
\hline Helen Rook & Maureen Coombs \\
Lecturer & Professor of Clinical Nursing \\
Graduate School of Nursing, Midwifery and & $\begin{array}{l}\text { Graduate School of Nursing, Midwifery and } \\
\text { Health. Victoria University of Wellington }\end{array}$ \\
Email: & Emalth. Victoria University of Wellington \\
\hline Ph: & Ph: \\
\hline
\end{tabular}




\section{RESULTS}

Due to the nature of the research there will be a delay between data collection and the completion of this study. Should you wish to receive a results summary report you can indicate this on the consent form. The results will be submitted as part of a Master's thesis to Victoria University of Wellington and may also be used in presentations and conferences or published in academic reports and journals.

\section{HUMAN ETHICS}

This research has received ethical approval from the Victoria University of Wellington Ethics Committee - approval number: 24799

If you have any concerns about the ethical conduct of the research you may contact the Victoria University HEC Convener

Email Or telephone

Please contact me at any stage if there is anything you would like to ask about this study. Thank you for time to consider participating in this study 


\section{Appendix 2 - Information poster}

\section{Do you use HUMOUR with your patients?}

\section{Would you like to share YOUR VIEWS ON USING HUMOUR with patients?}

\section{If so I would love to talk to you!}

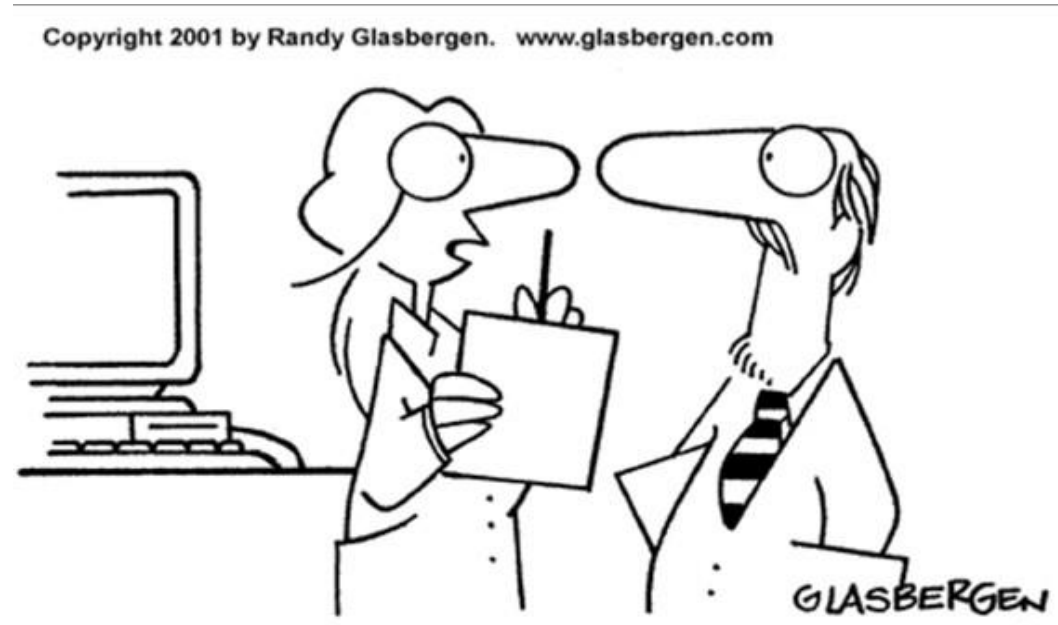

"According to my research, laughter is the best medicine, giggling is good for mild infections, chuckling works for minor cuts and bruises, and snickering only makes things worse."

My name is Shelley van der Krogt and I am a registered nurse completing my Masters research project on humour use in surgical nursing.

I am running focus groups to gather views and opinions from nurses working in $x x x x x$ and xxxxx on using humour with their patients.

If you are interested in taking part or would like some more information please email me.

\section{Email:}

\footnotetext{
${ }^{6}$ Permission was sort and granted from the Glasbergen family to use this cartoon for my information poster displayed in the hospital.
} 


\section{Appendix 3 - Focus group guidelines and ground rules}

\section{VICTORIA UNIVERSITY OF WELLINGTON \\ Te Whare Wananga o te Upoko o te Ika a Maui}

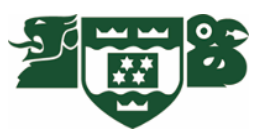

Graduate School of Nursing, Midwifery and Health

\section{Focus Group Guideline and Ground Rules}

Prior to attending the focus group, participants will already have received the Participant Information Form, which provides the outline of the research.

The following will be outlined at the start of the focus group.

- Welcome participants and introduce myself

- Explain the purpose of the research

- Discuss the purpose and process of focus groups

- Address the issue of confidentiality

- Explain the presence and purpose of recording equipment

- Outline general ground rules (as below) and gain participant consent before proceeding.

\section{Introduction}

Many thanks for coming to this focus group today. My name is Shelley van der Krogt and I am a nurse and a Masters student. This focus group discussion will last for about half an hour.

\section{The Purpose}

The purpose of this focus group is to get your views and experiences of using humour with your patients. I am here to facilitate the discussion and I have some questions to help the discussion along. Rest assured there is no right or wrong answer. Please do not wait to be asked before you respond, just respond to comments as they are made. I will ensure that everyone gets an opportunity to participate.

\section{Confidentiality}

You may know each other and consequently the identity of who is participating today. Therefore, I would ask that you be mindful about maintaining the confidentiality of those here today. Also, if any other colleagues or patients are discussed, the details mentioned also remain confidential. 
The focus group will be audio recorded and then transcribed (written out exactly as it was said) by myself. After transcription pseudonyms will be used, so your anonymity will be protected within the written material. No material that could personally identify you will be used in any written or verbal reports on this study.

During the focus group activity, you do not have to answer all the questions, and you may stop and withdraw at any time. If you withdraw, your contribution up to that point will remain with the focus group data and will be included in the data analysis.

\section{The Rules}

To be agreed upon before the group starts:

- To show respect to all in the group by listening when anyone is talking

- Just one person talking at a time if possible

- Cell phones be turned to silent

- The researcher will give everyone the opportunity to participate and share their views

- There are no right or wrong answers so please feel to share whether you agree or disagree

- All the information and opinions shared today remain confidential

- All participant identities are to be kept confidential

- All colleague or patient details shared today are to be kept confidential

- The group discussion will be audio recorded today and written notes will also be taken by the researcher

- You can choose not to answer a question or withdraw from the group at anytime

Are there any questions?

You all have a copy of the consent form that outlines the information I have just gone through.

If you are still willing to participate in the focus group, could I get you to sign the consent form now, and then we will start the discussion.

If you do not wish to participate in this focus group, I thank you for your time and please feel free to leave the discussion before we commence recording. 


\section{Appendix 4 - Interview questions and prompts}

\section{VICTORIA UNIVERSITY OF WELLINGTON \\ Te Whare Wananga o te Upoko o te Ika a Maui}

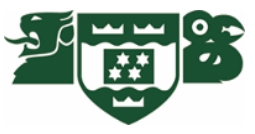

\section{Graduate School of Nursing, Midwifery and Health}

\section{FOCUS GROUP SEMI -STRUCTURES QUESTIONS}

Icebreaker questions: (10 minutes)

- Starting with the researcher, go around the group asking for introductions, how long each nurse has worked at Wellington hospital, where else they have worked. And the following questions.

- Tell me about why you became a nurse?

- What makes you feel good about being a nurse?

- Can you tell me what interested you to work in surgical nursing?

Questions: (40 minutes)

- Can you tell me how you would describe/define humour?

- What makes you laugh or smile?

- Do you use humour with your patients?

- Why do you use humour with your patients?

- Is using humour important in your clinical practice?

- Can you tell me how you use humour with your patients?

- How does using humour with your patients make you feel?

- Can you describe a time you felt that humour made a difference to your patient?

- Can you describe how you know you can use humour with patients?

- Can you tell me when you think you could use humour with patients?

- Can you tell me when you think it is best to avoid using humour with patients?

- Can you describe a time when you felt that humour was used inappropriately?

Prompts through the discussion:

- Can you tell me more about that?

- Can you tell me what past experiences have influenced that decision?

- Can you give me a little more detail?

- How did that make you feel?

- What was that like for you?

- Is this a view shared by anyone else in the group?

Last question: (10 minutes)

- Is there anything else anyone would like to share before we finish this discussion? 


\section{Appendix 5 - Consent form}

\section{VICTORIA UNIVERSITY OF WELLINGTON \\ Te Whare Wananga o te Upoko o te Ika a Maui}

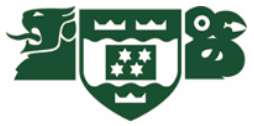

\section{Graduate School of Nursing, Midwifery and Health}

\section{Use of humour in surgical nursing - CONSENT TO PARTICIPATE IN A FOCUS GROUP}

Principal Researcher

Shelley van der Krogt

Registered Nurse

BN, PG Dip Health Care
Contact Information

Email:

- I have read the information sheet for nurses taking part in the study designed to explore the use of humour with patients by registered nurses in New Zealand surgical ward environments. Y

YES/NO

- I have had time to consider my participation in this study and the opportunity to discuss this study. I am satisfied with the answers I have been given.

YES /NO

- I understand and agree that due to the nature of focus group interviews, if I withdraw from the study my contribution up to the point of withdrawal will remain within the focus group data and will be included in the data analysis.

- I understand the final date for withdrawal from the study is April 1st 2018.

YES/NO

- I agree to the focus group being audio recorded and that there will be up to seven other people in the group.

YES /NO

- I understand and agree with the focus group rules

YES/NO

- I agree to protect the confidentiality of the other focus group participants

YES /NO

- I agree to protect the confidentiality of colleagues and patients who are mentioned in the focus group discussion

YES/NO

- I understand that my participation in this study is confidential and that no material that could identify me will be used in any academic reports, journals, at conferences, or in presentations of this study.

YES /NO

- I understand that the results from all of the focus groups will be used for a Master's thesis and a summary report of these results may be used in academic reports, journals and/or at presentations and conferences.

- I wish to receive a copy of the results summary report.

YES /NO 
Email address for results to be sent to:

Declaration by participant: I hereby consent to take part in this study.

Participants name:

Signature:

Date:

Declaration by researcher: I have given a verbal explanation of the research project and a written participant information sheet to the participant and I have answered the participant's questions about it. I believe that the participant understands the study and has given informed consent to participate.

Researcher's name:

Signature:

Date:

This consent form will be held for 5 years. 
Appendix 6 - Codes (Post it notes)

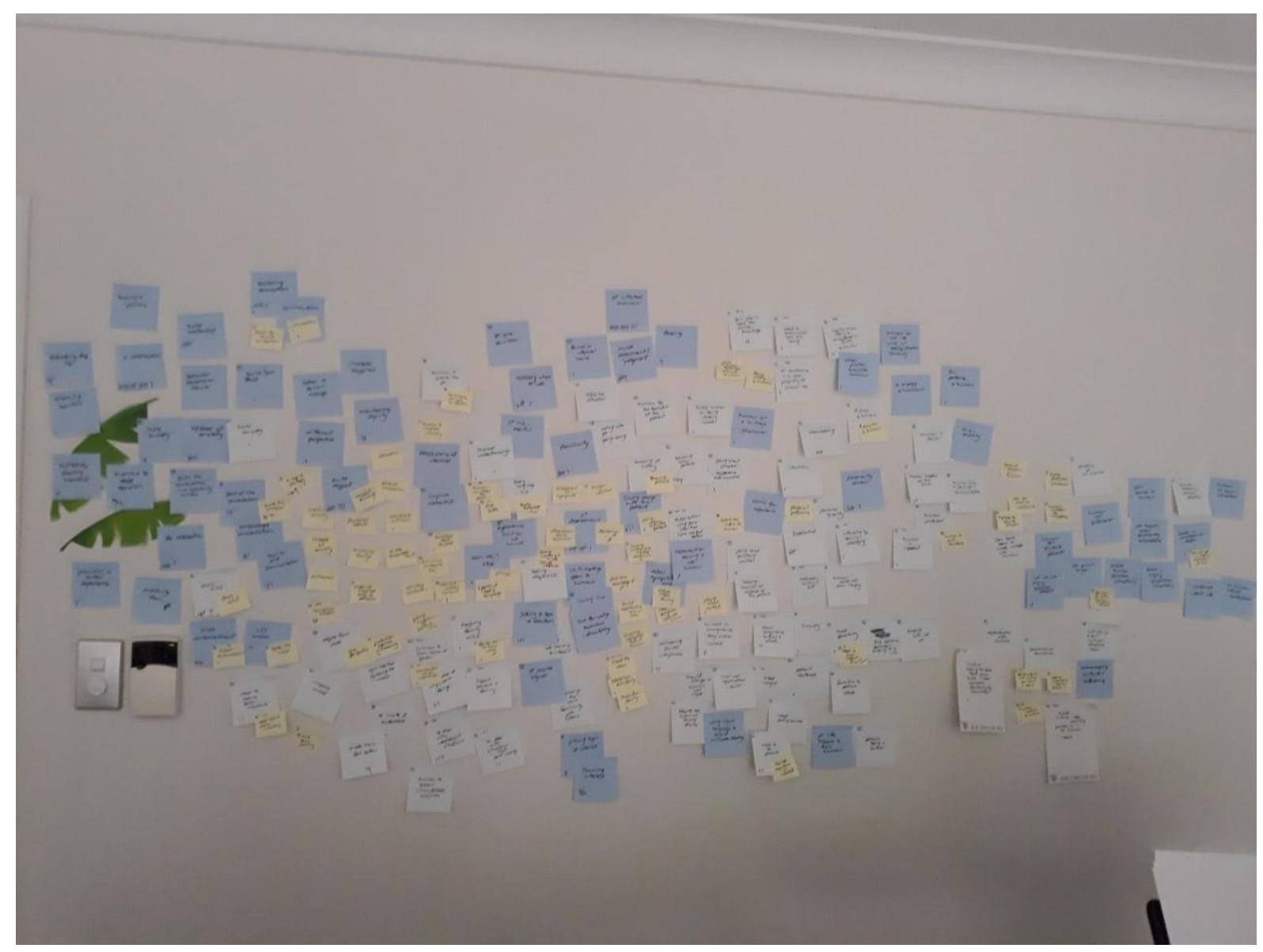




\section{Appendix 7 - Mind maps}
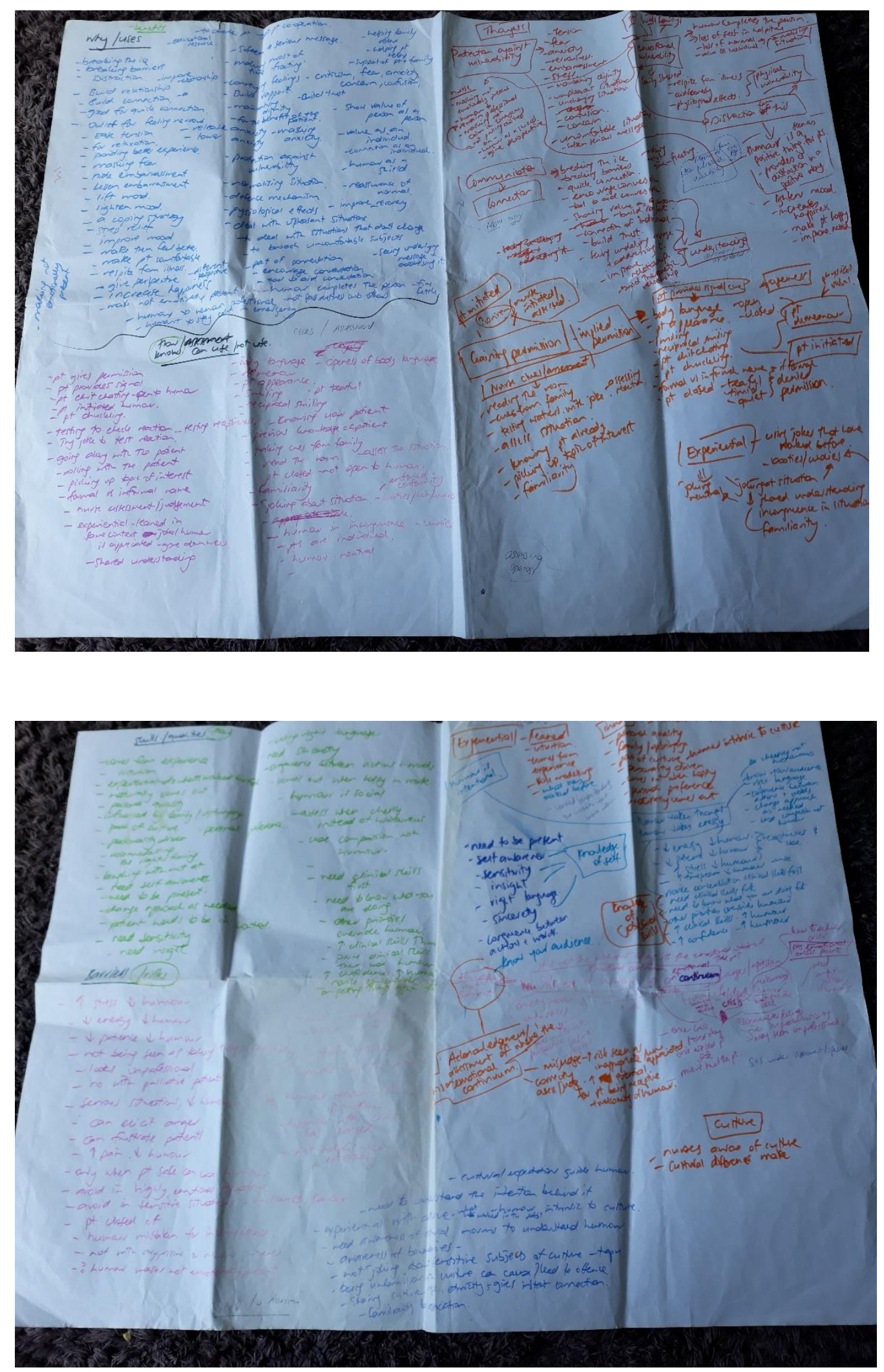


\section{Appendix 8 - Theme table}

\section{Themes Table - Protection against vulnerability}

\begin{tabular}{|c|c|c|c|c|}
\hline Theme & Subthemes & $\begin{array}{l}\text { Emerging } \\
\text { themes }\end{array}$ & Early Codes & Data Extract \\
\hline \multirow{6}{*}{$\begin{array}{l}\text { Protection } \\
\text { against } \\
\text { vulnerability }\end{array}$} & \multirow{6}{*}{$\begin{array}{l}\text { Addressing } \\
\text { Patient } \\
\text { vulnerability }\end{array}$} & \multirow[t]{3}{*}{$\begin{array}{l}\text { Reducing } \\
\text { emotional } \\
\text { distress }\end{array}$} & $\begin{array}{l}\text { Relieving stress } \\
\text { Relieving } \\
\text { tension }\end{array}$ & $\begin{array}{l}\text { because it is a very stressful and tensed } \\
\text { environment especially pre-operative and } \\
\text { they go for the surgery umm, and some } \\
\text { people umm can be stiff and only focus } \\
\text { about umm, I'm going to sleep I might not } \\
\text { wake up and that's very stressful for them, } \\
\text { they feel like running away like fright and } \\
\text { flight umm, just to distract to them, it's } \\
\text { really a good way of distracting them and } \\
\text { ease their nerves and yeah they feel so } \\
\text { good (RN 8) }\end{array}$ \\
\hline & & & $\begin{array}{l}\text { Relieving } \\
\text { nervousness }\end{array}$ & $\begin{array}{l}\text { yeah and then sometimes you get the } \\
\text { really nervous ones, } \\
\text { and you just umm, try and umm divert } \\
\text { their attention (RN 1) }\end{array}$ \\
\hline & & & $\begin{array}{l}\text { Lessening } \\
\text { Embarrassment }\end{array}$ & $\begin{array}{l}\text { but trying to make light of a situation so } \\
\text { you have people who have been unwell, } \\
\text { they've been urinary and faecally } \\
\text { incontinent and they are like apologising } \\
\text { for messing their beds and having to do all } \\
\text { this and I'm always like I don't do the } \\
\text { washing, (RN 6) }\end{array}$ \\
\hline & & \multirow[t]{2}{*}{$\begin{array}{l}\text { Reducing } \\
\text { physical } \\
\text { distress }\end{array}$} & $\begin{array}{l}\text { Distraction from } \\
\text { pain }\end{array}$ & $\begin{array}{l}\text { you can use it as a distraction quite a lot, } \\
\text { pain, you know people in pain and they've } \\
\text { had all the analgesia they can possibly } \\
\text { have (RN 9) }\end{array}$ \\
\hline & & & $\begin{array}{l}\text { Helping with } \\
\text { recovery }\end{array}$ & $\begin{array}{l}\text { I want them to be relaxed if they are too } \\
\text { tensed, umm, I don't think it is good for } \\
\text { their recovery, all their muscles are } \\
\text { strained and tensed and ah their blood } \\
\text { supply is going to their peripheries like } \\
\text { running, like flight fright mode (RN 8) }\end{array}$ \\
\hline & & $\begin{array}{l}\text { Regaining } \\
\text { sense of }\end{array}$ & $\begin{array}{l}\text { Humour } \\
\text { completes the } \\
\text { person }\end{array}$ & $\begin{array}{l}\text { the fact they are in pain, the fact they are } \\
\text { have nausea, the fact that they've got this } \\
\text { massive big wound across their stomach, }\end{array}$ \\
\hline
\end{tabular}




\begin{tabular}{|c|c|c|c|c|}
\hline \multirow{3}{*}{$\begin{array}{l}\text { Protection } \\
\text { Against } \\
\text { vulnerability }\end{array}$} & & self & & $\begin{array}{l}\text { will make a big difference to how they are, } \\
\text { and it's the fact that they are most } \\
\text { exposed and vulnerable, humour it makes } \\
\text { them a perfect, um how do you say it, } \\
\text { there's an element in Scottish language } \\
\text { you talk about somebody being in fine } \\
\text { fettle, so if you are in fine fettle, it means } \\
\text { that your body soul and mind are all in one } \\
\text { spirit, so you're not, you're not just feeling } \\
\text { good because your strong and you're head } \\
\text { strong but you are in fine fettle, all three } \\
\text { elements of you are in good humour (RN } \\
\text { 6) }\end{array}$ \\
\hline & \multirow[t]{2}{*}{$\begin{array}{l}\text { Addressing } \\
\text { Nurse's } \\
\text { vulnerability }\end{array}$} & \multirow{2}{*}{$\begin{array}{l}\text { Protection } \\
\text { from } \\
\text { Emotional } \\
\text { labour of } \\
\text { nursing }\end{array}$} & $\begin{array}{l}\text { Humour as a } \\
\text { shield }\end{array}$ & $\begin{array}{l}\text { actually, I'm not coping with what's } \\
\text { happening so I'm going to joke as well just } \\
\text { hide the fact that, I'm heartbroken for } \\
\text { whatever is happening to you, and I don't } \\
\text { want to cry (RN 5) }\end{array}$ \\
\hline & & & $\begin{array}{l}\text { Humour as a } \\
\text { mask }\end{array}$ & $\begin{array}{l}\text { so I try and be calm as much as I can but } \\
\text { umm, I also know that I don't have a great } \\
\text { poker face so I might use humour to } \\
\text { distract people from the fact that I might } \\
\text { actually be internally panicking and,crap } \\
\text { this patient has a heart rate of } 200 \text { and a } \\
\text { blood pressure of } 60 \text { you know like, so kind } \\
\text { of use humour in that it does help my } \\
\text { practice, in that, it it masks essentially, it } \\
\text { so, it it I kind of use it as a mask, yeah I } \\
\text { think umm so patients have that } \\
\text { confidence that you are not freaking out } \\
\text { (RN 7) }\end{array}$ \\
\hline
\end{tabular}




\section{Appendix 9 - Ethics Approval from Victoria University of Wellington}

TE WhARE WR̃NANGa o te Ópoko o te 1Ka A mĩut

MEMORANDUM

Phone
Email

\begin{tabular}{l|l}
\hline TO & Shelley van der Krogt \\
\hline COPY TO & Helen Rook \\
\hline FROM & \\
\hline DATE & 15 August 2017 \\
\hline PAGES & 1 \\
\hline SUBJECT & $\begin{array}{l}\text { Ethics Approval: } 24799 \\
\text { Humour use in surgical nursing }\end{array}$ \\
\hline
\end{tabular}

Thank you for your application for ethical approval, which has now been considered by the Standing Committee of the Human Ethics Committee.

Your application has been approved from the above date and this approval continues until 31 August 2018. If your data collection is not completed by this date you should apply to the Human Ethics Committee for an extension to this approval.

Best wishes with the research.

Kind regards

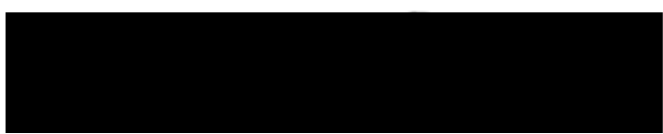

Convener, Victoria University Human Ethics Committee 


\section{Appendix 10 - Ethics approval from Research Governance Group - Research}

site

\section{Email confirmation after a verbal confirmation}

Tue 12/09/2017, 11:56 a.m.

Shelley Van Der Krogt

Good afternoon Shelley,

This is to confirm that you project has been approved by the XXXX Research Governance Group and can start in this locality.

kind regards,

Service Leader, Research Office 


\section{Appendix 11- Ethics amendment approval - Victoria University of Wellington}

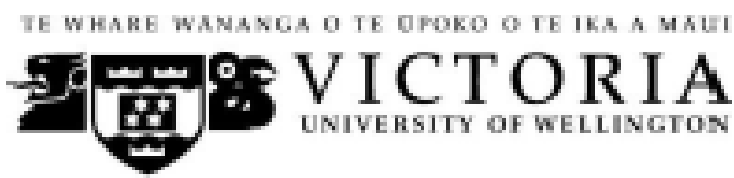

MEMORANDUM

Phore

Emall

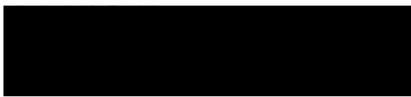

\begin{tabular}{l|l}
\hline TO & \multicolumn{2}{|c}{ Shelley van der Krogt } \\
\hline FROM & \multicolumn{1}{|l}{ Convener, Human Ethics Committee } \\
\hline DATE & 22 November 2017 \\
\hline PAGES & 1 \\
\hline SUBJECT & $\begin{array}{l}\text { Ethics Approval: 24799 } \\
\text { Humour use in surgical nursing }\end{array}$ \\
\hline
\end{tabular}

Thank you for your request to amend your ethics application. This has now been considered and the request granted.

Your application has approval until the project end date specified on your original application (31 August 2018). If your data collection is not completed by this date you should apply to the Human Ethics Committee for an extension to this approval.

Best wishes with the research.

Kind regards
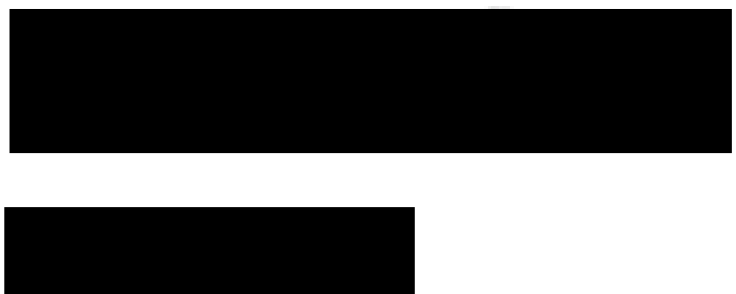

Convener, Victoria University Human Ethics Committee 


\section{REFERENCES}

Abel, M. (2002). Humor, stress and coping strategies. International Journal of Humor Research, 15(4), 365-381.

Adamle, K.N., \& Ludwick, R. (2005). Humour in hospice care: Who, where and how much? American Journal of Hospice and Palliative Medicine, 22(4), 287-290.

Adamle, K.N., Ludwick, R., Zeller., R., \& Winchell, J. (2008). Oncology nurse responses to patient initiated humour. Cancer Nursing, 31(6), 1-9.

Adamle, K.N., \& Turkoski, B. (2006). Responding to patient-initiated humour: Guidelines for practice. Home Healthcare Nurse, 24(10), 638-644.

Ahern, K. (2014). Gatekeepers: People who can (and do) stop your research in its tracks.

DOI: http://dx.doi.org/10.4135/978144627305014536673

Aotearoa New Zealand Association of Social Workers (n.d). Global definition of the social work profession. Retrieved from https://anzasw.nz/global-definition-social-work-profession/

Astedt-Kurki, P., \& Liukkonen, A. (1994). Humour in nursing care. Journal of Advanced Nursing Care, 20, 183-188.

Beck, C.T. (1994). Humour in nursing practice: A phenomenological study. International Journal of Nursing Studies, 34(5), 346-352.

Bradshaw, C., Atkinson, S., \& Doody, O. (2017). Employing a qualitative description approach in health care research. Global Qualitative Nursing Research, 4, 1-8.

Branney, P., Witty, K., Braybrook, D., Bullen, K., White, A., \& Eardley, I. (2014). Masculinities, humour and care for penile cancer: A qualitative study. Journal of Advanced Nursing, 70(9), 20512060.

Braun, V., \& Clarke, V. (2006). Using thematic analysis in psychology. Qualitative Research in Psychology, 3(2), 77-101.

Braun, V. \& Clarke, V. (2012). Thematic Analysis. In H. Cooper (Eds) APA handbook of Research Methods in Psychology Vol 2; Research Designs (pp 57-71). DOI: 10.1037/13620-004

Braun, V. \& Clarke, V. (2014). What can "thematic analysis" offer health and wellbeing researchers? International Journal of Qualitative Studies on Health and Wellbeing. 9, 1, 26152.

Braun, V., \& Clarke, V. (2016). (Mis)conceptualising themes, thematic analysis and other problems 
with Fugard and Potts' (2015) sample-size tool for thematic analysis. International Journal of Social Research Methodology. 19(6), 739-743.

Carey, M.A. (2016). Focus groups - what is the same, what is new, what is next? Qualitative Health Research, 26(6), 731-733.

Cargill, J. (2015). Finding the evidence in practice for Social Work. USA, IGI Global.

Carr, E.C.J., Thomas, V.N., \& Wilson-Barnet, J. (2005). Patient experiences of anxiety, depression and acute pain after surgery. International Journal of Nursing Studies, 42(5), 521-530.

Chapple, A., \& Ziebland, S. (2004). The role of humor for men with testicular cancer. Qualitative Health Research, 14(8), 1123-1139.

Clarke, V., \& Braun, V. (2017). Thematic Analysis. The Journal of Positive Psychology, 12(3), 297-298.

Collicut, J., \& Gray, A. (2012). A merry heart doeth good like a medicine: humour, religion and wellbeing. Mental Health, Religion and Culture, 15(8), 759-778.

Costello, M. (2016). Nurses' self-identified characteristics and behaviours contributing to patients' positive perceptions of their nursing care. Journal of Holistic Nursing, 35(1), $62-66$.

Dean, R.A., \& Gregory, D.M. (2005). More than trivial. Strategies for using humour in palliative care. Cancer Nursing, 28(4),292-300.

Dean, R.A., \& Major, J.E. (2008). Nurses' experiences: From critical care to comfort care; the sustaining value of humour. Journal of Clinical Nursing, 17(8), 1088-1095.

Denscombe, M. (2014). The good research guide. ( $5^{\text {th }}$ ed). McGraw-Hill Press, United Kingdom Doody, O., Slevin, E., \& Taggart, L. (2013). Preparing for and conducting focus groups in nursing research: Part 2. British Journal of Nursing, 22(3), 170-173.

Duffin, C. (2009). Send in the clowns. Nursing Management, 16(3), 22-24

Dunn, B. (1993). Use of therapeutic humour by psychiatric nurses. British Journal of Nursing, 2(9) 468-473.

Edwards, K.R., \& Martin, R.A. (2014). The conceptualization, measurement and role of humor as a character strength in positive psychology. Europe's Journal of Psychology, 10(3), 505-519.

Emerson, J.P. (1969). Negotiating the serious import of humor. Sociometry, 32(2), 169-181. 
Ford, K., Courtney-Pratt, H., Tesch, L., \& Johnson, C. (2014). More than just clowns -Clown doctor rounds and their impact for children, families and staff. Journal of Child Health Care, 18(3), 286-296.

Fusch, P.I., \& Ness, L.R. (2015). Are we there yet? Data saturation in qualitative research. The qualitative report, 20(9), 1408-1416.

Geanellos, R. (2005). Sustaining well-being and enabling recovery: The therapeutic effect of nurse friendliness on clients and nursing environments. Contemporary Nurse, 19(1), 242-252.

Ghaffari, F., Dehghan-Nayeri, N., \& Shali, M. (2015). Nurses' experience of humour in clinical settings. Medical Journal of the Islamic Republic of Iran. 28(182), 1-11.

Gildberg, F.A., Bradley, S.K., Paaske, K.J., \& Hounsgaard, L. (2014). The use of humor in forensic mental health staff-patient interactions. International Association of Forensic Nurses, 10(2) 98-105.

Greenberg, M. (2003). Therapeutic play: Developing humour in the nurse-patient relationship. Journal of the New York Nurses Association, 34(1), 25-31.

Haydon, G., \& van der Reit, P. (2014). A narrative inquiry: How do nurses respond to patients' use of humour? Contemporary Nurse, 46(2), 197-205.

Haydon, G., van der Reit, P., \& Browne, G. (2015). A narrative inquiry: Humour and gender differences in the therapeutic relationship between nurses and their patients. Contemporary Nurse, 50(2), 214-226.

James, I., Andershed, B., Gustavsson, B., \& Ternestedt, B.M. (2010). Knowledge constructions in nursing practice: Understanding and integrating different forms of knowledge. Qualitative Health Research, 20(11), 1500-1518.

Jangland, E., Larsson, J., \& Gunningberg, L. (2011). Surgical nurses' different understandings of their interactions with patients: A phenomenographic study. Scandinavian Journal of Caring Sciences, 25, 533-541.

Jangland, E., Teodorsson, T., Molander, K., \& Athlin, A.S. (2018). Inadequate environment, resources and values lead to missed nursing care: A focused ethnographic study on the surgical ward using the Fundamentals of Care framework. Journal of Clinical Nursing, 27, 2311-2321. 
Joffe, H. (2012). Thematic Analysis. In D. Harper \& A. Thompson (Eds). Qualitative Research Methods in Mental Health and Psychotherapy: A Guide for Students and Practitioners (pp 209-223). Wiley-Blackwell, Chichester, United Kingdom.

Johnson, P. (2002). The use of humor and its influences on spirituality and coping in breast cancer survivors. Oncology Nursing Forum, 29(4), 691-695.

Jones, P., \& Taney, M.A. (2016). Perceptions of nurses about potential barriers to the use of humour in practice: A literature review of qualitative research. Contemporary Nurse, 52(1), 106-118.

Jordon, S. (2017). Relationship based social work practice: the case for considering the centrality of humour in creating and maintaining relationships. Journal of Social Work Practice, 31(1), 95110.

Koch, T., \& Harrington, A. (2002). Reconceptualising rigour; the case for reflexivity. Journal of Advanced Nursing, 28(4), 882-890.

Kynoch, K., Crowe, McArdle, K., Munday, J., Cabilan, C.J., \& Hines, S. (2017). Structured communication intervention to reduce anxiety of family members waiting for relatives undergoing surgical procedures. Journal of Perioperative Nursing in Australia, 30(1), 29-35.

Lotzkar, M., \& Bottorff, J.L. (2001). An observational study of the development of a nurse-patient relationship. Clinical Nursing Research, 10(3), 275-294.

Leef, B.L., \& Hallas, D. (2013). The sensitivity training clown workshop: Enhancing therapeutic communication skills in nursing students. Nursing Education Perspectives, 34(4), 260-264.

Mackintosh, C. (2006). Protecting the self: A descriptive qualitative exploration of how registered Nurses cope with working in surgical areas. International Journal of Nursing Studies, 44(2007), 982-990.

Mallet, J., \& A'hern, R. (1996). Comparative distribution and use of humour within nurse-patient communication. International Journal of Nursing Studies, 33(5), 530 -550.

Marshall, A., Kitson, A., \& Zietz, K. (2012). Patients' views of patient-centred care: A phenomenological case study in one surgical unit. Journal of Advanced Nursing, 68 (12), 2664-2673.

McCabe, C. (2004). Nurse-patient communication: An exploration of patients' experiences. Journal of Clinical Nursing, 13, 41-49. 
McCormack, B., \& McCance, T. (2010). Person-centred nursing: Theory and practice. Wiley-Blackwell, United Kingdom.

McCreaddie, M. (2010). Harsh humour: A therapeutic discourse. Health and Social Care in the Community, 18(6), 633-642.

McCreaddie, M., \& Payne, S. (2011). Humour in health-care interactions: A risk worth taking. Health Expectations, 17, 332-344.

McCreaddie, M., Payne, S., \& Froggatt, K. (2010). Ensnared by positivity: A constructivist perspective on 'being positive' in cancer care. European Journal of Oncology Nursing, 14, 283-290.

McCreaddie, M., \& Wiggins, S. (2008). The purpose and functioning of humour in health, health care and nursing: A narrative review. Journal of Advanced Nursing, 61(6), 584 -595.

Melin-Johansson, C., Palmqvist, R., \& Ronnberg, L. (2017). Clinical intuition in the nursing process: A mixed studies review. Journal of Clinical Nursing, 26(23-24), 3936- 3049.

Ministry of Health (n.d). Ngā awe o te hauora: Socioeconomic determinants of health. Retrieved https://www.health.govt.nz/our-work/populations/maori-health/tatau-kahukura-maori-healthstatistics/nga-awe-o-te-hauora-socioeconomic-determinants-health

Moran, C.C., \& Hughes, L.P. (2006). Coping with Stress: Social work students and humour. Social Work Education, 25(5), 501-517.

Nursing Council of New Zealand (2012). Code of Conduct for Nurses. Wellington: Author.

Ofir, S., Tener, D., Lev-Wiesel, R., \& Lang-Franco, N. (2016). The therapy beneath the fun: Medical clowning during invasive examinations on children. Clinical Paediatrics, 55(1), 56-65.

Polit, D.F., \& Beck, C.T. (2008). Nursing Research: Generating and Assessing Evidence of Nursing Practice. ( $8^{\text {th }}$ Ed). Lippincott Williams \& Wilkins, London.

Polit, D.F., \& Beck, C.T. (2010). Generalization in quantitative and qualitative; myths and strategies. International Journal of Nursing Studies, 47(11), 1451-1458.

Ragan, S.L. (1990). Verbal play and multiple goals in the gynaecological exam interaction. Journal of Language and Social Psychology, 9(1-2), 67-84.

Ridley, J.R., Dance, D., \& Pare, D. (2014). The acceptability of humor between palliative care patients and health care providers. Journal of Palliative Medicine, 17(4), 472-474. 
Robert, C., \& Wilbanks, J.E. (2012). The wheel model of humor: Humor events and effect in organizations. Human Relations, 65(9), 1071-1099.

Robinson, D.T., \& Smith-Loving, L. (2001). Getting a laugh: Gender, status and humor in task discussions. Social Forces, 80(1), 123-158.

Rolfe, G. (2006). Validity, trustworthiness and rigour: Quality and the idea of qualitative research. Journal of Advanced Nursing, 53(3), 304-310.

Ruch, W., \& McGhee, P.E. (2014). Humour intervention programmes. In Parks \& Schueller (eds). The Wiley Blackwell handbook of positive psychological interventions (pg 180-193). Wiley \& sons, United Kingdom.

Ryan-Nicolls, K.D., \& Will, C.I. (2009). Rigour in qualitative research: Mechanisms for control. Nurse Researcher, 16(3), 70-85.

Sandelowski, M. (1986). The problem with rigor in qualitative research. Advances in Nursing Science 8(3), 27-37.

Sandelowski, M. (2000). Focus on research methods. What ever happened to qualitative description? Research in Nursing \& Health, 23, 334-340.

Sandelowski, M. (2010). What's in a name? Qualitative description revisited. Research in Nursing \& Health, 33, 77-84.

Sawbridge, Y., \& Hewison, A. (2013). Thinking about the emotional labour of nursing- supporting nurses to care. Journal of Health Organisation and Management, 29(2), 127-133.

Scanlon, A. (2006). Psychiatric nurses' perceptions of the constituents of the therapeutic relationship: A grounded theory study. Journal of Psychiatric and Mental Health Nursing, 13, 319-329.

Schneider, Z., Whitehead, D., LoBiondo-Wood, G., \& Haber, J. (2016). Nursing and Midwifery Research: Methods and appraisal of evidence-based practice. ( $5^{\text {th }}$ ed). Elsevier, Australia.

Scholl. J. (2007). The use of humor to promote patient-centred care. Journal of Applied Communication Research, 35(2), 156-176.

Schopf, A., Martin, G.S., \& Keating, M.A. (2017). Humour as a communication strategy in providerpatient communication in chronic care settings. Qualitative Health Research, 27(3), 374-390.

Sellman, D. (2011). What makes a good nurse: why the virtues are important for nurses. Jessica Kingsley Publishing, United Kingdom. 
Smuts, A. (n.d). Humour. Internet Encyclopaedia of Philosophy. Accessed at http://www.iep.utm.edu/humor/

Struthers, J. (1999). An investigation into community psychiatric nurses' use of humour during client interactions. Journal of Advanced Nursing, 29(5), 1197-1204.

Sumners, A.D. (1990). Professional nurses' attitudes towards humour. Journal of Advanced Nursing, $15,196-2000$.

Tanay, M.A., Wiseman, T., Roberts, J., \& Ream, E. (2014). A time to weep and a tie to laugh: Humour in the nurse-patient relationship in an adult cancer setting. Support Care Cancer, 22, 1295 1301.

Tavory, I. (2014). The situations of culture: humor and the limits of measurability. Theory and Society, 43(3-4), 275-289.

Thorne, S. (2008). Interpretive Description. Walnut Creek, CA; Left Coast Press.

Thornton, J., \& White, A. (1999). A Heideggerian investigation into the lived experience of humour by nurses in an intensive care unit. Intensive and Critical Care Nursing, 15, 226-278.

Thorsteinsson, L. (2002). The quality of nursing care as perceived by individuals with chronic illnesses: The magic touch of nursing. Journal of Clinical Nursing, 11, 32-40.

Treger, S., Spreacher, S., \& Erber, R. (2013). Laughing and liking: Exploring the interpersonal effects of humour use in social interactions. European Journal of Social Psychology, 43, 532-543.

Vaismoradi, M., Turunen, H., \& Bondas, T. (2013). Content analysis and thematic analysis: Implications for conducting a qualitative descriptive study. Nursing and Health Sciences, 15, 398-405.

Walsh, K., \& Kawanko, I. (2002). Nurses' and patients' perceptions of dignity. International Journal of Nursing Practice, 8, 143-151.

Wanat, C.L. (2008). Getting past the gatekeepers: Differences between access and cooperation in public school research. Field Methods, 20(2), 191-208.

Warner, S.L. (1998). Humor: A coping response for student nurses. Archives of Psychiatric Nursing, 5(1), 10-16. 
Wellenzoh, S., Proyer, R.T., \& Ruch, W. (2018). Who benefits from humour-based positive psychology interventions? The moderating effects of personality traits and sense of humour. Frontiers of Psychology, 9, 1-10.

Wiechula, R., Conroy, T., Kitson, A.L., Rhianon, J.M., Whitaker, N., \& Rasmussen, P. (2015). Umbrella review of the evidence: What factors influence the caring relationship between a nurse and patient? Journal of Advanced Nursing, 723-734.

Wigens, L. (1997). The conflict between 'new nursing' and 'scientific management' as perceived by surgical nurses. Journal of Advanced Nursing, 25, 1116 -1122.

Wrigley, A. (2015). An eliminativist approach to vulnerability. Bioethics, 29(7), 478-487. 